Florida International University FIU Digital Commons

6-30-2014

\title{
Essays on Intergenerational and Regional Aspects of Water Management
}

Yu Chen

ychen010@fiu.edu

DOI: $10.25148 /$ etd.FI14071148

Follow this and additional works at: https://digitalcommons.fiu.edu/etd

\section{Recommended Citation}

Chen, Yu, "Essays on Intergenerational and Regional Aspects of Water Management" (2014). FIU Electronic Theses and Dissertations. 1525.

https://digitalcommons.fiu.edu/etd/1525

This work is brought to you for free and open access by the University Graduate School at FIU Digital Commons. It has been accepted for inclusion in FIU Electronic Theses and Dissertations by an authorized administrator of FIU Digital Commons. For more information, please contact dcc@fiu.edu. 


\title{
FLORIDA INTERNATIONAL UNIVERSITY
}

Miami, Florida

\section{ESSAYS ON INTERGENERATIONAL AND REGIONAL ASPECTS OF WATER MANAGEMENT}

\author{
A dissertation submitted in partial fulfillment of \\ the requirements for the degree of \\ DOCTOR OF PHILOSOPHY \\ in \\ ECONOMICS \\ by \\ Yu Chen
}

2014 
To: Interim Dean Michael R. Heithaus

College of Arts and Sciences

This dissertation, written by $\mathrm{Yu}$ Chen, and entitled Essays on Intergenerational and Regional Aspects of Water Management, having been approved in respect to style and intellectual content, is referred to you for judgment.

We have read this dissertation and recommend that it be approved.

Pallab Mozumder

Jesse Bull

Assefa M. Melesse

Mahadev Bhat, Major Professor

Date of Defense: June 30, 2014

The dissertation of Yu Chen is approved.

Interim Dean Michael R. Heithaus

College of Arts and Sciences

Dean Lakshmi N. Reddi

University Graduate School

Florida International University, 2014 
(C) Copyright 2014 by Yu Chen

All rights reserved. 


\section{DEDICATION}

I dedicate this dissertation to my father, Daqian Chen and my mother Dashu Li, and my boyfriend. Without their support the completion of this work would not have been possible. 


\section{ACKNOWLEDGMENTS}

Any words are pale to express my gratitude to Dr. Mahadev Bhat, my major professor. Without his guidance, mentoring and moral support this work would not have been possible to be accomplished. Dr. Bhat's kindness, patience to me and dedication to my dissertation made my doctoral life much easier.

I am deeply grateful for having Dr. Pallab Mozumder, Dr. Jesse Bull and Dr. Assefa Melesse as my dissertation committee members. I would like to show my special appreciation to Dr. Pallab Mozumder for the insightful advices and support to one of the chapters in my dissertation.

I am greatly thankful for Dr. Jesse Bull for his beneficial teaching and valuable suggestions to make my dissertation better.

The support and helpful ideas to my dissertation from Dr. Assefa Melesse is also very much appreciated.

I want to thank all the faculties and staffs in the Economics Department of FIU. 
ABSTRACT OF THE DISSERTATION

ESSAYS ON INTERGENERATIONAL AND REGIONAL ASPECTS OF WATER

MANAGEMENT

\author{
by
}

Yu Chen

Florida International University, 2014

Miami, Florida

\title{
Professor Mahadev Bhat, Major Professor
}

This dissertation consists of three essays on different aspects of water management. The first essay focuses on the sustainability of freshwater use by introducing the notion that altruistic parents do bequeath economic assets for their offspring. Constructing a two-period, over-lapping generational model, an optimal ratio of consumption and pollution for old and young generations in each period is determined. Optimal levels of water consumption and pollution change according to different parameters, such as, altruistic degree, natural recharge rate, and population growth. The second essay concerns water sharing between countries in the case of trans-boundary river basins. The paper recognizes that side payments fail to forge water-sharing agreement among the international community and that downstream countries have weak bargaining power. An interconnected game approach is developed by linking the water allocation issue with other non-water issues such as trade or border security problems, creating symmetry between countries in bargaining power. An interconnected game forces two countries to at least partially cooperate under some circumstances. The third essay introduces the concept of virtual water (VW) into a traditional international trade 
model in order to estimate water savings for a water scarce country. A two country, two products and two factors trade model is developed, which includes not only consumers and producer's surplus, but also environmental externality of water use. The model shows that VW trade saves water and increases global and local welfare. This study should help policy makers to design appropriate subsidy or tax policy to promote water savings especially in water scarce countries. 
TABLE OF CONTENTS

CHAPTER

PAGE

CHAPTER 1 PARENTAL ALTRUISM IN FRESHWATER MANAGEMENT .................1

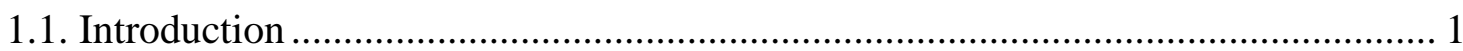

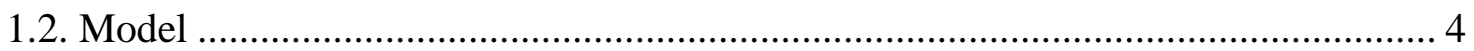

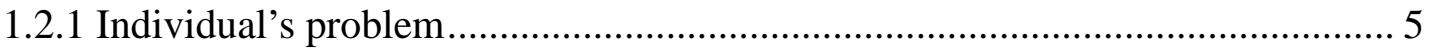

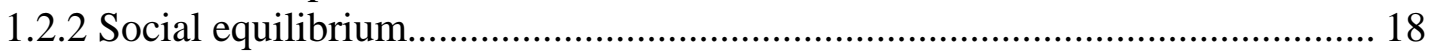

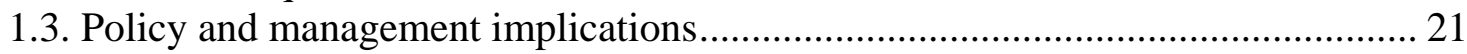

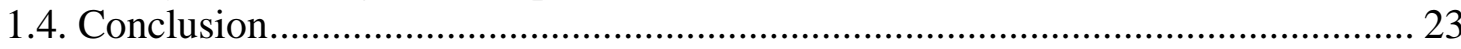

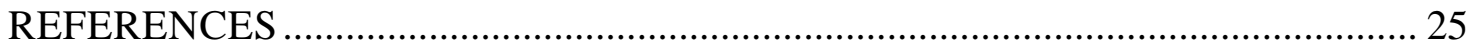

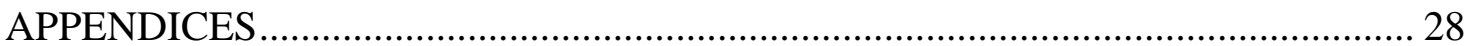

CHAPTER 2 INTERCONNECTED GAME IN WATER SHARING BETWEEN TWO

COUNTRIES UNDER EXTREME WEATHER SCENARIOS ………..........................42

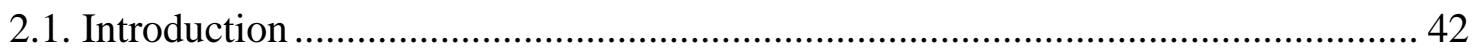

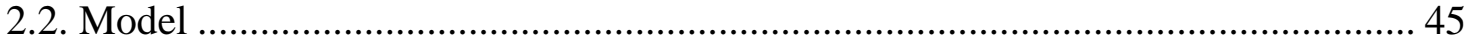

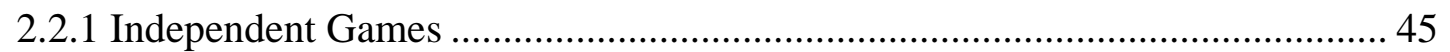

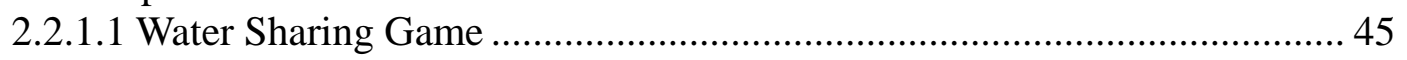

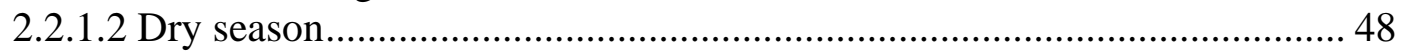

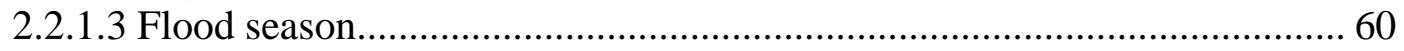

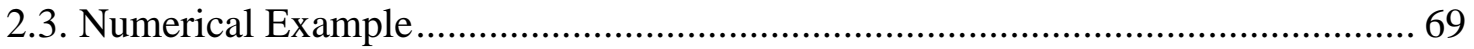

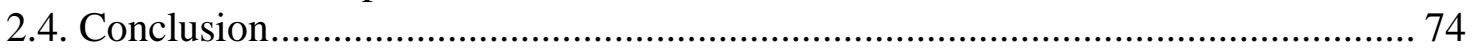

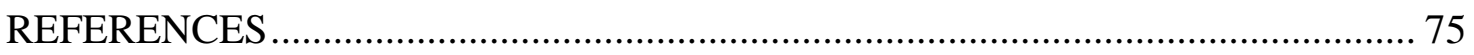

CHAPTER 3 VIRTUAL WATER TRADE AND ENVIRONMENTAL POLICIES .........77

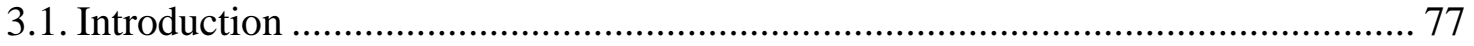

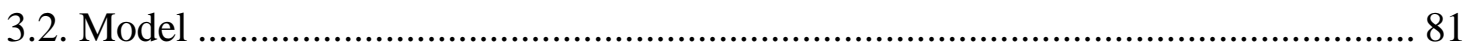

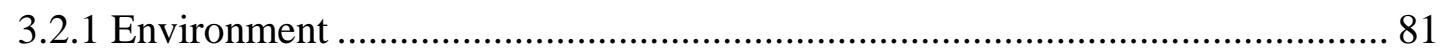

3.2.2 Social Welfare (Autarky) ................................................................................. 84

3.2.3 Open Economy with free trade (countries produce and trade both goods)...... 86

3.2.4 Open Economy with free trade and each country export the product they

have comparative advantage in............................................................................. 89

3.2.5 Terms of Trade .............................................................................................. 93

3.3. Empirical Application of the Model: The case of Saudi Arabia ............................. 94

3.4. Data for the Empirical Model............................................................................. 95

3.5. Simulation model and solution...................................................................... 96

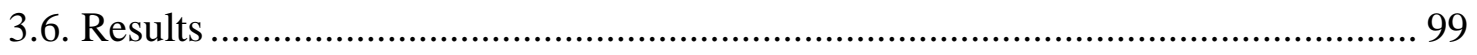

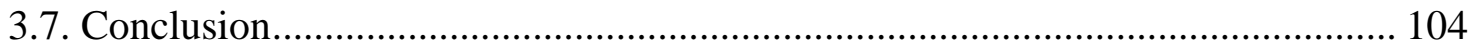

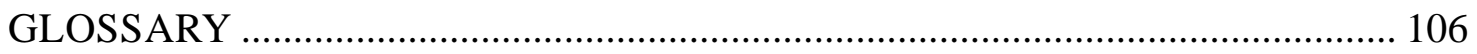

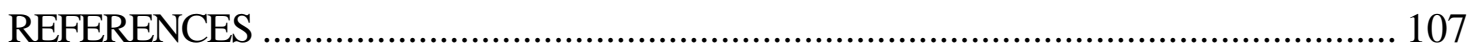

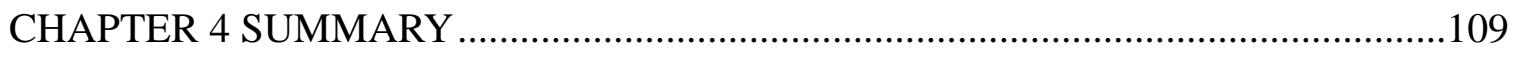




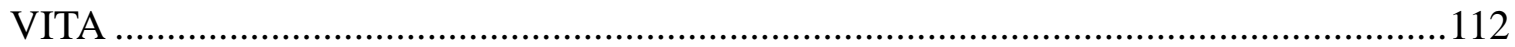




\section{LIST OF TABLES}

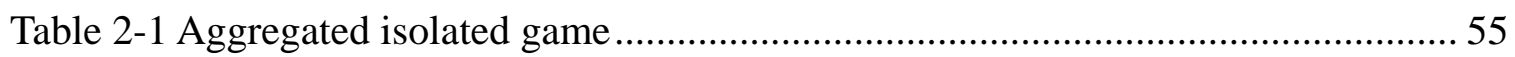

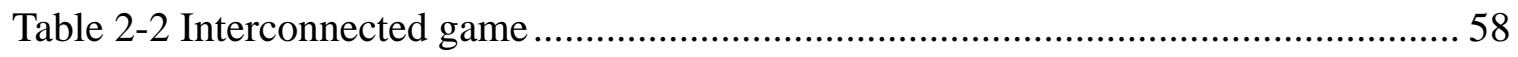

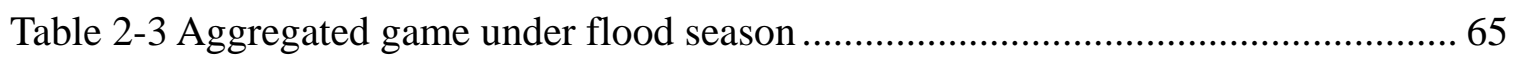

Table 2-3 (continued) Aggregated game under flood season....................................... 66

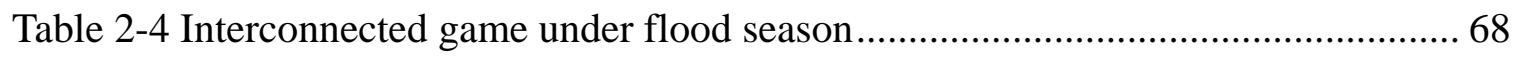

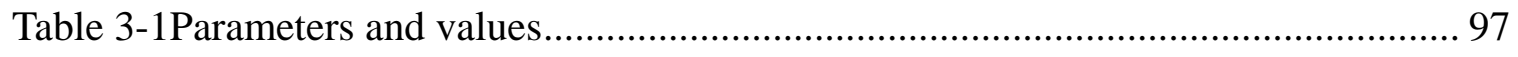

Table 3-2 Actual domestic production and import of Wheat and oil in Saudi Arabia and

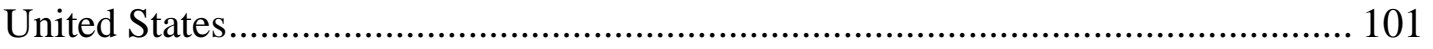

Table 3-3 Physical water saved for Saudi Arabia by importing wheat (From Observed

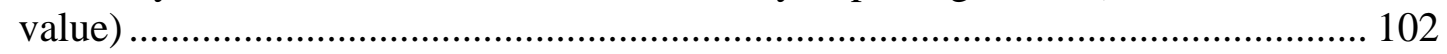

Table 3-4 Price comparison: Equilibrium price VS observed price.............................. 103

Table 3-5 Local welfare change VS. Global welfare change (From observed value to

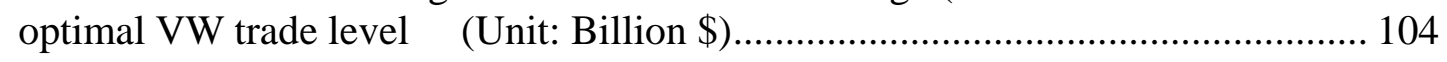




\section{TABLES OF FIGURES}

Figure 1-1. Shadow price ration over time (modified Hoteling’s Rule) ..........................13

Figure 1-2 Shadow price ratio shift when net recharge rate decreases...........................14

Figure 1-3 Marginal change of consumption of old to the pollution in period one...........17

Figure 1-4 Environmental damage curve..............................................................19

Figure 2-1Game 1: Water Sharing Game With Side Payment .......................................49

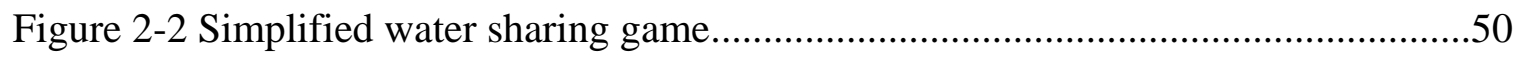

Figure 2-3 Possible frontier of repeated game on water sharing ..................................51

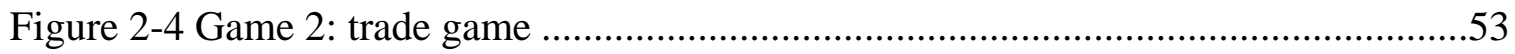

Figure 2-5 Possible frontier of repeated trade game ..................................................54

Figure 2-6 Possible frontier of aggregated game ...................................................57

Figure 2-7 Possible frontier of interconnected game in dry season..............................60

Figure 2-8 water sharing game under flood season ...............................................63

Figure 2-9 simplified water sharing game under flood season ...................................63

Figure 2-10 Possible frontier in repeated water sharing game under flood season ..........64

Figure 2-11 Possible frontier of aggregated game ..................................................67

Figure 2-12 Possible frontier of interconnected game vs. aggregated game under flood season

Figure 2-13 Possible frontier of repeated game on water sharing ................................70

Figure 2-14 Possible frontier of repeated game on water sharing .................................71

Figure 2-15 Infinite Repeated Water Sharing Game .................................................72 


\section{CHAPTER 1 \\ PARENTAL ALTRUISM IN FRESHWATER MANAGEMENT}

\subsection{Introduction}

Population growth, industrial development and attendant pollution put increasing stress on freshwater. Water becomes a locally scare resource at most places on earth (Ambec and Sprumont, 2002). Freshwater is a scarce resource and can be non-renewable if not managed properly. Only around $0.9 \%$ of the total water on earth is ground water and $0.009 \%$ is surface water, especially the fossil water. In the world's driest places, fossil water is becoming as valuable as fossil fuel. These water sources are highly vulnerable to excessive consumption and pollution by the current generation. For instance, countries in North Africa receive little rain, and its population is concentrated on the coasts, where groundwater reserves are becoming increasingly brackish and nearing depletion. The NASA observations found that humans are using more water than rains can replenish, and area groundwater levels declined by an average of one foot (30 centimeters) per year between 2002 and 2008 (www.nasa.org). Palmer (2007) predicts that 190/292, and Milly et al. (2005) predict that 97/152 of the rivers will face droughts in 2060, and the majority of the rivers they simulated may face reduction in water flows.

It is fairly common that individuals and societies bequeath economic, cultural and natural resources to future generations for altruistic reasons. The effort by the current generation to protect and save fresh water will directly affect its availability for the future generation. Both the quantity and quality of the water are equally important. Existing literature on freshwater management mainly concerns water consumption and regulations for one generation or particular regions (Frisvold and Caswell, 1995). There are a limited 
number of studies that consider overlapping intergenerational allocation in water consumption and pollution. Stephan (1996) separate overlapping generations (OLG) and infinitely lived agent (ILA) and argues that OLG should be adopted when it comes to the economics of global warming. John and Pechinino (1994) study overlapping intergenerational aspects of water consumption and pollution in a single period of time under certain limited circumstances. By extending the above models, this study attempts to address some of the key research questions: (i) does the parental altruism matter for the intergenerational water allocation? (ii) which economic factors (e.g., interest rate, wages, costs of pollution control, etc.), demographic factors (e.g., population growth rate), and environmental factors (e.g., water recharge rate, pollution assimilation rate, etc.) are the strongest predictors of parental altruism behavior? (iii) are there any policy approaches for improving altruistic behavior especially when under growing water shortage driven by demographic and natural factors?

The model of parental (current generation's) altruism developed in the study includes both quantity and quality aspects of freshwater. The study uses an approach similar to Jouvet, et al (2000), but with different constraints. The present model consists of an infinite-horizon economy with altruistic individuals living for two periods, a firm and two goods, one of which is a public good, i.e., water, and the other is a private good produced by the firm. The production of private good requires not only neoclassic production inputs (labor and capital), but also water resources. Individuals only work and earn wages in the first period during which they only consume water and save income. Then they retire in the second period during which they consume both water and 
the private good, leave some amount of water valued by the market water price, and voluntarily contribute some money to improve water quality. Households obtain utility from consuming both goods and suffer disutility by pollution in the second period. Since individuals are retired in the second period, the pollution can be only from the first period.

A representative parent tries to maximize the sum of utility from water consumption over his or her lifetime and an altruistic value derived from water bequeathed to his/her offspring, net of disutility from pollution from income-earning activity. This maximization is subject to income constraint, physical water constraint and pollution constraint. I characterize the effects of population growth, net recharge rate, degree of altruism, and the marginal utility from consumption or disutility from pollution on inter-generational water allocation. Next, individual parent's intergenerational decision will be integrated into a social planner's problem in order to characterize an inter-generational social equilibrium path for water allocation. I demonstrate the effect of climate uncertainty on the inter-generational water allocation by conducting a comparative static analysis of water recharge rate.

The current study provides the following key results: the last unit of pollution brings less disutility to households when the natural pollutant absorption rate is high. The more altruistic the parents are, the higher the marginal disutility they suffer from pollution. The higher the discount rate, the more satisfaction parents will have from the last unit of water consumption. The more altruistic the parents are or the faster the population grows, the less water they will consume in the first period. If the net water recharge rate is high, the marginal utility from consuming water in the first period could 
go down. Similar results are found for marginal utility of water consumption in the second period. Additional findings are that when the water market price increases in the second period, parents get more satisfaction consuming the last unit of water in the same period, and net recharge rate has ambiguous effect on the marginal utility for the second period. The results of the social planner's problem closely mirror that of the individual's problem above. Based on the above results, paper makes policy recommendations for improving altruistic behavior especially against climate-driven uncertainty in recharge rates and market-driven private water consumption behavior.

The rest of the paper is organizes as follows. In Section 1.2, I use OLG model for the Individual's optimal problem. Social planner's optimal problem is derived in Section 1.3, and some policies are suggested. The Last section will conclude.

\subsection{Model}

The model consists of an infinite-horizon economy with altruistic individuals living for two periods and a perfect competitive firm. The firm requires not only the neoclassic production inputs, labor $(L)$ and capital $(K)$, but also water resources $(X)$. Production function is denoted as $Y_{t}=f\left(K_{t}, L_{t}, X_{t}\right)=L_{t} f\left(\frac{K_{t}}{L_{t}}, \frac{X_{t}}{L_{t}}\right)$, and per capita output is $y_{t}=f\left(k_{t}, x_{t}\right)$, where $y_{t}=\frac{Y_{t}}{L_{t}}$ is the output-labor ratio, $k_{t}=\frac{K_{t}}{L_{t}}$ is the capital-labor ratio, and $x_{t}=\frac{X_{t}}{L_{t}}$ is the natural resource-labor ratio. $\mathrm{f}$ is twice continuously differentiable, positive, increasing, and strictly concave. I categorize the water use into two major groups: the use for producers $(X)$ and consumers $\left(C^{2}\right)$. The water consumption of 
households is assumed to be the water use for public supply and domestic use. Firms are to maximize their profit in the competitive market:

$\max _{K, L, X} \pi_{t}=Y_{t}-r_{t} K_{t}-w_{t} L_{t}$

Subject to

$Y_{t}=L_{t} f\left(\frac{K_{t}}{L_{t}}, \frac{X_{t}}{L_{t}}\right)$

Where $r_{t}$ is the interest rate, $w_{t}$ is the wage at which the labor gets paid. Water is used for free, and therefore, there is no cost for water in the profit function. However, it does not mean water can be used without any restriction. Water use by firm is constrained in later individual's problem. In this market, each factor is paid its marginal product:

$r_{t}=f_{k}\left(k_{t}, x_{t}\right), w_{t}=f\left(k_{t}, x_{t}\right)-k_{t} f_{k}\left(k_{t}, x_{t}\right)-x_{t} f_{x}\left(k_{t}, x_{t}\right)$,

where $f_{k}\left(k_{t}, x_{t}\right)=\frac{\partial f(\cdot)}{\partial k_{t}}, f_{x}\left(k_{t}, x_{t}\right)=\frac{\partial f(\cdot)}{\partial x_{t}}$.

\subsubsection{Individual's problem}

There are $\mathrm{N}$ homogeneous individuals in this economy, and they live for two periods with a constant population growth rate $\mathrm{n}, N_{t+1}=(1+n) N_{t}$. Each individual supplies one unit of labor inelastically. In the equilibrium, $N_{t}=L_{t}$. The population growth $\mathrm{n}$ could be either positive or negative for in most developing countries, population growth is positive and many developed countries have negative population growth. Whether or not population growth matters for the altruism is one of the key research concerns. The individuals not only derive utility from consuming water $c_{\mathrm{t}}^{2}$ when they are young and $c_{\mathrm{t}+1}^{2}$ when they are old for free. They also gain utility from the private good consumption while young (in the first period), $c_{t+1}^{1}$, and old (the second period) $c_{t+1}^{1}$. Previous studies (e.g., Karp et al., 2012) focus on altruism on pollution abatement, consumption of private 
goods, but not consumption of water. Individuals also derive disutility from the pollution when they are old, $\mathrm{P}_{\mathrm{t}+1}$. Generations only earn wages in the first period and consume in the second period (for the private goods). Following Agnani et al. (2005) we assume that households suffer disutility by pollution in the second period. Since individuals are retired in the second period, they produce goods and cause pollution only in the first period. Additive concave utility function can represent these preferences:

$U\left(c_{t, y}^{1}, c_{t+1, o}^{1}, c_{t, y}^{2}, c_{t+1, o}^{2}, P_{t+1}\right)=u\left(c_{t, y}^{1}, c_{t+1, o}^{1}, c_{t, y}^{2}, c_{t+1, o}^{2}\right)+v\left(P_{t+1}\right)$

Where $U_{c} \geq 0, U_{P} \leq 0, U_{c c} \leq 0, U_{p p} \leq 0$ and the cross-derivatives, $U_{c P}$ and $U_{P c}$ are zero. For the individuals, their optimal problem is to not only maximize their own net utility, but their offspring's. And $\beta$ is the utility discount rate, but also denotes the intergenerational degree of altruism, $\beta \epsilon[0,1]$. The higher $\beta$ is, the more the parents value their offspring's utility, or the more they care about the children. Formally, the individual's problem is to maximize

$V_{t}=U\left(c_{t, y}^{1}, c_{t+1, o}^{1}, c_{t, y}^{2}, c_{t+1, o}^{2}, P_{t+1}\right)+\beta V_{t+1}=\sum_{s=t}^{+\infty} \beta^{s-t} U\left(c_{s, y}^{1}, c_{s+1, o}^{1}, c_{s, y}^{2}, c_{s+1, o}^{2}, P_{s+1}\right)$

Subject to

$$
\begin{aligned}
& s_{t}=w_{t}+m_{t}-c_{t, y}^{1} \\
& R_{t+1} s_{t}=c_{t+1, o}^{1}+z_{t+1}+(1+n) m_{t+1} \\
& W_{t+1}=(1+\omega) W_{t}-N_{t} c_{t, y}^{2}-N_{t-1} c_{t, 0}^{2}-P_{t}-X_{t} \\
& P_{t+1}=\varphi Y_{t+1}+(1-\alpha) P_{t}-b \bar{Z}_{t+1}-b z_{t+1}, \quad(1-\alpha)>0 \\
& a_{t+i} \geq 0, \quad i=0,1,2, \ldots \infty \\
& z_{t+i} \geq 0, \quad i=0,1,2, \ldots \infty \\
& m_{t+i} \geq 0, \quad i=0,1,2, \ldots \infty
\end{aligned}
$$




$$
\begin{aligned}
& N_{t} c_{t, y}^{2}=c_{t, y}^{2}+\left(N_{t}-1\right) \bar{c}_{t, y}^{2} \\
& N_{t-1} c_{t, 0}^{2}=c_{t, 0}^{2}+\left(N_{t-1}-1\right) \bar{c}_{t, 0}^{2}
\end{aligned}
$$

In the first period (equation (1.5)), young altruists save $s_{t}$ from the wage they earn from work $w_{t}$ and monetary heritage from his/her ancestor $m_{t}$ net the private good consumption $c_{t}^{1}$. When those altruists grow old in the second period (equation (1.6)), they spend all their savings from the first period and interest $R_{t+1} s_{t}$ on the private good consumption $c_{t+1}^{1}$, pollution abatement $z_{t+1}$, and monetary bequest $m_{t+1}$, which is non negative, to their offspring with a population growth rate $\mathrm{n}$. The water naturally recharges in each period at a constant net rate $\omega$, the source of which can be local natural recharge or import from offsite. Equations (1.5) and (1.6) can be combined to form $R_{t+1}\left(w_{t}+\right.$ $\left.m_{t}-c_{t, y}^{1}\right)=c_{t+1, o}^{1}+z_{t+1}+(1+n) m_{t+1}$, which is the bequest constraint. Altruists not only care about the monetary bequest to their offspring, but also concern natural resource, water. Therefore, they contribute to water pollution abatement on the one hand; on the other hand, they physically save water for the next generations. Equation (1.7) represents the future water physical stock that will be left after current period consumption by young and old generations, use in production, and loss as a result of pollution and addition because of the net recharge. $N_{t} c_{t, y}^{2}=c_{t, y}^{2}+\left(N_{t}-1\right) \bar{c}_{t, y}^{2}$ and $N_{t-1} c_{t, 0}^{2}=c_{t, 0}^{2}+\left(N_{t-1}-\right.$ 1) $\bar{c}_{t, 0}^{2}$ means that the total water consumption consists of an individual's consumption and the rest of the population's consumption, population times the average individual consumption level.

Pollution is generated from two sources: industry and households. The EPA (Environmental Protection Agency) had identified point source, of which $80 \%$ is 
industrial sources and $20 \%$ were municipal discharge. The term $z_{t+1}$ is the contribution to the pollution abatement by an individual, and $\bar{Z}_{t+1}$ is how much the ones other than this individual contribute to abate the pollution. Individual's decision of whether or not to abate pollution is independent with each other, hence, they contribute $z_{t}$ to the pollution abatement, considering the others contribute $\bar{Z}_{t+1}$. Dynamic pollution change is captured by $\mathrm{P}_{\mathrm{t}+1}=\varphi \mathrm{Y}_{\mathrm{t}+1}+(1-\alpha) \mathrm{P}_{\mathrm{t}}-\mathrm{b} \overline{\mathrm{Z}}_{\mathrm{t}+1}-\mathrm{bz}_{\mathrm{t}+1}$. Pollution is accumulated by linear technology production and past pollution netting the pollution abatement from the individuals' contribution, which is also linear technology. Pollution results from production of industry at time $\mathrm{t}$ and is assumed to be linearly related to production with parameter $\varphi: \varphi Y_{t}$. A portion of the pollution naturally degrades at constant rate $\alpha$.

Empirically water price is usually underestimated since marginal user cost is not included. In my model, however, water price could be efficient since marginal user cost/water scarcity rent is considered, which is represented by the shadow price. Water price increases over time, not only because the scarcity rent rises over time, but also because as population grows each period, larger water project needs to be built, and higher operation and other fees will be applied.

To ensure that the economy and environment are sustainable, condition $\rho_{t+1} W_{t+1} \geq \rho_{t} W_{t}$ is imposed. Scarcity rent should be considered in the water price. That is, the less the available water, the higher the economic value of water is. The more water bequest for the future, the slower the water price rises.

Since firms borrow money from household's savings, market clears at $(1+$ $n) k_{t+1}=s_{t}$. In the model, monetary bequest, water bequest and pollution are state 
variables and all consumptions are control variables. Optimality conditions and results are developed in Appendix A.

$$
\text { Result 1: } \frac{U_{c_{t, y}^{1}}}{U_{c_{t+1, o}^{1}}}=R_{t+1} \geq 1 \text { or } c_{t+1, o}^{1}=R_{t+1} c_{t, y}^{1}
$$

Proposition 1: MRS (Marginal Rate of Substitution) of individual's consumption when they are young and old is equal to the interest rate factor. In another word, at the same level of utility, individual would give up amount of $R_{t+1}$ units of the private good consumption when they are old to obtain one unit of consumption when they are young. Therefore, individuals would prefer to consume the private good when they are old. And the higher the interest rate, the more individuals would prefer to consume when old. Especially when the utility function is CRRA (Constant Relative Risk Aversion) and in the form of natural logarithm, individuals prefer to consume the private good more when they are old, which is consumption when they are young plus the interest.

$$
\text { Result 2: } \frac{\beta U_{c_{t, y}^{2}}}{U_{c_{t+1, o}^{2}}}=\frac{\rho_{t+1}}{\rho_{t+2}} \text { or } \beta \rho_{t+2} c_{t+1, o}^{1}=c_{t, y}^{1} \rho_{t+1}
$$

Proposition 2: the discounted Marginal Rate of Substitution of the water consumption for individuals when they are young and old equals to the ratio of the water shadow price. The higher the shadow price ratio, the more of water consumption individuals have to give up for when they are old to obtain same amount of water consumption when they are young, Ceteris Paribas. The lower of discount rate, or the less altruistic the individuals are, they would like to give up more future consumption to their current consumption, Ceteris Paribas. If the utility function is CRRA and in the form of 
natural logarithm, the discounted value of water consumption of individuals when they are old equates the value of water consumption when they are young.

$$
\text { Result 3: } U_{c_{t+1, o}^{2}}-U_{P_{t+1}}=\beta v_{t+1}-(1-\alpha) \beta^{2} v_{t+2}
$$

Proposition 3: the net marginal benefit (marginal benefit from water consumption nets the marginal cost of water pollution) is the discounted value of the difference of shadow prices of pollution between two periods. The higher natural absorption rate $(\alpha)$ is, the higher net marginal benefit is.

$$
\text { Result 4: }(1+\omega) U_{c_{t+1, o}^{2}} \leq U_{c_{t, y}^{2}} \text { or }(1+\omega) \leq \frac{U_{c_{t, y}^{2}}^{2}}{U_{c_{t+1, o}^{2}}^{2}}
$$

Proposition 4: MRS of water consumption of one generation between two periods depends on the natural net recharge rate of water. The higher the net recharge rate, the more water consumption at old individuals have to give up for the water consumption at young, keeping the same utility level. When physical water bequest is operative, $(1+\omega)=\frac{U_{c_{t, y}^{2}}}{U_{c_{t+1, o}^{2}}^{2}}$ and when physical water bequest is not operative, $(1+$ $\omega)<\frac{U_{c_{t, y}^{2}}}{U_{c_{t+1, o}^{2}}^{2}}$. Therefore, individuals are more likely to consume water when they are old than that when they are young, when the water bequest is not operative. On the one hand, no water bequest from their forefather, they would have to consume less at young age. On the other hand, they do not have to leave water for their offspring, hence, they could consume more when they are old.

$$
\text { Result } 5: U_{c_{t, y}^{1}}-\frac{1+n}{\beta} U_{c_{t, o}^{1}} \leq 0 \text { or } \frac{U_{c_{t, o}^{1}}}{U_{c_{t, y}^{1}}} \geq \frac{\beta}{1+n}
$$


Proposition 5: MRS of private good consumption between two generations depends on the altruistic degree and population growth. If the individual is more altruistic (higher $\beta$ ), then he/she has to give up more of consuming for their offspring in the exchange of consuming for themselves. Therefore, it is intuitive that individual tends to leave more private good to the next generation when they are more altruistic. When the population growth rate increases, future generation will have to consume less on average if the parents' altruism degree stays the same level.

Steady state solutions vary in different scenarios when specific objective function form is given (see in Appendix A):

1) Contribution to pollution abatement is not operative ( $\mathrm{z}=0$, then $\left.b>\frac{\varphi \gamma(\beta+\delta)^{1-\lambda} \mathrm{A} \varepsilon^{-\varepsilon+1}\left(\frac{1-\varepsilon-\lambda}{w}\right)^{\varepsilon-\lambda}(\beta)^{\frac{1}{1-\varepsilon}(\varepsilon \beta+\varepsilon \delta-\delta(1-\beta \varepsilon-\lambda))^{\lambda} \ln P_{t}^{\max }}}{\alpha(1+n)^{2+\frac{\varepsilon}{1-\varepsilon}(1-\gamma-\eta)(1-\beta \varepsilon-\lambda) \ln c_{y}^{1}}{ }^{\max }} \equiv \underline{b}\right)$

a. When monetary bequest is operative $\left(\beta>\frac{\delta(1-\varepsilon-\lambda)}{\varepsilon(1+\delta)} \equiv \underline{\beta}\right)$

Result 6: $\frac{\beta R_{t+1}}{1+n} \theta_{t+1}=\theta_{t}$

Proposition 6: When the monetary bequest is operative, no matter whether the contribution to abatement or water bequest applies or not, the opportunity cost of monetary bequest is high in the future if there is fast population growth, or low altruistic degree, or low interest rate in the last period. Also, if the future monetary bequest has higher opportunity cost, altruists prefer to slow down the consumption of the private good now. The marginal rate of substitution of consumption between future and now depends positively on the population growth rate and negatively on the altruistic degree and current interest rate. 
Result 7: $\mathrm{k}^{*}=\frac{1-\varepsilon-\lambda}{\varepsilon w}\left(\frac{\beta}{1+n}\right)^{\frac{1}{1-\varepsilon}} R^{\frac{\varepsilon}{1-\varepsilon}}$

$$
\begin{aligned}
& \mathrm{m}^{*}=\frac{w}{1-\varepsilon-\lambda}\left(\varepsilon-\frac{\delta(1-\beta \varepsilon-\lambda)}{\beta+\delta}\right) \\
& \mathrm{P}^{*}=\frac{\varphi}{\alpha} \mathrm{A} \varepsilon^{-\varepsilon}\left(\frac{1-\varepsilon-\lambda}{w}\right)^{\varepsilon-\lambda}\left(\frac{\beta}{1+n}\right)^{\frac{\varepsilon}{1-\varepsilon}} R^{\frac{\varepsilon^{\varepsilon}}{1-\varepsilon}}\left(\varepsilon-\frac{\delta(1-\beta \varepsilon-\lambda)}{\beta+\delta}\right)^{\lambda}
\end{aligned}
$$

Proposition 7: since $\frac{\partial m^{*}}{\partial \beta}=\frac{w}{1-\varepsilon-\lambda}\left(\frac{\delta(1-\lambda)+\delta^{2} \varepsilon}{(\beta+\delta)^{2}}\right)>0$, then when monetary bequest is operative, the more altruistic the parents are, the more monetary bequest they are willing to leave to their offspring.

Proposition 8: since $\frac{\partial k^{*}}{\partial \beta}>0$, then when monetary bequest is applicable, the more altruistic the parents are, the more capital level will be because individuals will save more to leave bequest to the next generation.

Water pollution or pollution abatement relies on natural assimilation and private good production without individual's contribution.

a.1 when the water bequest is operative $(\mathrm{W}>0)$

$$
\beta(1+\omega)=\frac{\rho_{t+1}}{\rho_{t+2}}=\frac{\beta U_{c_{t, y}^{2}}}{U_{c_{t+1, o}^{2}}}
$$

Proposition 9: Hoteling's Rule applies (see the proof in the appendix A) when water bequest is operative. Water price increases over time as the recharge rate drops (during the drought year/years), or when people are less altruistic. When there is higher recharge rate, additional water consumption of the young generation brings more addition utility for them, as they do not have to worry too much about their future water consumption 


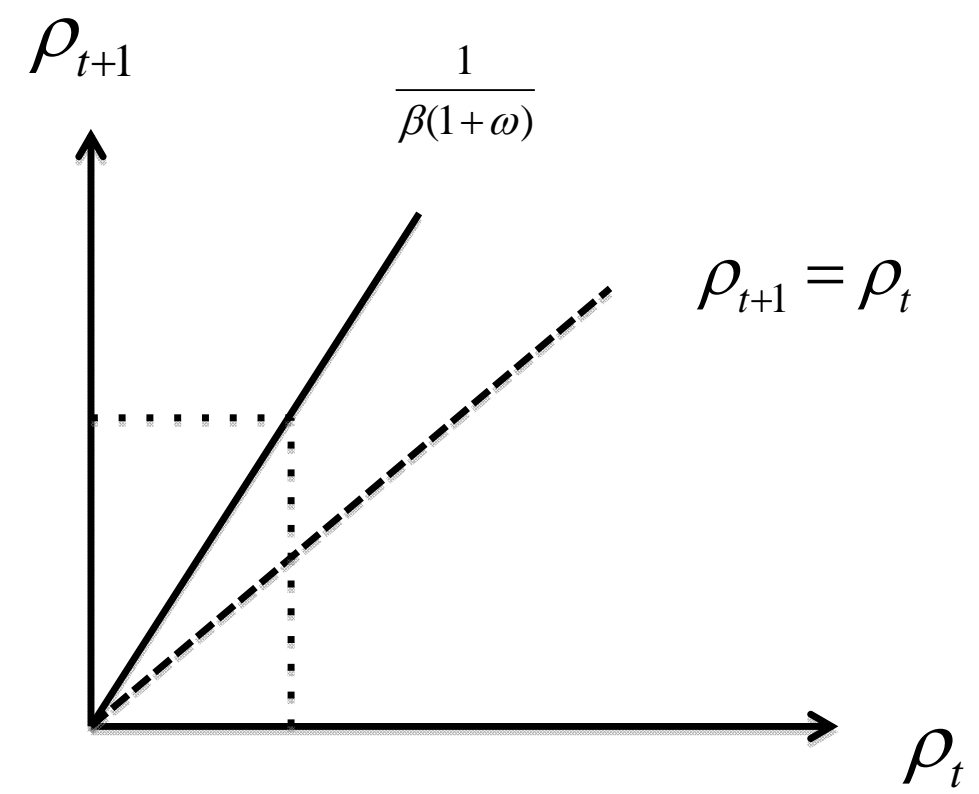

Figure 1-1. Shadow price ration over time (modified Hoteling's Rule)

In figure 1-1, the 45 degree line is obtained when shadow prices are equal over time, $\rho_{t}=\rho_{t+1}$. The dashed line captures the shadow price ratio over time as water becomes scarce, the slope of scarcity rent ratio line (the dash line) is above 45 degree and sustainability condition enforces $\frac{\rho_{t+2}}{\rho_{t+1}}$ which is represented by the arc with arrows below the line of $\frac{1}{\beta(1+\omega)}$. In this case, $W^{*}=\frac{1}{\omega}\left(N_{t} c_{y}^{2 *}+N_{t-1} c_{0}^{2 *}+P^{*}+X^{*}\right)$

a. 2 when the water bequest is non-operative $(\mathrm{W}=0)$

Proposition 10: The sustainability constraint is automatically satisfied. However, water might become scarce in this case if the natural net recharge is not sufficient enough to reach the consumption level and pollution level. 


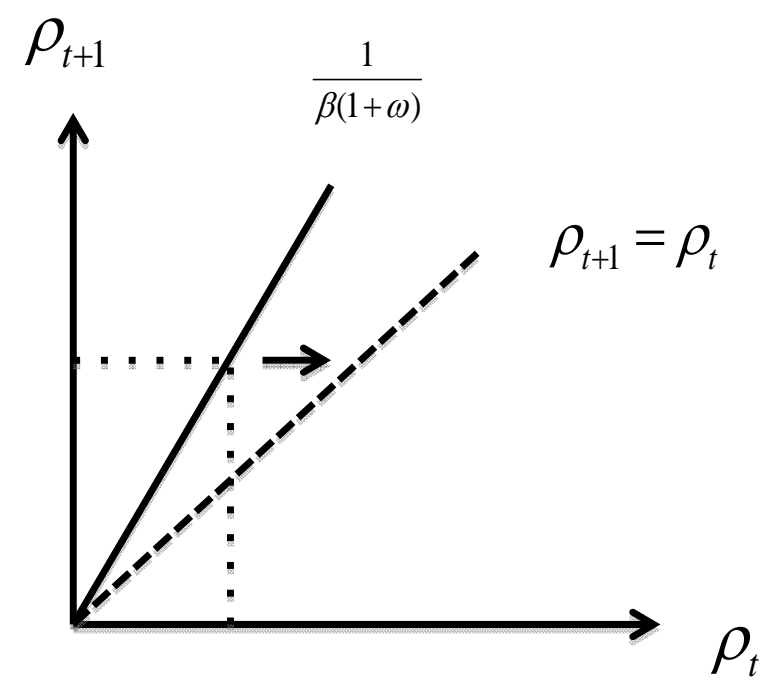

Figure 1-2 Shadow price ratio shift when net recharge rate decreases.

The price momentum line tilts to the right when there is no physical water bequest. Future price is lower than the one when there is water bequest, ceteris paribus.

b. When monetary bequest is non-operative $\left(\beta \leq \frac{\delta(1-\varepsilon-\lambda)}{\varepsilon(1+\delta)} \equiv \underline{\beta}\right)$ $m^{*}=0$ and $k^{*}=\frac{(1+n) \varepsilon \gamma \delta}{(1+n) \varepsilon \gamma \delta-R_{t}(1-\varepsilon-\lambda)+(1+n) \varepsilon^{2} \gamma}$

b.1. when the water bequest is operative $(\mathrm{W}>0)$

$$
\begin{gathered}
P^{*}=\frac{\varphi}{\alpha} A k^{* \varepsilon} x^{* \lambda} \\
W^{*}=\frac{1}{\omega}\left(N_{t} c_{y}^{2 *}+N_{t-1} c_{0}^{2 *}+P^{*}+X^{*}\right)
\end{gathered}
$$

b.2. when the water bequest is non-operative $(\mathrm{W}=0)$

$$
N_{t} c_{y}^{2 *}+N_{t-1} c_{0}^{2 *}+P^{*}+X^{*}=0
$$

2) When contribution to pollution abatement is operative $(\mathrm{z}>0$, then $\left.-\frac{\boldsymbol{\beta} \boldsymbol{\theta}_{t+1}}{\mathbf{1 + n}}+b \beta v_{t+1}\left[N_{t}(1+n)-1\right]-\beta v_{t+1}=0\right)$

a. When monetary bequest is operative $\left(\beta>\frac{(1-\varepsilon)}{\varepsilon}-\frac{\gamma}{\varepsilon \ln c_{y}^{1}}{ }^{\max } \equiv \underline{\beta}\right)$ 


$$
P^{*}=\frac{-(1-\gamma-\eta)}{\left[\beta^{2} \frac{\eta}{\beta c_{0, y}^{2} \ln c_{t, y}^{2 \max }}\left[\frac{1}{\beta(1+\omega)}\right]^{t+1}+\frac{\beta \theta_{t+1}-(1-\alpha) \beta^{2} \theta_{t+2}}{\left[b N_{t}(1+n)-b-1\right](1+n)}\right] \ln P_{t}^{\max }}
$$

a.1. when the water bequest is operative $(\mathrm{W}>0)$.

$\omega W^{*}=$

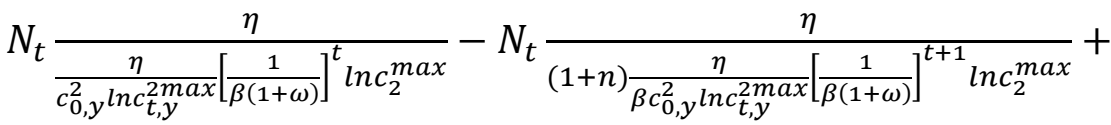

$\frac{-(1-\gamma-\eta)}{\left[\beta^{2} \frac{\eta}{\beta c_{0, y}^{2} \ln c_{t, y}^{2 \max }}\left[\frac{1}{\beta(1+\omega)}\right]^{t+1}+\frac{\beta \theta_{t+1}-(1-\alpha) \beta^{2} \theta t+2}{\left[b N_{t}(1+n)-b-1\right](1+n)}\right] \ln P_{t}^{\max }}-N_{t}\left(\frac{w_{t}{ }^{1-\varepsilon} R_{t}{ }^{\varepsilon}}{A \varepsilon^{\varepsilon}(1-\varepsilon-\lambda)^{1-\varepsilon}}\right)^{1 / \lambda}$

a.2. when the water bequest is non-operative (W=0). $N_{t} c_{y}^{2 *}+N_{t-1} c_{0}^{2 *}+P^{*}+$ $X^{*}=0$

b. When monetary bequest is non-operative $\left(\beta>\frac{(1-\varepsilon)}{\varepsilon}-\frac{\gamma}{\varepsilon \ln c_{y}^{1} \max } \equiv \underline{\beta}\right)$.

$$
\begin{aligned}
& z^{*}=\frac{(1+n)(1-\lambda+\delta \varepsilon) w-\delta R w(1-\varepsilon-\lambda)}{1-\varepsilon-\lambda} \\
& k^{*}=\frac{\varepsilon w}{R(1-\varepsilon-\lambda)} \text { and } m^{*}=0
\end{aligned}
$$

b.1. when the water bequest is operative $(\mathrm{W}>0)$

$$
\begin{gathered}
\omega W^{*}=N_{t} \frac{\eta}{\frac{\eta}{c_{0, y}^{2} \ln c_{t, y}^{2 \max }}\left[\frac{1}{\beta(1+\omega)}\right]^{t} \ln c_{2}^{\max }} \\
-N_{t} \frac{\eta}{(1+n) \frac{\eta}{\beta c_{0, y}^{2} \ln c_{t, y}^{2 \max }}\left[\frac{1}{\beta(1+\omega)}\right]^{t+1} \ln c_{2}^{\max }} \\
+\frac{-(1-\gamma-\eta)}{\left[\beta^{2} \frac{\eta}{\left.\beta c_{0, y}^{2} \ln c_{t, y}^{2 \max }\left[\frac{1}{\beta(1+\omega)}\right]^{t+1}+\frac{\beta \theta_{t+1}-(1-\alpha) \beta^{2} \theta_{t+2}}{\left[b N_{t}(1+n)-b-1\right](1+n)}\right] \ln P_{t}^{\text {max }}}\right.} \\
-N_{t}\left(\frac{w_{t}{ }^{1-\varepsilon} R_{t}{ }^{\varepsilon}}{A \varepsilon^{\varepsilon}(1-\varepsilon-\lambda)^{1-\varepsilon}}\right)^{1 / \lambda}
\end{gathered}
$$


b.2. when the water bequest is non-operative $(\mathrm{W}=0)$

$N_{t} c_{y}^{2 *}+N_{t-1} c_{0}^{2 *}+P^{*}+X^{*}=0$

Proposition 11: the real water price should be more than what individuals are willing to pay to pollute. From (a5) and (a7) $(1+b+\alpha b \beta-b \beta) U_{P}-U_{c_{o}^{2}}-\alpha U_{c_{o}^{1}}=0$.

$\frac{d c_{t+1,0}^{2}}{d P_{t+1}}=\frac{(1+b+\alpha b \beta-b \beta) U_{P P}}{u_{c_{O}^{2} c_{o}^{2}}}>0$

The higher the pollution, the higher the water consumption is. If more pollution is caused by more production, then individuals have more income and saving to make more contribution to the pollution abatement, so that they can also consume more water without affecting the sustainability. If more pollution is caused by less abatement, then individuals prefer to consume less water when they are young and more when they are old. It is easy to reason that higher self-absorption rate of water, more advanced technology of abatement, or less altruism makes this effect stronger. The graph in figure 3 tilts outward.

$\frac{d c_{0}^{1}}{d P}=\frac{\alpha(1+b+\alpha b \beta-b \beta) U_{P P}}{u_{c_{o}^{1} c_{o}^{1}}}>0$

When there is more pollution, individuals tend to consume more of the private good. If more pollution is caused by more production, then individuals have more income to spend on private good consumption. If more pollution is caused by less abatement, then individuals have more purchasing power from less spending on the pollution abatement, so that they prefer to consume more private good. It is the trade-off between private good and water quality. The effect will be reinforced by higher natural absorption rate of water. Obviously, if water is more self-cleaned, individuals do not have to spend 
as much money on the pollution abatement, and therefore, they can spend more on the private good consumption. Also, more advanced technology of abatement, or less altruism makes the effect stronger. The line in figure 1-3 will tilt outward in the situation.

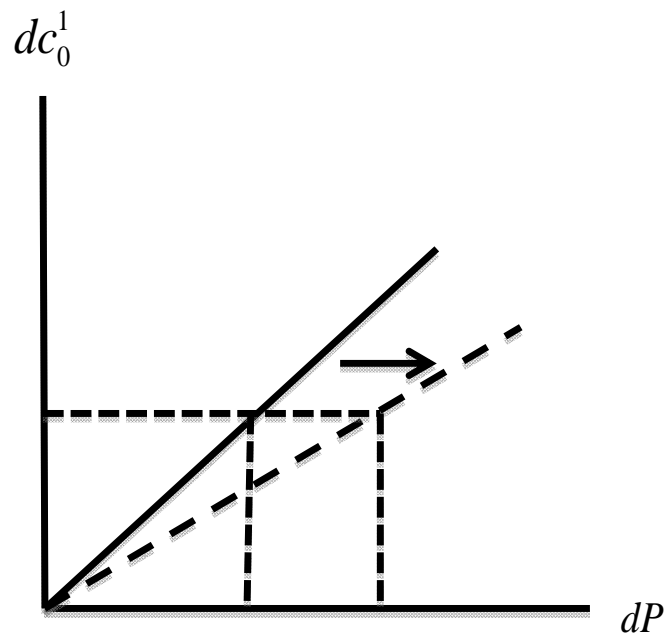

Figure 1-3 Marginal change of consumption of old to the pollution in period one

Proposition 12: When physical water bequest is not applicable, but other bequests are, from equation 1.7, consumption from individual and firm are non-zero if and only if accumulative pollution is negative. In another words, the pollution decreases from last period, or the pollution abatement is more than the new pollution: $\mu Y_{t+1}<$ $\alpha P_{t}+b \bar{Z}_{t+1}+b z_{t+1}$ (from equation 1.8). Therefore, individuals tend to use larger proportion of their savings than before to make enough contribution to the pollution abatement.

Proposition 13: When monetary bequest is not applicable, but other bequests are, from equation 1.6, wage is the only source of income that is distributed to private good consumption and pollution abatement contribution. Marginal disutility of pollution increases than that when there is no monetary bequest, since the individuals have to work 
harder and earn extra income so that pollution control level is not decreasing. If there is not more pollution control, individual has to consume less of private goods.

\subsubsection{Social equilibrium}

Extra pollution will cause externality or social cost, so intervention is needed. Individual consumers or producers may not take the external costs of production into account. However, a social planner may be interested in internalizing the external costs of pollution which is represented by the damage function, $D_{t+j}\left(P_{t+j}\right), \mathrm{j}=0,1,2$. Following Hershaft et al. (1976), the damage function has an "S" shape (Figure 1-4). At the beginning the marginal damage is increasing as more pollution, and at the end the marginal damage becomes stable and reaches zero.

In order to simplify the problem, I, here use a concave function as it shows at the

middle section and the last section of the curve. Formally, $D\left(P_{t}\right)=\kappa \frac{\ln P_{t}-\ln P_{t}^{\min }}{\ln P_{t}^{\max }}$. Where $\kappa$ can be greater, less than or even equal to 1 , since for such pollutant as nuclear waste, $\kappa \geq 1$; for some minor pollution, $\kappa<1$. The damage function represents the relationship between damage and pollution from same period.

For the social planner, the problem is maximize the present value of utility net of the external cost of pollution:

$V_{t}=\max \quad \sum_{t=0}^{+\infty} \beta^{t}\left[U\left(c_{t, y}^{1}, c_{t+1, o}^{1}, c_{t, y}^{2}, c_{t+1, o}^{2}, P_{t+1}\right)-D\left(P_{t+1}\right)\right]$

Subject to

$$
\begin{aligned}
& W_{t+1}=(1+\omega) W_{t}-N_{t} c_{t, y}^{2}-N_{t-1} c_{t, 0}^{2}-P_{t}-X_{t} \\
& P_{t+1}=\mu N f\left(k_{t+1}\right)+(1-\alpha) P_{t}-b N z_{t+1}
\end{aligned}
$$




$$
\begin{aligned}
& f\left(k_{t}\right)=(1+n) k_{t+1}+c_{t, y}^{1}+\frac{c_{t, 0}^{1}}{1+n}+b z_{t+1} \\
& z_{t+1} \geq 0, W_{t+1} \geq 0
\end{aligned}
$$

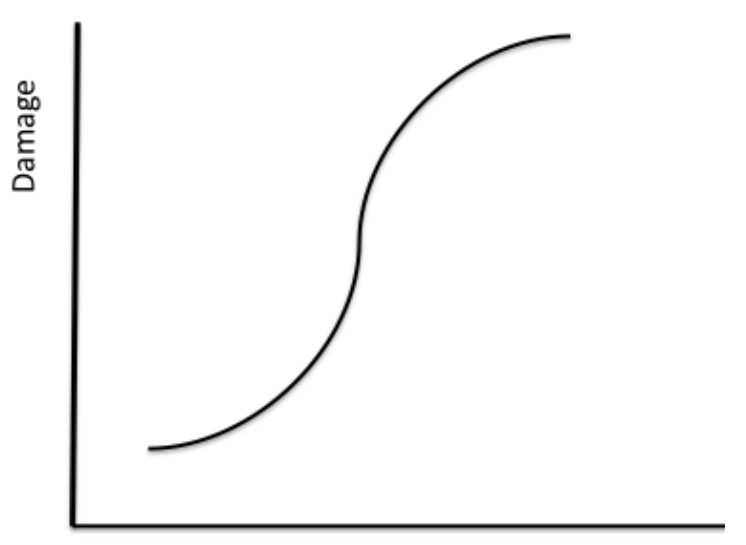

Amount of water-borne pollution

Figure 1-4 Environmental damage curve

Social planner considers the same altruistic degree, $\beta$, and the same utility function, U, as individuals do. Solution for the social planner's problem is shown in the Appendix B. From equation (b1 and a2), we obtain

$$
\frac{u_{c_{t, y}^{1}}}{u_{c_{t+1, o}^{1}}}=\frac{c_{t+1, o}^{1}}{\delta c_{t, y}^{1}}=\frac{(1+n) \varrho_{t+1}}{\beta \varrho_{t+2}}
$$

Note that MRS of private good consumption between two periods is different from that of the individual's problem, as seen in equation (a1, a2). However, note that

$$
\frac{u_{c_{t, y}^{2}}}{u_{c_{t+1, o}^{2}}}=\frac{c_{t+1, o}^{2}}{\delta c_{t, y}^{2}}=\frac{q_{t+1}}{\beta q_{t+2}}
$$

That is, MRS of water consumption between two periods is the same as that of the individual's problem; both are equal to the shadow price ratio with discount factor. 
When water bequest is non-negative, then $\beta^{2} q_{t+2}(1+\omega)=\beta q_{t+1}=>\frac{q_{t+2}}{q_{t+1}}=\frac{1}{\beta(1+\omega)}$, which is the same as that in the individual's problem. Modified Hoteling's Rule still holds. $\frac{d c_{t+1,0}^{2}}{d P_{t+1}}=\frac{N\left(g_{P P}-D_{P P}\right)}{u_{c_{o}^{2} c_{o}^{2}}}>0$

Water consumption when individuals are old is positively related to pollution created during their working period. That is, if individuals cause more pollution when young, they would have paid a larger amount toward pollution abatement, and thus, will have left themselves with more than proportionate amount of water for consumption when they are old.

$\frac{d c_{t+1,0}^{1}}{d P_{t+1}}=\frac{b N\left(g_{P P}-D_{P P}\right)}{-u_{c_{o}^{1} c_{o}^{1}}}<0$

More pollution makes individuals consume less of private good? when they are old, since they have to contribute more of their savings to the pollution abatement so that they can keep the water consumption level and sustainability.

$\frac{d c_{t+2, o}^{1}}{d P_{t+1}}=\frac{b N\left(g_{P P}-D_{P P}\right)}{(1-\alpha) U_{c_{o}^{1} c_{o}^{1}}}>0$

However, more pollution will make the private good consumption more affordable for their offspring, since the more pollution means the more production and in turn, more income. With higher income, the current generation will have the ability to provide for more monetary bequest for its offspring, which results into higher consumption of private goods by the latter. 


\subsection{Policy and management implications}

As we saw in the previous sections, individuals' behavior is different from social planner's decision. When pollution increases, private good consumption decreases in social planner's problem but increases in the individual's problem. An increase in interest rate might fix this discrepancy. To make sure the water consumption level does not decrease, government may subsidize water pollution abatement. Since the firm causes most pollution, government may impose a lump-sum tax/fine on firms as well. The final effect of taxes and subsidies on pollution would be the same.

Policies can be designed to promote the three types of bequests as introduced before: monetary bequest, physical water bequest and water quality bequest (the individuals' contributions to water pollution abatement), without hurting the social welfare. One of the major concerns is the physical water bequest, which is governed by the two coupled, dynamic constraints of available water and pollution, $W_{t+1}=$ $(1+\omega) W_{t}-N_{t} c_{t, y}^{2}-N_{t-1} c_{t, 0}^{2}-P_{t}-X_{t} \quad$ and $\quad P_{t+1}=\mu N f\left(k_{t+1}\right)+(1-\alpha) P_{t}-$ $b N z_{t+1}$. Any changes on the right hand side of the first constraint affects how much water is left for the next generation. However, the current physical water level is not controllable, and the other four terms are. There are three instruments that could be applied by the government. First, raising interest rate can influence the behavior of altruists. With higher interest rate applied to the individuals' following budget constraint, $m_{t+1}^{\prime}=R_{t+1}^{h}\left(w_{t}+m_{t}-c_{t, y}^{1}{ }^{\prime}\right)-c_{t+1, o}^{1}-z_{t+1}{ }^{\prime}$

Individuals tend to consume fewer amounts of private goods when they are young. They will save more money towards the second period, i.e., when they are old. More monetary 
contribution to pollution abatement also will occur because of more savings from the first period. Those savings could be used as more monetary bequest or water quality bequest.

First, if the extra savings from raising the interest rate is only used to monetary bequest, then $z_{t+1}^{\prime}=z_{t+1}$, and $m_{t+1}^{\prime}-m_{t+1}=R_{t+1}^{h}\left(w_{t}+m_{t}-c_{t, y}^{1}{ }^{\prime}\right)-c_{t+1, o}^{1}{ }^{\prime}-$ $R_{t+1}^{L}\left(w_{t}+m_{t}-c_{t, y}^{1}\right)+c_{t+1, o}^{1}$, where $R_{t+1}^{h}$ and $R_{t+1}^{L}$ are highly and low interest rates, respectively. The increment of interest rate should guarantee that the decrease of social welfare from reducing the consumption of good 1 when individuals are young at least equals the increase of social welfare from the rise of the consumption of good 1 when individuals are old. The change in the interest rate would not have any influence on the current generation's behavior of water consumption; nevertheless, it would affect their offspring since the next generation will face higher budget constraint.

Secondly, if the extra savings from raising the interest rate is only used for monetary bequest, then $m_{t+1}^{\prime}=m_{t+1}$, and $z_{t+1}^{\prime}-z_{t+1}=R_{t+1}^{h}\left(w_{t}+m_{t}-c_{t, y}^{1}\right)-$ $c_{t+1, o}^{1}{ }^{\prime}-R_{t+1}^{L}\left(w_{t}+m_{t}-c_{t, y}^{1}\right)+c_{t+1, o}^{1}$. The incremental contribution to pollution abatement results in more physical water bequest. And social welfare increases as less environmental damage occurs.

The other policy is to extend subsidies to individuals encouraging them to contribute more to the pollution abatement. By denoting subsidy as $s u b$, the budget constraint becomes

$$
\begin{aligned}
& m_{t+1}+s u b=R_{t+1}^{L}\left(w_{t}+m_{t}-c_{t, y}^{1}\right)-c_{t+1, o}^{1}-z_{t+1}{ }^{\prime} \\
& \text { and } s u b=z_{t+1}-z_{t+1}{ }^{\prime}
\end{aligned}
$$

At the same time, the firm's profit becomes: (pen=penalty) 
$\pi_{t}=Y_{t}-r_{t} K_{t}-w_{t} L_{t}-p e n$

Lump sum punishment, i.e., tax to the firm's pollution, is exogenous and like the Ricardian Equilibrium, optimal consumption levels of both goods in two periods and pollution level will stay the same. Moreover, the tax imposed to the firm could be used to subsidize the individual's consumption of private good or water, so that there will be no financial burden to the government for managing such water issue. Therefore, this policy would result in more pollution abatement from individuals and less pollution from the industry so that it guarantees the availability of physical water for the next generation.

Another way to change individual's behavior of water consumption is to set a higher real water price, which is more than what individuals are willing to pay for pollution. In this case, water price should be set at the shadow price of physical water bequest in social planner's problem, $q$, which is the marginal utility of water consumption. Therefore, the individual's and firm's water consumption could be reduced. Even though the total water consumption might not decrease as the population grows over time, yet this way could keep the total amount of water bequest not drop for less industrial consumption.

\subsection{Conclusion}

Freshwater as a special good that is demanded by households, firms and farms. It is a source of satisfaction to households, a factor of production for firms and farms, and a sink that absorbs all kinds of waste from human beings. Economic literature is replete with studies that recognize that individuals do express altruism for saving wealth and income for future generations. Very few studies have looked at altruism in the context of 
environmental resources and sustainability. I introduce parental altruism and sustainability in water management. If we care about our next generation, we would carefully choose the consumption level and control the pollution level of freshwater, and leave certain amount to them. The paper follows Jouvat, et al. (2000), and introduces parental altruism via three forms of bequest for managing the water resource. By solving individual's and social planner's problems, the study shows that the two problems are partially consistent with each other.

The study analyzes how individuals treat the trade offs of three types of bequest: monetary bequest, physical water bequest and water quality bequest (the contribution to abating water pollution). I find that altruistic degree, population growth rate, water natural assimilation rate affect those results. Based on the analysis on individual's problem and social planner's problem, it is evident that government instruments can be applied to promote economically and environmentally sustainable altruism. For instance, an increase in the interest rate, subsidies to water pollution abatement, or a lump-sum tax/fine to the firm could influence individuals' altruistic behavior. Those policy instruments are exogenous and will not reduce social welfare.

My model is applicable to other scarce natural and environmental resources like mines, and helpful for the policy maker to reinforce the environment sustainability. Further work on empirical testing of the model can be done by using some local data in order to design accurate policies specific to individual situations. Also, the model can be further improved by imposing the strong sustainability conditions that the amount of physical capital of natural resources will not decrease over time. Such a model would call for more stringent management and policy choices in the current period. 


\section{REFERENCES}

Ambec, S., \& Sprumont, Y. (2002). Sharing a river. Journal of Economic Theory, 107(2), 453-462.

Bhaduri, A., \& Barbier, E. B. (2003). Water Transfer and International River Basin Cooperative Management: The Case of the Ganges. Dept. of Economics, University of Wyoming.

Chakravorty, U., \& Umetsu, C. (2003). Basinwide water management: a spatial model. Journal of environmental economics and management, 45(1), 1-23.

De Stefano, L., Duncan, J., Dinar, S., Stahl, K., Strzepek, K., \& Wolf, A. T. (2010). Mapping the resilience of international river basins to future climate change-induced water variability. World Bank Water Sector Board Discussion Paper Series, 15.

Delin, Geoffrey N. and Risser, Dennis W., Ground-Water Recharge in Humid Areas of the United States--A Summary of Ground-Water Resources Program Studies, 2003-2006, USGS Fact Sheets 2007-3007

Dubey, Ram Sewak (2010). Fair Allocations in an Overlapping Generations Economy. Working paper.

Dinar, A., Rosegrant, M. W., \& Meinzen-Dick, R. S. (1997). Water allocation mechanisms: principles and examples (No. 1779). World Bank Publications.

Earnhart, Dietrich and Lizal, Lubomir, Pollution Control in Transition Economy: Do Firms Face Economies and/or Diseconomies of Scale.

Escapa, M., Ansuategui Cobo, J. A., \& Pérez, A. (2003). International and Intergenerational Dimensions of Climate Change: North-South Cooperation in an Overlapping Generations Framework (No. 2003-06). Universidad del País VascoDepartamento de Fundamentos del Análisis Económico I.

Frisvold, George B. and Caswell, Margriet F. (1995). A bargaining Model for Water Transfers Including Water Quality. ISBN 0-275-94782-3.

Gerlagh, R., \& van der Zwaan, B. C. C. (2001). Overlapping generations versus infinitely-lived agent: The case of global warming. Advances in the Economics of Environmental Resources, 3, 287-313.

Hajispyrou, S., Koundouri, P., \& Pashardes, P. (2002). Household demand and welfare: implications of water pricing in Cyprus. Environment and Development Economics, 7(4), 659-685. 
Hettige, Hemamala, Mani, Muthukumara, and Wheeler, David, 1998 study, "Industrial Pollution in Economic Development:Kuznets Revisited”

Hershaft, A. (1976). Air pollution damage functions. Environmental Science \& Technology, 10(10), 992-995. H. T. Heintz, Jr.,A. Hershaft, and G. C. Horak, National Damages of Air and Water Pollution.

Hoff, Ayoe, The Linear Approximation of the CES Function with $\mathrm{n}$ Input Variables,Marine Resource Economics, Volume 19, pp. 295-306

Hoos, Anne B., Recharge Rates and Aquiferhydraulic Characteristics for Selected Drainage Basins in Middle and East Tennessee, U.S. GEOLOGICAL SURVEY, WaterResources Investigations Report 90-4015

Huggett, M. (1993). The risk-free rate in heterogeneous-agent incomplete-insurance economies. Journal of economic Dynamics and Control, 17(5), 953-969.

John, A., \& Pecchenino, R. (1994). An overlapping generations model of growth and the environment. The Economic Journal, 1393-1410.

Karp, L., \& Rezai, A. (2012). The Political economy of environmental policy with overlapping generations.

Kløve, B., Allan, A., Bertrand, G., Druzynska, E., Ertürk, A., Goldscheider, N., ... \& Schipper, P. (2011). Groundwater dependent ecosystems. Part II. Ecosystem services and management in Europe under risk of climate change and land use intensification. Environmental Science \& Policy, 14(7), 782-793.

Koundouri, P. (2004). Current issues in the economics of groundwater resource management. Journal of Economic Surveys, 18(5), 703-740.

Koundouri, P., \& Christou, C. (2006). Dynamic adaptation to resource scarcity and backstop availability: theory and application to groundwater*. Australian Journal of Agricultural and Resource Economics, 50(2), 227-245.

Knapp, K. C., \& Olson, L. J. (1995). The economics of conjunctive groundwater management with stochastic surface supplies. Journal of Environmental Economics and Management, 28(3), 340-356.

Michel, P., Thibault, E., \& Vidal, J. P. (2006). Intergenerational altruism and neoclassical growth models. Handbook of the Economics of Giving, Altruism and Reciprocity, 2, 1055-1106. 
Milly PCD, Dunne KA, Vecchia AV (2005) Global pattern of trends in streamflow and water availability in a changing climate. Nature 438: 347-350

Palmer RN (2007) Final report of the Climate Change Technical Committee. A report prepared by the Climate Change Technical Subcommittee of the Regional Water Supply Planning Process, Seattle, WA.

Rockafellar, R. T. (2010). Hamiltonian trajectories and saddle points in mathematical economics. Control \& Cybernetics, 39(4).

Stephan, G. U. N. T. E. R., Müller-Fürstenberger, G., \& Previdoli, P. A. S. C. A. L. (1997). Overlapping generations or infinitely-lived agents: intergenerational altruism and the economics of global warming. Environmental and Resource Economics, 10(1), 27-40.

Vives, Antonio, Paris, Angela M., Benavides, Juan, Raymond, Peter D., Quiroga, Dario and Marcus, Javier, 2006. Financial Structuring of Infrastucture Projects in PublicPrivate Partnerships: An Application to Water Projects.Inter-American Development Bank.

Weil, P. (1989). Overlapping families of infinitely-lived agents. Journal of public economics, 38(2), 183-198. 


\section{APPENDIX A}

Langrage equation is set up as the following based on from equation 1.4 to equation 1.13

$$
\begin{aligned}
L=\sum_{s=t}^{\infty} \beta^{s-t} U & \left(c_{s, y}^{1}, c_{s+1, o}^{1}, c_{s, y}^{2}, c_{s+1, o}^{2}, P_{s+1}\right) \\
& +\sum_{s=t}^{\infty} \frac{\beta^{s-t+1} \theta_{s+1}}{1+n}\left[R_{s+1}\left(w_{s}+m_{s}-c_{s, y}^{1}\right)-c_{s+1, o}^{1}-z_{s+1}\right] \\
& +\sum_{s=t}^{\infty} \beta^{s-t+1} \rho_{s+1}\left\{(1+\omega) W_{\mathrm{s}}-\left[c_{t, y}^{2}+\left(\mathrm{N}_{\mathrm{t}}-1\right) \bar{c}_{t, y}^{2}\right]-\left[c_{t, 0}^{2}+\left(\mathrm{N}_{\mathrm{t}-1}\right.\right.\right. \\
& \left.\left.-1) \bar{c}_{t, 0}^{2}\right]-\mathrm{P}_{\mathrm{s}}-X_{s}\right\} \\
& +\sum_{s=t}^{\infty} \frac{\beta^{s-t+1} v_{s+1}}{b}\left[-\mathrm{P}_{\mathrm{s}+1}+\varphi \mathrm{Y}_{\mathrm{s}+1}+(1-\alpha) \mathrm{P}_{\mathrm{s}}+\bar{Z}_{t+1}\right]-\sum_{s=t}^{\infty} \beta^{s-t} \theta_{s} m_{s} \\
& -\sum_{s=t}^{\infty} \beta^{s-t} \rho_{s} W_{s}-\sum_{s=t}^{\infty} \beta^{s-t} v_{s} z_{s}
\end{aligned}
$$

$\lim _{t \rightarrow \infty} \beta^{t+1} \rho_{t+1}\left[(1+\omega) W_{\mathrm{t}}-\mathrm{N}_{\mathrm{t}} c_{t, y}^{2}-\frac{\mathrm{N}_{\mathrm{t}}}{1+n} c_{t, o}^{2}-\mathrm{P}_{\mathrm{t}}-X_{t}\right]=0$

$\lim _{t \rightarrow \infty} \beta^{t+1} v_{t+1} z_{t+1}=0$

$\lim _{t \rightarrow \infty} \beta^{t+1} \theta_{t+1}\left[R_{t+1}\left(w_{t}+m_{t}\right)-c_{t+1}^{1}-z_{t+1}\right]=0$

$\rho$ is considered as the water scarcity rent, which is the real value/price of water. Langrage is set up for there is a sustainability, such condition as below is applied.

$$
\rho_{t+1} W_{t+1} \geq \rho_{t} W_{t}
$$

Which represent the definition of sustainability.

(The control variables of $c_{t+1}^{1}, c_{t, y}^{2}, c_{t+1, y}^{2}, c_{t+1, o}^{2}, \mathrm{P}_{\mathrm{t}+1}$ ).

FOCs:

$$
\frac{\partial L}{\partial c_{t}^{1}}=U_{c_{t, y}^{1}}-\frac{\beta R_{t+1}}{1+n} \theta_{t+1}=0
$$




$$
\begin{aligned}
& \frac{\partial L}{\partial c_{t+1}^{1}}=U_{c_{t+1, o}^{1}}-\frac{\beta}{1+n} \theta_{t+1}=0 \\
& \frac{\partial L}{\partial c_{t, y}^{2}}=U_{c_{t, y}^{2}}-\beta \rho_{t+1}=0 \\
& \frac{\partial L}{\partial c_{t+1, o}^{2}}=U_{c_{t+1, o}^{2}}-\beta^{2} \rho_{t+2}=0 \\
& \frac{\partial L}{\partial P_{t+1}}=U_{P_{t+1}}-\beta^{2} \rho_{t+2}-\beta v_{t+1}+(1-\alpha) \beta^{2} v_{t+2}=0 \\
& \frac{\partial L}{\partial W_{t}}=\beta \rho_{t+1}(1+\omega)-\rho_{t} \leq 0(=0 \text { if } \mathrm{W}>0) \\
& \frac{\partial L}{\partial z_{t+1}}=-b U_{P_{t+1}}-\frac{\beta \theta_{t+1}}{1+n}-\beta v_{t+1} \leq 0(=0 \text { if } \mathrm{z}>0) \\
& \frac{\partial L}{\partial m_{t}}=\frac{\beta R_{t+1}}{1+n} \theta_{t+1}-\theta_{t} \leq 0(=0 \text { if } \mathrm{m}>0)
\end{aligned}
$$

Combining equations a1 and a2 : $U_{c_{t, y}^{1}}=R_{t+1} U_{c_{t+1, o}^{1}}$

Combining equations a3 and a4: $\frac{U_{c_{t, y}^{2}}}{U_{c_{t+1, o}^{2}}}=\frac{\rho_{t+1}}{\beta \rho_{t+2}}$

Combining equations a5 and a4:

$U_{c_{t+1, o}^{2}}-U_{P_{t+1}}=\beta v_{t+1}-(1-\alpha) \beta^{2} v_{t+2}$

If pollution abatement contribution is operative, then

$-b U_{P_{t+1}}-\frac{\beta \theta_{t+1}}{1+n}-\beta v_{t+1}=0$.

And equation (a9) combining (a1) and (a2) becomes

$U_{c_{t+1, o}^{2}}-(1-b) U_{P_{t+1}}+U_{c_{t+1, o}^{1}}-(1-\alpha) \beta\left(b U_{P_{t+2}}+\frac{U_{c_{t+1, y}^{1}}}{R_{t+1}}\right)=0$

Taking total differentials (by the assumption that $U$ is an additive function of $u$ and $v$, the cross derivatives are zero):

$\frac{d c_{t+1, y}^{1}}{d P_{t+1}}=-\frac{(1-\mathrm{b}) R_{t+2} U_{P P}}{(1-\alpha) \beta U_{c_{y}^{1} c_{y}^{1}}}<0$ 
$\frac{d P_{t+1}}{d c_{t+1,0}^{2}}=\frac{U_{c_{0}^{2} c_{o}^{2}}}{(1-b) U_{P P}}>0$

$\frac{d P_{t+1}}{d c_{t+1, o}^{1}}=\frac{U_{c_{o}^{1} c_{o}^{1}}}{(1-b) U_{P P}}>0$

Combing equations a6, a3 and a4: $(1+\omega) U_{c_{t+1, o}^{2}} \leq U_{c_{t, y}^{2}}$

Combining equations a8, a1 and a2: $U_{c_{t, y}^{1}}-\frac{1+n}{\beta} U_{c_{t, o}^{1}} \leq 0$

Denote

$U=\frac{\gamma\left(\ln c_{t, y}^{1}-\ln c_{t, y}^{1 \min }\right)}{\ln c_{t, y}^{1 \max }}+\frac{\gamma \delta\left(\ln c_{t+1, o}^{1}-\ln c_{t+1, o}^{1 \min }\right)}{\ln c_{t+1,0}^{1 m a x}}+\frac{\eta\left(\ln c_{t, y}^{2}-\ln c_{t, y}^{2 \min }\right)}{\ln c_{t, y}^{2 \max }}+\frac{\eta \delta\left(\ln c_{t+1, o}^{2}-\ln c_{t+1, o}^{2 \min }\right)}{\ln c_{t+1, o}^{2 m a x}}-$

$(1-\gamma-\eta) \frac{\ln P_{t}-\ln P_{t}^{\min }}{\ln P_{t}^{\max }}$

Assume that $\ln c_{t, y}^{1 \max }=\ln c_{t+1, o}^{1 \max }$ and $\ln c_{t, y}^{2 \max }=\ln c_{t+1, o}^{2 \max }, f\left(k_{t+1}, x_{t+1}\right)=A k_{t+1}^{\varepsilon} x_{t+1}^{\lambda}$

$R_{t+1}=A \varepsilon k_{t+1}^{\varepsilon-1} x_{t+1}^{\lambda}$

$w_{t}=f\left(k_{t}, x_{t}\right)-k_{t} f_{k}-x_{t} f_{x}=A k_{t}^{\varepsilon} x_{t}^{\lambda}-A \varepsilon k_{t}^{\varepsilon} x_{t}^{\lambda}-A \lambda k_{t}^{\varepsilon} x_{t}^{\lambda}=A(1-\varepsilon-\lambda) k_{t}^{\varepsilon} x_{t}^{\lambda}$

Therefore, the optimal levels of capital and water used in industry are as below.

$$
\begin{aligned}
& k_{t+1}=\frac{\varepsilon w_{t+1}}{R_{t+1}(1-\varepsilon-\lambda)} \\
& x_{t+1}^{\lambda}=\frac{1}{A}\left(\frac{1-\varepsilon-\lambda}{w_{t+1}}\right)^{\varepsilon-1}\left(\frac{R_{t+1}}{\varepsilon}\right)^{\varepsilon}
\end{aligned}
$$

Simplifying equation a1

$$
\frac{\gamma}{c_{t, y}^{1} \ln c_{y}^{1} \max }=\frac{\beta R_{t+1}}{1+n} \theta_{t+1}=>c_{t, y}^{1 *}=\frac{\gamma(1+n)}{\beta A \varepsilon k_{t+1}^{\varepsilon-1} x_{t+1}^{\lambda} \theta_{t+1} \ln c_{y}^{1}{ }^{\max }}
$$

It is the demand function of good 1 for the individual when they young.

Simplifying equation a2 


$$
\frac{\gamma \delta}{c_{t+1, o}^{1} \ln c_{y}^{1} \max }=\frac{\beta}{1+n} \theta_{t+1}=>c_{t+1, o}^{1 *}=\frac{\gamma \delta(1+n)}{\beta \theta_{t+1} \ln c_{y}^{1}{ }^{\max }}=>\theta_{t+1}=\frac{\gamma \delta(1+n)}{\beta c_{t+1, o}^{1} \ln c_{y}^{1}{ }^{\max }}
$$

I. when contribution is not operative $\left(\mathrm{z}=0\right.$, then $-\mathrm{b} \beta \rho_{t+2}-(1+b) v_{t+1}+$

$$
\left.\mathrm{b}(1-\alpha) \beta v_{t+2}-\frac{\theta_{t+1}}{1+n}<0\right)
$$

from (1.6) and combing market clearing condition $s_{t}=(1+n) k_{t+1}$

$$
\begin{aligned}
& m_{t+1}=A \varepsilon k_{t+1}^{\varepsilon} x_{t+1}^{\lambda}-\frac{1}{1+n} \frac{\gamma \delta(1+n)}{\beta \theta_{t+1} \ln c_{y}^{1}}{ }^{\max } \\
& m_{t}=A \varepsilon k_{t}^{\varepsilon} x_{t}^{\lambda}-\frac{\gamma \delta}{\beta \theta_{t} \ln c_{y}^{1}}{ }^{\max }
\end{aligned}
$$

Plugging into equation 1.5 and update one period forward,

$$
(1+n) k_{t+1}=A(1-\varepsilon-\lambda) k_{t}^{\varepsilon} x_{t}^{\lambda}+A \varepsilon k_{t}^{\varepsilon} x_{t}^{\lambda}-\frac{\gamma \delta}{\beta \theta_{t} \ln c_{y}^{1 \max }}-\frac{\gamma(1+n)}{\beta A \varepsilon k_{t+1}^{\varepsilon-1} x_{t+1}^{\lambda} \theta_{t+1} \ln c_{y}^{1}}{ }^{\max }
$$

When monetary bequest is operative, then a8 becomes:

$$
\frac{\beta A \varepsilon k_{t+1}^{\varepsilon-1} x_{t+1}^{\lambda}}{1+n} \theta_{t+1}=\theta_{t}
$$

Multiplying $\theta_{t}$ on the both sides of equation a15,

$$
(1+n) k_{t+1} \theta_{t}=\theta_{t} A(1-\lambda) k_{t}^{\varepsilon} x_{t}^{\lambda}-\frac{\gamma \delta}{\beta \ln c_{y}^{1}{ }^{\max }}-\frac{\gamma(1+n) \theta_{t}}{\beta A \varepsilon k_{t+1}^{\varepsilon-1} x_{t+1}^{\lambda} \theta_{t+1} \ln c_{y}^{1}{ }^{\max }}
$$

Define $\theta_{t} A k_{t}^{\varepsilon} x_{t}^{\lambda}=\xi_{t}$

Then

$\beta \varepsilon \xi_{t+1}=(1-\lambda) \xi_{t}-\frac{\gamma}{\ln c_{y}^{1} \max }\left(1+\frac{\delta}{\beta}\right)$

At the steady state: $\xi_{t+1}=\xi_{t}$

$(1-\beta \varepsilon-\lambda) \xi=\frac{\gamma}{\ln c_{y}^{1} \text { max }}\left(1+\frac{\delta}{\beta}\right)=>\xi=\frac{\gamma\left(1+\frac{\delta}{\beta}\right)}{(1-\beta \varepsilon-\lambda) \ln c_{y}^{1} \text { max }}$, 
Plugging into equations a18 and a19

$\frac{\beta \varepsilon \xi}{1+n}=\theta_{t}$, and $\theta_{t+1}=\frac{\xi}{A k_{t+1}^{\varepsilon} x_{t+1}^{\lambda}}$

Plugging into equation a14,

$$
\begin{gathered}
m^{*}=A k_{t}^{\varepsilon} x_{t}^{\lambda}\left(\varepsilon-\frac{\gamma \delta}{\xi \beta \ln c_{y}^{1} \text { max }}\right)=\frac{w}{1-\varepsilon-\lambda}\left(\varepsilon-\frac{\gamma \delta}{\frac{\gamma\left(1+\frac{\delta}{\beta}\right)}{(1-\beta \varepsilon-\lambda) \ln c_{y}^{1}{ }^{\text {max }}} \beta \ln c_{y}^{1}{ }^{\text {max }}}\right) \\
=\frac{w}{1-\varepsilon-\lambda}\left(\varepsilon-\frac{\delta(1-\beta \varepsilon-\lambda)}{\beta+\delta}\right)
\end{gathered}
$$

As long as $\varepsilon-\frac{\delta(1-\beta \varepsilon-\lambda)}{\beta+\delta}>0$, monetary bequest $m^{*}$ is applicable. Therefore,

$\beta>\frac{\delta(1-\varepsilon-\lambda)}{\varepsilon(1+\delta)} \equiv \underline{\beta}$

Therefore, when $\beta>\underline{\beta}$, monetary bequest is operative, which is $\frac{w}{1-\varepsilon-\lambda}\left(\varepsilon-\frac{\delta(1-\beta \varepsilon-\lambda)}{\beta+\delta}\right)$

$$
\begin{aligned}
& (1+n) k_{t+1}=A k_{t}^{\varepsilon} x_{t}^{\lambda}\left(\varepsilon-\frac{\delta(1-\beta \varepsilon-\lambda)}{\beta+\delta}\right) \\
& +A(1-\varepsilon-\lambda) k_{t}^{\varepsilon} x_{t}^{\lambda}-\frac{\gamma(1+n)}{\beta A \varepsilon k_{t+1}^{\varepsilon-1} x_{t+1}^{\lambda} \theta_{t+1} \ln c_{y}^{1} \max } \\
& =A k_{t}^{\varepsilon} x_{t}^{\lambda}\left(1-\frac{\delta(1-\beta \varepsilon-\lambda)}{\beta+\delta}-\lambda\right)-\frac{(1+n)(1-\beta \varepsilon-\lambda) k_{t+1}}{\beta \varepsilon+\varepsilon \delta} \\
& k_{t+1}=\frac{\varepsilon(\beta+\delta)}{(1+n)(1+\varepsilon \delta-\lambda)} A k_{t}^{\varepsilon} x_{t}^{\lambda}\left(\frac{\beta(1+\delta \varepsilon-\lambda)}{\beta+\delta}\right)=A k_{t}^{\varepsilon} x_{t}^{\lambda} \frac{\varepsilon \beta}{(1+n)}
\end{aligned}
$$

In the equilibrium, $k_{t+1}=k_{t}$

$$
k^{*}=\left(\frac{A \varepsilon \beta x_{t}^{\lambda}}{1+n}\right)^{\frac{1}{1-\varepsilon}}=\left(\frac{\varepsilon \beta\left(\frac{1-\varepsilon-\lambda}{w_{t+1}}\right)^{\varepsilon-1}\left(\frac{R_{t+1}}{\varepsilon}\right)^{\varepsilon}}{1+n}\right)^{\frac{1}{1-\varepsilon}}=\frac{1-\varepsilon-\lambda}{\varepsilon w}\left(\frac{\beta}{1+n}\right)^{\frac{1}{1-\varepsilon}} R^{\frac{\varepsilon}{1-\varepsilon}}
$$


And $\mathrm{P}^{*}=\frac{\varphi}{\alpha} \mathrm{Ak}^{* \varepsilon} \mathrm{X}^{* \lambda}$ from equation 1.8

$$
\begin{aligned}
& \mathrm{P}^{*}=\frac{\varphi}{\alpha} \mathrm{A}^{-\varepsilon}\left(\frac{1-\varepsilon-\lambda}{w}\right)^{\varepsilon-\lambda}\left(\frac{\beta}{1+n}\right)^{\frac{\varepsilon}{1-\varepsilon}} R^{\frac{\varepsilon^{\varepsilon}}{1-\varepsilon}}\left(\varepsilon-\frac{\delta(1-\beta \varepsilon-\lambda)}{\beta+\delta}\right)^{\lambda} \\
& \theta_{t+1}=\frac{\beta \varepsilon \xi}{1+n}=\frac{\beta \varepsilon}{(1+n)} \frac{\gamma\left(1+\frac{\delta}{\beta}\right)}{(1-\beta \varepsilon-\lambda) \ln c_{y}^{1} \text { max }}
\end{aligned}
$$

From a7:

$$
v_{t+1}=\frac{-b U_{P_{t+1}}}{\beta}-\frac{\theta_{t+1}}{1+n}
$$

$$
\begin{aligned}
& =-\frac{\beta \varepsilon}{(1+n)^{2}} \frac{\gamma\left(1+\frac{\delta}{\beta}\right)}{(1-\beta \varepsilon-\lambda) \ln c_{y}^{1} \text { max }} \\
& +\frac{b(1-\gamma-\eta)}{\frac{\varphi \beta}{\alpha} A \varepsilon^{-\varepsilon}\left(\frac{1-\varepsilon-\lambda}{w}\right)^{\varepsilon-\lambda}\left(\frac{\beta}{1+n}\right)^{\frac{\varepsilon}{1-\varepsilon}}\left(\varepsilon-\frac{\delta(1-\beta \varepsilon-\lambda)}{\beta+\delta}\right)^{\lambda} \ln P_{t}^{\max }}
\end{aligned}
$$$$
>0
$$

Therefore, simplifying the equation above,

$$
\begin{gathered}
b>\frac{\varphi \gamma(\beta+\delta)^{1-\lambda} A \varepsilon^{-\varepsilon+1}\left(\frac{1-\varepsilon-\lambda}{w}\right)^{\varepsilon-\lambda}(\beta)^{\frac{1}{1-\varepsilon}}(\varepsilon \beta+\varepsilon \delta-\delta(1-\beta \varepsilon-\lambda))^{\lambda} \ln P_{t}^{\max }}{\alpha(1+n)^{2+\frac{\varepsilon}{1-\varepsilon}}(1-\gamma-\eta)(1-\beta \varepsilon-\lambda) \ln c_{y}^{1} \max } \\
\equiv \underline{b}
\end{gathered}
$$

Therefore, this is the constraint for pollution abatement contribution being applicable.

When $\beta \leq \underline{\beta}$, the motive of monetary bequest is too low to take action.

$m^{*}=0$, then from equation 1.5 ,

$(1+n) k_{t+1}=A(1-\varepsilon-\lambda) k_{t}^{\varepsilon} x_{t}^{\lambda}-\frac{\gamma(1+n)}{\beta A \varepsilon k_{t+1}^{\varepsilon-1} x_{t+1}^{\lambda} \theta_{t+1} \ln c_{y}^{1}}$

From 1.6 


$$
\begin{aligned}
& (1+n) k_{t+1} A \varepsilon k_{t+1}^{\varepsilon-1} x_{t+1}^{\lambda}=\frac{\gamma \delta(1+n)}{\beta \theta_{t+1} \ln c_{y}^{1}}{ }^{\max }=(1+n) k_{t+1} R_{t+1} \\
& A k_{t+1}^{\varepsilon-1} x_{t+1}^{\lambda}=\frac{\gamma \delta}{\varepsilon k_{t+1} \beta \theta_{t+1} \operatorname{lnc} c_{y}^{\text {max }}} \text { or } \theta_{t}=\frac{\gamma \delta}{k_{t} R_{t} \beta \operatorname{lnc} c_{y}^{\text {max }}}
\end{aligned}
$$

Therefore, equation a20 becomes

$$
(1+n) k_{t+1}=(1-\varepsilon-\lambda) \frac{k_{t} R_{t}}{\varepsilon \gamma \delta}-\frac{\varepsilon k_{t+1}(1+n)}{\delta}
$$

In the steady state, $k_{t}=k_{t+1}$, therefore,

$$
k^{*}\left(1-(1-\varepsilon-\lambda) \frac{R_{t}}{(1+n) \varepsilon \gamma \delta}+\frac{\varepsilon}{\delta}\right)=\frac{(1+n) \varepsilon \gamma \delta}{(1+n) \varepsilon \gamma \delta-R_{t}(1-\varepsilon-\lambda)+(1+n) \varepsilon^{2} \gamma}
$$

II. When contribution is operative $\left(\mathrm{z}>0\right.$, then $\frac{\beta \theta_{t+1}}{1+n}+\beta(1+b) v_{t+1}=$

$$
-b \beta^{2} \rho_{t+2}+\mathrm{b}(1-\alpha) \beta^{2} v_{t+2}
$$

From (2), combining $s_{t}=(1+n) k_{t+1}$

$$
m_{t}^{*}=(1+n) k_{t+1}-A(1-\varepsilon-\lambda) k_{t}^{\varepsilon} x_{t}^{\lambda}+\frac{\gamma(1+n)}{\beta A \varepsilon k_{t+1}^{\varepsilon-1} x_{t+1}^{\lambda} \theta_{t+1} \ln c_{y}^{1}}{ }^{\max }(\mathrm{a} .21)
$$

Therefore, $m_{t+1}^{*}=(1+n) k_{t+2}-A(1-\varepsilon-\lambda) k_{t+1}^{\varepsilon} x_{t+1}^{\lambda}+\frac{\gamma(1+n)}{\beta A \varepsilon k_{t+2}^{\varepsilon-1} x_{t+2}^{\lambda} \theta_{t+2} \ln c_{y}^{1}}$

$$
z_{t+1}=(1+n) A \varepsilon k_{t+1}^{\varepsilon-1} x_{t+1}^{\lambda} k_{t+1}-\frac{\gamma \delta(1+n)}{\beta \theta_{t+1} \operatorname{lnc} c_{y}^{\text {max }}}-(1+n)\left[(1+n) k_{t+2}-\right.
$$

$\left.A(1-\varepsilon-\lambda) k_{t+1}^{\varepsilon} x_{t+1}^{\lambda}+\frac{\gamma(1+n)}{\beta A \varepsilon k_{t+2}^{\varepsilon-1} x_{t+2}^{\lambda} \theta_{t+2} \operatorname{lnc} c_{y}^{\max }}\right]=(1+n)(1-\lambda) A k_{t+1}^{\varepsilon} x_{t+1}^{\lambda}-$

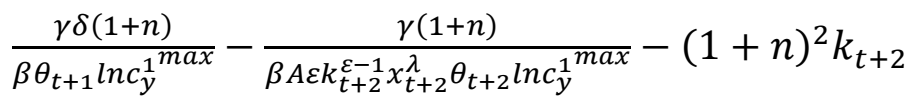

i. When monetary bequest is not operative:

Now equation (a21) $=0$, therefore, with define $\theta_{t} A k_{t}^{\varepsilon} x_{t}^{\lambda}=\xi_{t}$

$$
z_{t+1}=\frac{(1+n)(1-\lambda) w_{t+1}}{1-\varepsilon-\lambda}-\delta R_{t+1} c_{t, y}^{1}
$$

And $(1+n) s_{t+1}-w_{t}+c_{t, y}^{1}=0$ 
Therefore, $z^{*}=\frac{(1+n)(1-\lambda) w}{1-\varepsilon-\lambda}+\delta R\left[(1+n) \frac{\varepsilon w}{R(1-\varepsilon-\lambda)}-w\right]=\frac{(1+n)(1-\lambda+\delta \varepsilon) w-\delta R w(1-\varepsilon-\lambda)}{1-\varepsilon-\lambda}$

$$
k^{*}=\frac{\varepsilon W}{R(1-\varepsilon-\lambda)}
$$

ii. When monetary bequest is operative, then a8:

$$
\frac{\beta A \varepsilon k_{t}^{\varepsilon-1} x_{t}^{\lambda}}{1+n} \theta_{t+1}=\theta_{t}=\frac{\beta \varepsilon \xi_{t+1}}{(1+n) k_{t+1}}
$$

Assume $c_{0, y}^{1}$ is givien, then $\theta_{1}=\frac{\gamma \delta(1+n)}{\beta c_{1, o}^{1} \ln c_{y}^{1}}{ }^{\max }$, and then $\theta_{t}=\left(\frac{1+n}{\beta A \varepsilon k_{t}^{\varepsilon-1} x_{t}^{\lambda}}\right)^{t}$

Equation (a22) becomes:

$$
\begin{aligned}
\theta_{t+1} z_{t+1}=(1 & +n) \theta_{t+1} A k_{t+1}^{\varepsilon} x_{t+1}^{\lambda}-\frac{\gamma \delta(1+n)}{\beta \ln c_{y}^{1} \max }-\frac{\theta_{t+1} \gamma(\mathbf{1}+\boldsymbol{n})^{2}}{\beta A \varepsilon k_{t+1}^{\varepsilon-1} x_{t+1}^{\lambda} \theta_{t+2} \ln c_{y}^{1} \max } \\
& +(1+n)^{2} k_{t+2} \theta_{t+1} \\
& =(1+n) \theta_{t+1} A k_{t+1}^{\varepsilon} x_{t+1}^{\lambda}-\frac{\gamma \delta(1+n)(1+\beta)}{\beta \ln c_{y}^{1}} \\
& +(1+n) \theta_{t+2} \beta A \varepsilon k_{t+2}^{\varepsilon} x_{t+2}^{\lambda}
\end{aligned}
$$

With $\theta_{t} A k_{t}^{\varepsilon} x_{t}^{\lambda}=\xi_{t}$,

$$
\begin{aligned}
& \frac{\beta \varepsilon \xi_{t+2}}{(1+n) k_{t+2}} z_{t+1}=\left(\xi_{t+1}+\beta \varepsilon \xi_{t+2}\right)(1+n)-\frac{\gamma \delta(1+n)(1+\beta)}{\beta \ln c_{y}^{1} \text { max }} \\
& z_{t+1}=\left[\left(\xi_{t+1}+\beta \pi \xi_{t+2}\right)(1+n)-\frac{\gamma \delta(1+n)(1+\beta)}{\beta \ln c_{y}^{1} \max }\right] \frac{(1+n) k_{t+2}}{\beta \pi \xi_{t+2}}>0
\end{aligned}
$$

Therefore, $\left(\xi_{t+1}+\beta \varepsilon \xi_{t+2}\right)-\frac{\gamma \delta(1+\beta)}{\beta \ln c_{y}^{1}}{ }^{\max }>0$

At the steady state: $\xi_{t+1}=\xi_{t+2}$

Hence, $\xi(1+\beta \varepsilon)>\frac{\gamma \delta(1+\beta)}{\beta \ln c_{y}^{1}}=>\xi(1+\beta \varepsilon)>\frac{\gamma \delta(1+\beta)}{\beta \ln c_{y}^{1}}$ 
Plugging in

$$
\begin{aligned}
& \frac{\beta \varepsilon \xi_{t+1}}{(1+n) k_{t+1}} m_{t}=\beta \varepsilon \xi_{t+1}-(1-\varepsilon) \xi_{t}+\frac{\gamma \xi_{t+1}}{\ln c_{y}^{1} \max }>0 \\
& \beta \varepsilon-(1-\varepsilon)+\frac{\gamma}{\ln c_{y}^{1} \text { max }}>0=>\beta>\frac{(1-\varepsilon)}{\varepsilon}-\frac{\gamma}{\varepsilon \ln c_{y}^{1} \text { max }} \equiv \underline{\beta}
\end{aligned}
$$

Wquation a3 is expressed as

$$
\frac{\eta}{c_{t, y}^{2} \ln c_{t, y}^{2 m a x}}=\beta \rho_{t+1}=>c_{t, y}^{2}=\frac{\eta}{\beta \rho_{t+1} \ln c_{2}^{\max }}=>\rho_{1}=\frac{\eta}{\beta c_{0, y}^{2} \ln c_{t, y}^{2 \max }}
$$

Equation a4 is expressed as

$$
\frac{\eta \delta}{c_{t+1, o}^{2} \ln c_{t+1, o}^{2 \max }}=\beta^{2} \rho_{t+2}=>c_{t+1, o}^{2}=\frac{\eta}{\beta^{2} \rho_{t+2} \ln c_{2}^{\max }}
$$

When the water bequest is operative, a6:

$\beta \rho_{t+1}(1+\omega)=\rho_{t}$

Therefore, $\rho_{t}=\frac{\eta}{\beta c_{0, y}^{2} \ln c_{t, y}^{2 \max }}\left[\frac{1}{\beta(1+\omega)}\right]^{t-1}$

When contribution to abatement is operative: a7 becomes:

$$
\begin{aligned}
& \frac{\beta \theta_{t+1}}{1+n}=b \beta v_{t+1}\left[N_{t}(1+n)-1\right]-\beta v_{t+1} \\
& \frac{\theta_{t+1}}{1+n}=v_{t+1}\left[b N_{t}(1+n)-b-1\right] \quad \Rightarrow \quad v_{t+1}=\frac{\beta \pi \xi_{t+1}}{\left[b N_{t}(1+n)-b-1\right](1+n)^{2} k_{t+1}}=>v_{t+2}= \\
& \frac{\beta \pi \xi_{t+2}}{\left[b N_{t+1}(1+n)-b-1\right](1+n)^{2} k_{t+2}}
\end{aligned}
$$

Equation a5 is express as

$$
\begin{aligned}
& -\frac{(1-\gamma-\eta)}{P_{t} \ln P_{t}^{\max }}=\beta^{2} \rho_{t+2}+\beta v_{t+1}-(1-\alpha) \beta^{2} v_{t+2}=> \\
& P_{t}=\frac{-(1-\gamma-\eta)}{\left[\beta^{2} \frac{\eta}{\beta c_{0, y}^{2} \ln c_{t, y}^{2 \max }}\left[\frac{1}{\beta(1+\omega)}\right]^{t+1}+\frac{\beta \theta_{t+1}-(1-\alpha) \beta^{2} \theta_{t+2}}{\left[b N_{t}(1+n)-b-1\right](1+n)}\right] \ln P_{t}^{\max }}
\end{aligned}
$$




$$
P_{t+1}=\frac{-(1-\gamma-\eta)}{\left[\beta^{2} \frac{\eta}{\beta c_{0, y}^{2} \ln c_{t, y}^{2 m a x}}\left[\frac{1}{\beta(1+\omega)}\right]^{t+2}+\frac{\beta \theta_{t+2}-(1-\alpha) \beta^{2} \theta_{t+3}}{\left[b N_{t}(1+n)-b-1\right](1+n)}\right] \ln P_{t}^{\max }}
$$

From equation (5) and combing (a9)

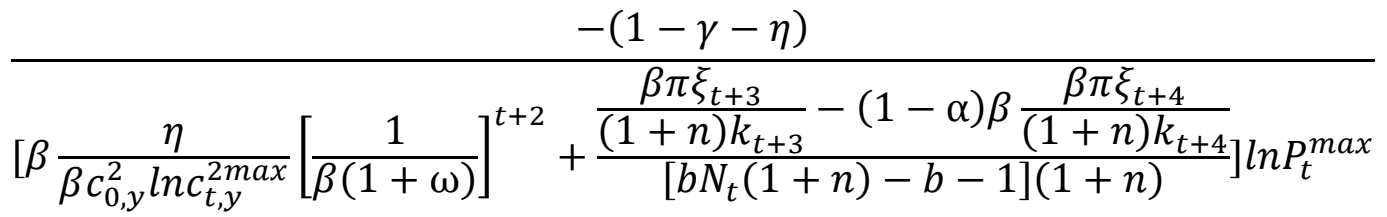

$$
\begin{aligned}
& =\beta \varphi A k_{t+1}^{\varepsilon} x_{t+1}^{\lambda} \\
& -(1
\end{aligned}
$$

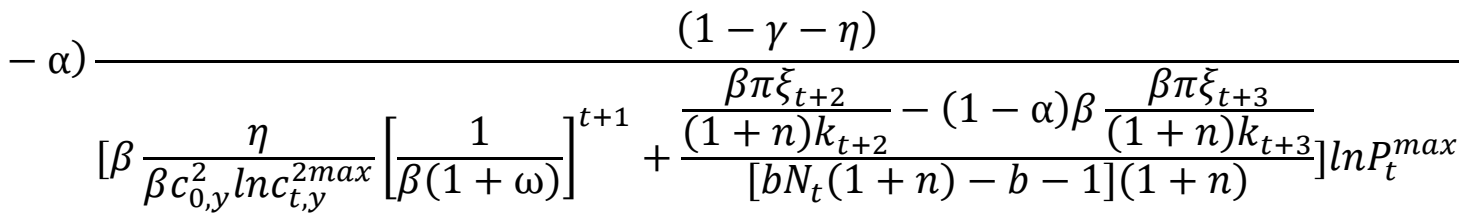

$$
\begin{aligned}
& -\beta b N_{t}\left[\left(\xi_{t+1}+\beta \pi \xi_{t+2}\right)(1+n)-\frac{\gamma \delta(1+n)(1+\beta)}{\ln c_{y}^{1}}\right] \\
& -(1-\gamma-\eta) \frac{\beta \pi \xi_{t+2}}{(1+n) k_{t+2}} \\
& {\left[\beta \frac{\eta}{\beta c_{0, y}^{2} \ln c_{t, y}^{2 \max }}\left[\frac{1}{\beta(1+\omega)}\right]^{t+2}+\frac{\left.\frac{\beta \pi \xi_{t+3}}{(1+n) k_{t+3}}-(1-\alpha) \beta \frac{\beta \pi \xi_{t+4}}{(1+n) k_{t+4}}\right] \ln P_{t}^{\max }}{\left[b N_{t}(1+n)-b-1\right](1+n)}\right.} \\
& =\beta \varphi \xi_{t+1}-(1-\alpha)
\end{aligned}
$$




$$
\begin{gathered}
\frac{(1-\gamma-\eta) \frac{\beta \pi \xi_{t+2}}{(1+n) k_{t+2}}}{\left[\beta \frac{\eta}{\beta c_{0, y}^{2} \ln c_{t, y}^{2 m a x}}\left[\frac{1}{\beta(1+\omega)}\right]^{t+1}+\frac{\frac{\beta \pi \xi_{t+2}}{(1+n) k_{t+2}}-(1-\alpha) \beta \frac{\beta \pi \xi_{t+3}}{(1+n) k_{t+3}}}{\left[b N_{t}(1+n)-b-1\right](1+n)}\right] \ln P_{t}^{\text {max }}} \\
-\beta b N_{t}\left[\left(\xi_{t+1}+\beta \pi \xi_{t+2}\right)(1+n)-\frac{\frac{\beta \pi \xi_{t+2}}{(1+n) k_{t+2}} \gamma \delta(1+n)(1+\beta)}{\ln c_{y}^{1} \text { max }^{2}}\right]
\end{gathered}
$$

In steady state, $\xi_{t+1}=\xi_{t+2}=\xi_{t+3}=\xi_{t+4}$

Equation (4) becomes:

$$
\begin{aligned}
& W_{\mathrm{t}+1}=(1+\omega) W_{\mathrm{t}}-\mathrm{N}_{\mathrm{t}} \frac{\eta}{\frac{\eta}{c_{0, y}^{2} \ln c_{t, y}^{2 \max }}\left[\frac{1}{\beta(1+\omega)}\right]^{t} \ln c_{2}^{\max }}-\mathrm{N}_{\mathrm{t}} \frac{\eta}{(1+n) \frac{\eta}{\beta c_{0, y}^{2} \ln c_{t, y}^{2 \max }}\left[\frac{1}{\beta(1+\omega)}\right]^{t+1} \ln c_{2}^{\max }}+ \\
& \frac{-(1-\gamma-\eta)}{\left[\beta^{2} \frac{\eta}{\beta c_{0, y}^{2} \ln c_{t, y}^{2 \max }}\left[\frac{1}{\beta(1+\omega)}\right]^{t+1}+\frac{\beta \theta_{t+1}-(1-\alpha) \beta^{2} \theta_{t+2}}{\left[b N_{t}(1+n)-b-1\right](1+n)} \ln P_{t}^{\max }\right.}-\mathrm{N}_{\mathrm{t}}\left(\frac{w_{t}^{1-\varepsilon} R_{t}{ }^{\varepsilon}}{A \varepsilon^{\varepsilon}(1-\varepsilon-\lambda)^{1-\varepsilon}}\right)^{1 / \lambda}
\end{aligned}
$$

Equations a5 and a7 are combined as :

$$
\begin{aligned}
& (1+b+\alpha b \beta-b \beta) U_{P}-U_{c_{o}^{2}}-\alpha U_{c_{o}^{1}}=0 \\
& \frac{d c_{t+1,0}^{2}}{d P_{t+1}}=\frac{(1+b+\alpha b \beta-b \beta) U_{P P}}{u_{c_{o}^{2} c_{o}^{2}}}>0
\end{aligned}
$$

Since $1+b+\alpha b \beta-b \beta>0, u_{c_{o}^{2} c_{o}^{2}}<0$ and $u_{c_{o}^{2} c_{o}^{2}}<0$, then

$$
\frac{d c_{0}^{1}}{d P}=\frac{\alpha(1+b+\alpha b \beta-b \beta) U_{P P}}{u_{c_{o}^{1} c_{o}^{1}}}>0
$$




\section{APPENDIX B}

Social Equilibrium

$$
\begin{aligned}
& L=\sum_{t=-1}^{+\infty} \beta^{t}\left[U\left(c_{t, y}^{1}, c_{t+1, o}^{1}, c_{t, y}^{2}, c_{t+1, o}^{2}, P_{t+1}\right)-D\left(\mathrm{P}_{\mathrm{t}+1}\right)\right]-\sum_{t=0}^{+\infty} \beta^{t} q_{t}\left[W_{\mathrm{t}+1}-(1+\omega) W_{\mathrm{t}}\right. \\
& \left.+\mathrm{N}_{\mathrm{t}} c_{t, y}^{2}+\mathrm{N}_{\mathrm{t}-1} c_{t, 0}^{2}+\mathrm{P}_{\mathrm{t}}+X_{t}\right] \\
& +\sum_{t=0}^{+\infty} \beta^{t} \varpi_{t}\left[\mathrm{P}_{\mathrm{t}+1}-\mu \mathrm{Nf}\left(\mathrm{k}_{\mathrm{t}+1}\right)-(1-\alpha) \mathrm{P}_{\mathrm{t}}+b N z_{t+1}\right]+\sum_{t=0}^{+\infty} \beta^{t} \varrho_{t}\left[\mathrm{f}\left(\mathrm{k}_{\mathrm{t}+1}\right)\right. \\
& \left.-(1+\mathrm{n}) \mathrm{k}_{\mathrm{t}+2}-\mathrm{c}_{\mathrm{t}+1, \mathrm{y}}^{1}-\mathrm{c}_{\mathrm{t}+1, \mathrm{o}}^{1}-z_{t+1}\right]+\sum_{t=0}^{+\infty} \beta^{t} \phi_{t} z_{t+1}+\sum_{t=0}^{+\infty} \beta^{t} \psi_{t} W_{t+1} \\
& U(c, P)-D(P) \\
& \begin{array}{l}
=\frac{\gamma\left(\ln c_{t, y}^{1}-\ln c_{t, y}^{1 \min }\right)}{\ln c_{t, y}^{1 \max }}+\frac{\gamma \delta\left(\ln c_{t+1, o}^{1}-\ln c_{t+1, o}^{1 \min }\right)}{\ln c_{t+1, o}^{1 \max }}+\frac{\eta\left(\ln c_{t, y}^{2}-\ln c_{t, y}^{2 \min }\right)}{\ln c_{t, y}^{2 \max }} \\
+\frac{\eta \delta\left(\ln c_{t+1, o}^{2}-\ln c_{t+1, o}^{2 \min }\right)}{\ln c_{t+1, o}^{2 \max }}-(1-\gamma-\eta-\kappa) \frac{\ln P_{t}-\ln P_{t}^{\min }}{\ln P_{t}^{\max }}
\end{array}
\end{aligned}
$$

F.O.C.s:

$$
\begin{aligned}
& \frac{\partial L}{\partial c_{t}^{1}}=U_{c_{t, y}^{1}}-\varrho_{t}=0=\frac{\gamma}{c_{t, y}^{1} \ln c^{1 \max }}-\varrho_{t} \\
& \frac{\partial L}{\partial c_{t+1}^{1}}=U_{c_{t+1, o}^{1}}-\beta \varrho_{t+1}=\frac{\gamma \delta}{c_{t+1, o}^{1} \ln c^{1 m a x}}-\beta \varrho_{t+1}=0 \\
& \frac{\partial L}{\partial c_{t, y}^{2}}=U_{c_{t, y}^{2}}-\beta q_{t+1} \mathrm{~N}_{\mathrm{t}}=\frac{\eta}{c_{t, y}^{2} \ln c^{1 \max }}-\beta q_{t+1} \mathrm{~N}_{\mathrm{t}}=0 \\
& \frac{\partial L}{\partial c_{t+1, o}^{2}}=U_{c_{t+1, o}^{2}}-\beta^{2} q_{t+2} \mathrm{~N}_{\mathrm{t}}=\frac{\eta \delta}{c_{t+1, o}^{2} \ln c^{2 m a x}}-\beta^{2} q_{t+2} \mathrm{~N}_{\mathrm{t}}=0 \\
& \frac{\partial L}{\partial P_{t+1}}=U_{P_{t+1}}-\mathrm{D}_{\mathrm{P}_{\mathrm{t}+1}}-\beta^{2} q_{t+2}+\beta \varpi_{t+1}-(1-\alpha) \beta^{2} \varpi_{t+2}=-(1-\gamma-\eta- \\
& \kappa) \frac{1}{P_{t+1} \ln P^{\max }}-\beta^{2} q_{t+2}+\beta \varpi_{t+1}-(1-\alpha) \beta^{2} \varpi_{t+2}=0
\end{aligned}
$$


$\frac{\partial L}{\partial W_{t+1}}=\beta^{2} q_{t+2}(1+\omega)-\beta q_{t+1}+\beta \psi_{t+1}=0$

$\frac{\partial L}{\partial z_{t+1}}=\beta b N_{t+1} \varpi_{t+1}-\beta \varrho_{t+1}+\beta \phi_{t+1}=0$

$\frac{\partial L}{\partial k_{t+1}}=\beta \varrho_{t+1} \mathrm{f}^{\prime}\left(k_{t+1}\right)-(1+n) \varrho_{t}-\beta \varpi_{t+1} \mu \mathrm{N}_{\mathrm{t}+1} \mathrm{f}^{\prime}\left(\mathrm{k}_{\mathrm{t}+1}\right)=0$

Define $U(c, P)-D(P)=u(c)+g(P)-D(P)$

Solutions are as the following:

Equations b1 and $\mathrm{b} 2=>\frac{U_{c_{t, y}^{1}}}{U_{c_{t+1, o}^{1}}}=\frac{c_{t+1, o}^{1}}{\delta c_{t, y}^{1}}=\frac{(1+n) \varrho_{t}}{\beta \varrho_{t+1}} \quad$ MRS of private good consumption between two period is different from that of the individual's problem.

Equations b3 and b4 $=>\frac{U_{c_{t, y}^{2}}}{U_{c_{t+1, o}^{2}}}=\frac{c_{t+1, o}^{2}}{\delta c_{t, y}^{2}}=\frac{q_{t+1}}{\beta q_{t+2}}$ MRS of water consumption between two period are the same as that of the individual's problem, both are equal to the shadow price ratio with discount factor.

Equation $b 6=>$ when water bequest is non-negative, then $\beta^{2} q_{t+2}(1+\omega)=$ $\beta q_{t+1}=>\frac{q_{t+2}}{q_{t+1}}=\frac{1}{\beta(1+\omega)}$, which is the same as that in the individual's problem.

Equation $\mathrm{b} 7=>\varpi_{t+1}=\frac{1}{b N_{t+1}} \varrho_{t+1}$ when contribution is non-negative.

Equations b7 and b8=> $\left(\beta \varrho_{t+1}-\frac{\beta \varrho_{t+1} \mu}{\mathrm{b}}\right) \mathrm{f}^{\prime}\left(k_{t+1}\right)=(1+n) \varrho_{t}$

$f^{\prime}\left(k_{t+1}\right)=\frac{\frac{(1+n) \varrho_{t}}{\varrho_{t+1}}}{\left(1-\frac{\mu^{\prime}}{\mathrm{b}}\right)}=\frac{\beta \frac{c_{t+1, o}^{1}}{\delta c_{t, y}^{1}}}{\left(1-\frac{\mu^{\prime}}{\mathrm{b}}\right)}$

Equations b5 and b7 $=>g_{P}-\mathrm{D}_{\mathrm{P}}=\frac{u_{c_{t+1, o}^{2}}}{N_{t}}-\frac{u_{c_{t+1, o}^{1}}}{b N_{t}}+\frac{(1-\alpha) u_{c_{t+2, o}^{1}}}{b N_{t}}$ 


$$
\begin{aligned}
& \frac{d c_{t+1,0}^{2}}{d P_{t+1}}=\frac{N\left(g_{P P}-\mathrm{D}_{\mathrm{PP}}\right)}{u_{c_{o}^{2} c_{o}^{2}}}>0 \\
& \frac{d P_{t+1}}{d c_{t+1,0}^{1}}=\frac{-u_{c_{o}^{1} c_{o}^{1}}}{b N\left(g_{P P}-D_{P P}\right)}<0 \\
& \frac{d c_{t+2, o}^{1}}{d P_{t+1}}=\frac{b N\left(g_{P P}-D_{P P}\right)}{(1-\alpha) U_{c_{o}^{1} c_{o}^{1}}}>0
\end{aligned}
$$




\section{CHAPTER 2}

INTERCONNECTED GAME IN WATER SHARING BETWEEN TWO COUNTRIES UNDER EXTREME WEATHER SCENARIOS

\subsection{Introduction}

Allocation of water in the case of trans-boundary rivers often involves contested claims and difficult management choices. According to UN Water's statistics, there are 276 trans-boundary river basins in the world: 64 in Africa, 60 in Asia, 68 in Europe, 46 in North America and 38 in South America (UN World Water Development Report 4, 2012). Over 90 percent of them are shared by two or more countries, with a maximum of 18 countries in the case of Danube river basin. As countries share transboundary rivers, especially when at least one party loses her benefit, tensions rise. How to allocate water efficiently and fairly between countries becomes prominent.

In many cases, the parties may reach sharing agreement but fail to enforce the same. This paper concerns water allocation when two countries have to share a river or other common water body with non-enforceable or weak water rights (Abbink, et al, 2005; Adams, et al, 1996). When water rights do not exist, traditional contracts or agreements are difficult to reinforce since arbitration is complex to implement. For instance, on April 22, 2010, China announced that it would be building the Zangmu Dam across the Brahmaputra river (The Economic Times. 2010), but assured India that the project would not have any significant effect on the downstream flow to India (The Indian Express, 2010). However, India, being in a geographically weaker position to bargain, still expects China not to have any incentives to deviate. Some studies on international resource sharing game have suggested a side payment (e.g., from India to China) to maintain self-enforceable agreement. 
Many river sharing agreement are in the core (the set of feasible allocations that cannot be improved upon by a subset/a coalition of the players) and side payment by downstream country to the upstream country is the major solution to the water sharing problem in an agreement. One type of water sharing agreement is so-called downstream incremental introduced by Ambec and Sprumont (2002). It assigns to any country its marginal contribution to the set of predecessors in the river. Doing so, it maximizes lexicographically the welfare of the most downstream countries in the river in the set of core river sharing agreements. It thus favors downstream countries against upstream countries.

This kind of agreement seems to work quite well under normal situation. However, a NASA observation found that humans are using more water than rains can replenish, and area groundwater levels declined by an average of one foot (30 centimeters) per year between 2002 and 2008 (www.nasa.org). In addition, with global warming, Palmer et al. (2008) predict that 190 out of 292 rivers will face droughts in 2060, and the majority of the rivers they simulated may face reduction in water flows. Ambec and Dinar (2009) proved that with the climate change, specifically dry season, the downstream incremental scheme does not work properly since the upstream country has incentive to deviate. Therefore, upstream incremental fixed water sharing agreement (FWSA) is introduced in their work and it is proven that this scheme is stable under the scenario of dry season.

Past studies such as Ambec and Dinar (2009) address water-sharing agreement when there is a drought. However, warming climate results in extreme weather events such as flood as well as drought. In my study, different extreme weather situations is 
applied into both upstream and downstream incremental scheme, and some results conflict with what Ambec and Dinar have found.

Further, only side payment or victim payment in an agreement is not politically appealing for the victim country (India), which risks a reputation of being a weak negotiator (Just and Netanyahu, 2004). Using interconnected game introduced by Folmer 1993 to solve such environmental issues become popular. My study will investigate what types, more precisely, combination of economic or politically strategies that India will have to exercise in order to force China to share water without side payments. Most studies in the past [e.g., Hauer and Runge (2007)] consider that the payoffs of each country when there is no trade for both countries are zero. I argue that this is not the case since when taking consumer's surplus and the amount of net export into account. Hauer and Runge (2007) shed a light on how to calculate the probabilities of mixed strategy preferences, yet their study misses 4 strategy sets for both countries. In order to understand different strategy options that India will have in order to avoid side payment and have access to river water in perpetuity, I introduce two independent games. The first game is the water sharing game (Bennet, at el, 1998) whereby India chooses whether to make side payment to China to gain access to water and China will react accordingly. The second game is a game of iron ore trade. India decides whether to export iron ore to China due to its high demand, and therefore, former could use this game to threaten latter to share water. I will then link these two games with the combined strategy sets. China's combined strategy set is to Share and Import; India's combined strategy set is to make side payment and Export. It is hypothesized that when the two countries could repeatedly 
play mix strategies with certain probability, interconnected game works perfectly. On the one hand, China would share the river water with India without a side payment in return, which is desired by the international community; on the other hand, India will not export the ore to China, an outcome that depends on the relative values of marginal benefit and marginal cost of import

While Just et al. (2004) developed an interconnected game between two countries, to the best of my knowledge, no studies have investigated the extreme situation of wet/flooding season. The theoretical results from this study are expected to shed light on how the two countries may negotiate an appropriate river sharing agreement, including flood management agreement in the future.

The rest of the chapter proceeds as follows. In the next section, the model of interconnected game is presented under two extreme weather scenarios: drought and flood, and some results are generated from the analysis from section II. Conclusion will be drawn in the third section.

\subsection{Model}

Before applying interconnected game to solve water-sharing issue by linking with some other non-water issue, it is vital to design reasonable and stable independent games.

\subsubsection{Independent Games}

2.2.1.1Water Sharing Game 
I would like to start with the water sharing game by testing the downstream incremental and upstream incremental agreement by Ambec, et al (2010). Take China (the upstream country) and India (the downstream country) as an example. The two countries share the river called Brahmaputra. China plans to dam the river. China assured India at the 2013 BRICS summit that the proposed dams would be run-of-the-river hydroelectric projects and that it would neither store water nor adversely affect its downstream flow to India. India expects China to share the water during drought season and desires less water or expects China to conduct some flood control during wet/flood season. So far there is no water sharing agreement for this river between those two countries, therefore, it is urgent and substantial to construct a mechanism so that no party will lose water-related benefits.

Suppose that China controls $e_{1}$ units of water and India controls $e_{2}$ units of water. Water consumption gives each country different benefits. That is, the downstream, water-scarce country benefits more from a given level of water consumption than the upstream, water-rich country. Different uses of water also give different benefits: water intensive industry, like agriculture, derives more benefit than less water intensive industry like food processing. Denote $b_{i}\left(x_{i}\right)$ the benefit function from consuming $x_{i}$ amount of water, where $i=1$ stands for the upstream country and $i=2$ the downstream country. In my case, country 1 is China and country 2 is India. $x^{*}$, which makes $b\left(x^{*}\right)=0$, is the satiated level, meaning before this level, more water gives country more benefit and exceeding this level, benefits decreases by more water, such as flood. $b^{\prime}(x) \geq$ 0 when $x \leq x^{*}$ and $b^{\prime}(x)<0$ when $x>x^{*} ; b^{\prime \prime}(x) \leq 0$. Therefore, countries, especially from downstream expect upstream countries to control water release in the latter case. In 
Ambec et al. (2010), the fair allocation of water resources among trans-boudary countries is the mean flow. However, it is fair to consider average per capita water consumption level into the water resource reallocation. China and India has merely the same population, and therefore, for analytical simplicity, I kept their populations the same. The fair allocation, therefore, is to equalize the benefits of two countries, that is when $b_{1}\left(\hat{x}_{1}\right)=b_{2}\left(\hat{x}_{2}\right)$, where $e_{1}-\hat{x}_{1}=\hat{x}_{2}-e_{2}$ and $\hat{x}_{1} \leq x_{1}^{*}, \hat{x}_{2} \leq x_{2}^{*}$.

i. Downstream Incremental River Sharing Agreement (DIRSA) :

Agreement is to let China transfer the amount of water $e_{1}-\hat{x}_{1}$ and India receive $\hat{x}_{2}-e_{2}$

$$
\begin{gathered}
v_{1}^{d}=v(1)=b_{1}\left(x_{1}\right)=b_{1}\left(\hat{x}_{1}\right)+t_{1}^{d} \\
t_{1}^{d}=v_{1}^{d}-b_{1}\left(\hat{x}_{1}\right) \\
t_{2}^{d}=t_{1}^{d}
\end{gathered}
$$

$v$ is the welfare for each country, which is represented by the benefit function $b(x)$. Superscripts stand for the index of water sharing agreement scheme ( $d=$ downstream, $u=$ upstream). $t$ is the payment transfer in exchange of more water control. Negative value means the payment for the water to the other country, and positive value, on the contrary, means receiving payment from the other country.

ii. Upstream Incremental River Sharing Agreement (UIRSA):

$$
\begin{gathered}
v_{1}^{u}=v(1,2)-v(2)=b_{1}\left(\hat{x}_{1}\right)+b_{2}\left(\hat{x}_{2}\right)-b_{2}\left(x_{2}\right) \\
t_{1}^{u}=v_{1}^{u}-b_{2}\left(\hat{x}_{2}\right)=b_{1}\left(\hat{x}_{1}\right)-b_{2}\left(x_{2}\right) \\
t_{2}^{u}=t_{1}^{u}
\end{gathered}
$$




\subsubsection{Dry season}

Assume that in the dry season, China only controls $e_{1}{ }^{\prime}$ units of water: $e_{1}^{\prime}<e_{1}$, but under the agreement, China still has to transfer $e_{1}-\hat{x}_{1}$ units to India. Then the welfare of China with DIRSA during dry season, denoted as $v_{1}^{d, d}$, becomes:

$$
v_{1}^{d, d}=b_{1}\left(e_{1}^{\prime}-\left(e_{1}-\hat{x}_{1}\right)\right)+t_{1}^{d}=b_{1}\left(e_{1}^{\prime}-\left(e_{1}-\hat{x}_{1}\right)\right)+b_{1}\left(x_{1}\right)-b_{1}\left(\hat{x}_{1}\right)
$$

If $v_{1}^{d, d} \leq b_{1}\left(\hat{x}_{1}\right)$, then China has an incentive to deviate from the agreement during the dry season.

$$
\begin{aligned}
& \text { And with UIRSA, China's welfare, } v_{1}^{u, d} \text {, is: } \\
& \begin{aligned}
v_{1}^{u, d}=b_{1}\left(e_{1}^{\prime}-\left(e_{1}-\hat{x}_{1}\right)\right)+t_{1}^{u}=b_{1}\left(e_{1}^{\prime}-\left(e_{1}-\hat{x}_{1}\right)\right)+b_{1}\left(\hat{x}_{1}\right)-b_{2}\left(x_{2}\right) \\
=b_{1}\left(e_{1}^{\prime}-\left(\hat{x}_{2}-e_{2}\right)\right)+b_{2}\left(\hat{x}_{2}\right)-b_{2}\left(x_{2}\right)
\end{aligned}
\end{aligned}
$$

Ambec and Dinar (2010) proved that the downstream incremental River Share Agreement is not sustainable in more severe drought, but the constrained (when water consumption and controlled water are less than the satiated level) upstream incremental RSA is. Therefore, China has no motivation to deviate from the agreement under such circumstances. However, their River Sharing Agreement is presumed that India makes monetary transfer (victim payment) to China in exchange of water share from upstream. Also, the water sharing game with side payment demonstrated belowdoes not guarantee this (share, pay) interaction.

In this game, China has the action set (share, not share), which is denoted as $a_{1} \ni(S, N S)$. India's action $a_{2}$ is chosen from the action set (pay, not pay), denoted as $a_{2} \in(P, N P)$. The normal water sharing game (with externality) is demonstrated in Figure 2-1. 


\begin{tabular}{|l|l|l|l|}
\cline { 3 - 4 } \multicolumn{2}{c|}{} & \multicolumn{2}{l|}{ India } \\
\cline { 3 - 4 } \multicolumn{2}{c|}{} & Pay & Not Pay \\
\hline China & Share & $v_{1}^{u, d}, b_{2}\left(\hat{x}_{2}\right)-t_{2}^{u}$ & $b_{1}\left(e_{1}^{\prime}-\left(e_{1}-\hat{x}_{1}\right)\right), b_{2}\left(\hat{x}_{2}\right)$ \\
\cline { 2 - 4 } & Not Share & $b_{1}\left(e_{1}^{\prime}\right)+t_{1}^{u}, b_{2}\left(e_{2}\right)-t_{2}^{u}$ & $b_{1}\left(e_{1}^{\prime}\right), b_{2}\left(e_{2}\right)$ \\
\hline
\end{tabular}

Figure 2-1 Game 1: Water Sharing Game With Side Payment

In each cell, the first payoff is China's welfare and the second is India's. I use the welfare from the constrained upstream incremental scheme as the payoffs of (share, pay). When India chooses to make a payment for sharing, China chooses not to share the river and India Pays the amount of $t_{2}^{u}$ to China, which makes China's welfare $v_{1}^{u, d}=$ $b_{1}\left(e_{1}^{\prime}-\left(e_{1}-\hat{x}_{1}\right)\right)+t_{1}^{u}$, and India's welfare $b_{2}\left(\hat{x}_{2}\right)-t_{2}^{u}$. Clearly, for China, 'Not Share' is the dominant strategy and for India, the strategy 'Not Pay' dominates 'Pay'. Hence, the Nash equilibrium in this river sharing game is when China does not share and India does not pay. To simplify analysis, subtract the first payoff in each cell by $b_{1}\left(e_{1}^{\prime}\right)$, and the second payoff by $b_{2}\left(e_{2}\right)$. Therefore, the new water sharing pay-off matrix becomes as follows:

Obviously this non-cooperative result is not what the countries prefer, and for this prisoner's dilemma game between two countries, players do not usually choose “single-shot” interaction. Bennet et al. (1998) proved that infinite repeated game with certain discount factor could result (share, pay). The area under solid lines in Figure 2 shows the feasible results for the infinite repeated game. The possible payoffs are the intersection of two axes and the frontier point in the first quadrant: $\left(0, b_{2}\left(\hat{x}_{2}\right)-\mathrm{t}_{2}^{u}+\right.$ 
$\left.\frac{t_{2}^{u}}{v_{1}^{u, d}-b_{1}\left(e_{1}^{\prime}-\left(e_{1}-\hat{x}_{1}\right)\right)}\left(v_{1}^{u, d}-b_{1}\left(e_{1}^{\prime}\right)\right)\right),\left(t_{1}^{u}-\frac{v_{1}^{u, d}-b_{1}\left(e_{1}^{\prime}\right)-t_{1}^{u}}{b_{2}\left(\hat{x}_{2}\right)} t_{2}^{u}, 0\right),\left(v_{1}^{u, d}-b_{1}\left(e_{1}^{\prime}\right), b_{2}\left(\hat{x}_{2}\right)-\right.$ $\left.t_{2}^{u}\right)$

\begin{tabular}{|c|c|c|c|}
\hline \multicolumn{2}{|c|}{ Simplified Game 1} & \multicolumn{2}{|l|}{ India } \\
\hline & & Pay & Not Pay \\
\hline \multirow[t]{2}{*}{ China } & Share & $\begin{array}{l}v_{1}^{u, d}-b_{1}\left(e_{1}^{\prime}\right) \\
b_{2}\left(\hat{x}_{2}\right)-t_{2}^{u}-b_{2}\left(e_{2}\right)\end{array}$ & $\begin{array}{l}b_{1}\left(e_{1}^{\prime}-\left(e_{1}-\hat{x}_{1}\right)-b_{1}\left(e_{1}^{\prime}\right),\right. \\
b_{2}\left(\hat{x}_{2}\right)-b_{2}\left(e_{2}\right)\end{array}$ \\
\hline & Not Share & $t_{1}^{u},-t_{2}^{u}$ & 0,0 \\
\hline
\end{tabular}

Figure 2-2 Simplified water sharing game

It has been proved, however, by Maler (1990) that victim payment in an agreement is not preferable for the victim country (India in this case) because it makes the victim country have a weak negotiation power. Therefore, I choose the interconnected game, which was introduced by (Folmer 1993) to solve this transboundary river sharing problem. Just and Netanyahu (2004) summarized that interconnected game are preferable if when (1) each player has an advantage over the other player in at least one issue, (2) the asymmetry of advantages is sufficiently comparable in magnitude, and (3) interconnection expands the set of feasible strategies. 


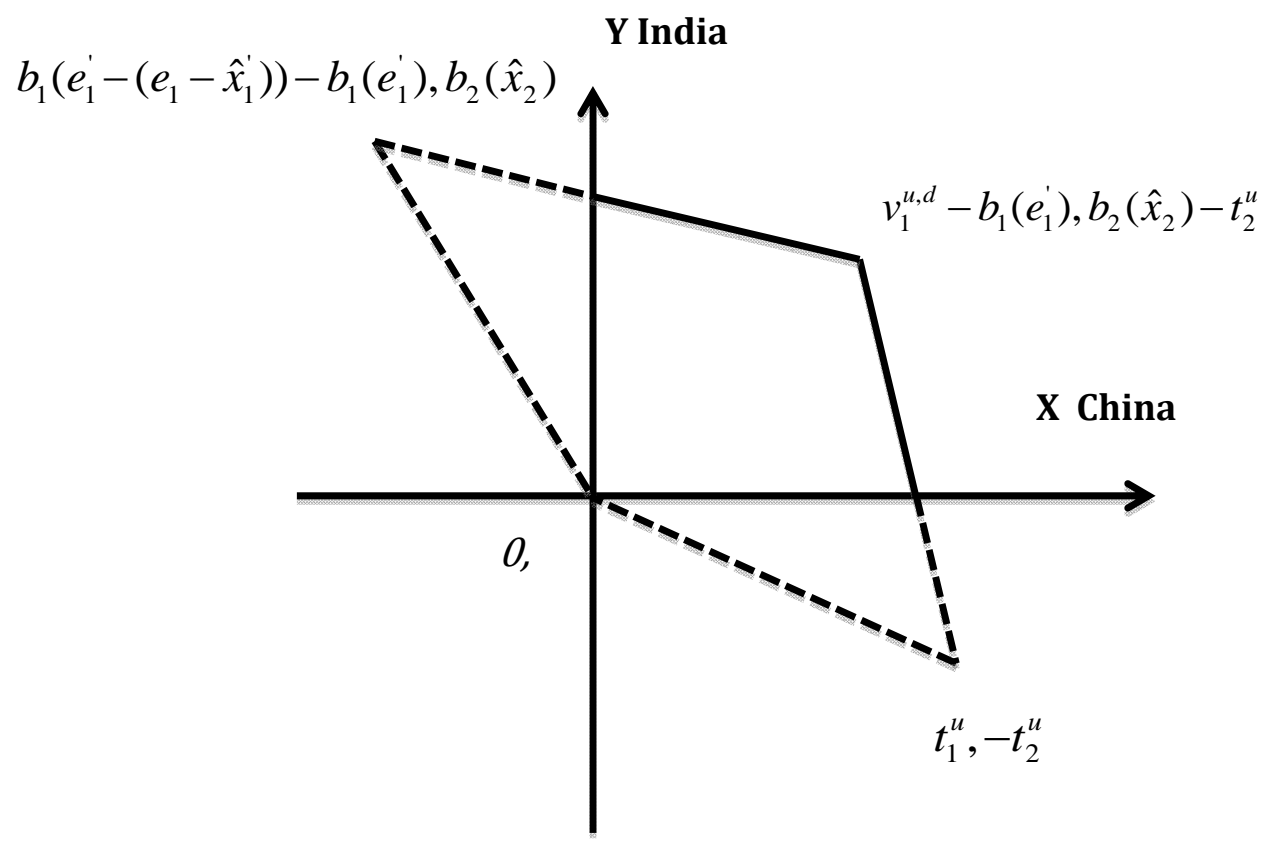

Figure 2-3 Possible frontier of repeated game on water sharing

Even though the victim payment in an agreement is not politically appealing, yet it is still useful for the payoff calculation in a game. So far, both cooperative and noncooperative results are not preferable for the international community. In order to achieve another result, especially (share, not pay), I create an asymmetric and independent game in which India has comparative strength over China. Therefore, linking two games, a sustainable equilibrium can be possibly found. That is to say, in this asymmetric game, India has some kind of credible threat to China to make China choose to share the river in the River Sharing Game. In the other game, in another word, India has stronger negotiation leverage compared to China, so that at the end there will be a win-win for both China and India. Like in Just et al. (2004), the other game can use the boarder issue game in which the downstream country has more advantage. 
China and India have been having trade and border security issues in recent times. Even in 2013, there was a military conflict between the two countries at the IndoTibetan boarder. China places ‘harmonious development' one of the most important place in its economic development. Therefore, India could agree to support China to keep the border peaceful in exchange for China to share the river. However, this broad issue game is not politically or economically preferred. First of all, destroying the border peace might not be a "creditable threat" to China since India does not gain much benefit from it. Secondly, it is not a long-term strategy since border issue will be solved eventually.

Currently China is planning to invest 300 billion dollars on India's infrastructure, such as railroad, Medicare, and etc., but India is hesitating whether or not to accept this offer because of political reasons (since it might cause national security issue). Meanwhile, Japan also have the same intendancy to invest to India, therefore, India could use this opportunity to ask China to import more products from India, such as iron ore. That is, India will agree to accept China's investment on its infrastructure, but China has to import more iron ore every year. Payoffs of this game are presented as the utility function $\boldsymbol{U}$ with the superscript denoting the players and subscript denoting the cell position.

The area under the solid lines in Figure 2-5 represents the possible frontier when repeating this game infinitely. Therefore, the possible payoffs of this repeated game are $\left(0, U_{1}^{2}+\frac{U_{1}^{2}-U_{2}^{2}}{U_{1}^{1}-U_{2}^{1}} U_{1}^{1}\right),\left(U_{1}^{1}+\frac{U_{1}^{1}-U_{2}^{1}}{U_{1}^{2}-U_{3}^{2}} U_{1}^{2}, 0\right),\left(U_{1}^{1}, U_{1}^{2}\right)$, which are the intersection of $\mathrm{Y}$ axis, $\mathrm{X}$ axis and the frontier point in the first quadrant. Where $U_{3}^{1}>U_{1}^{1}>0>U_{2}^{1}$, and $U_{2}^{2}>$ $U_{1}^{2}>0>U_{3}^{2}$, so that it is still a prisoner's dilemma game. The Nash Equilibrium 


\begin{tabular}{|l|l|l|l|}
\cline { 3 - 4 } \multicolumn{2}{|c|}{} & \multicolumn{2}{|l|}{ India } \\
\cline { 3 - 4 } \multicolumn{2}{c|}{} & Accept & Not accept \\
China & Impostment & Investment \\
\cline { 3 - 4 } & Not import iron & $U_{3}^{1}, U_{3}^{2}$ & $U_{2}^{1}, U_{2}^{2}$ \\
\hline
\end{tabular}

Figure 2-4 Game 2: trade game

is for India to "Not accept investment" and for china to "not import iron”. Meanwhile, to make this game work interconnected with the water sharing game, assume that for China, $U_{3}^{1}>t_{1}^{u}$, and $U_{1}^{1}>v_{1}^{u, d}-b_{1}\left(e_{1}^{\prime}\right)$, on the one hand, China will gain more benefit from the investment to India than not to share the river, on the other hand, the harm to China caused by sharing the river but not get paid than is less than that from import iron from India but rejected to invest, i.e. $b_{1}\left(e_{1}^{\prime}-\left(e_{1}-\hat{x}_{1}\right)\right)-b_{1}\left(e_{1}^{\prime}\right)>U_{2}^{1}$.

For India, on the one hand, the gain from water shared by China is greater than that from the iron ore export to china, i.e. $U_{1}^{2}<b_{2}\left(\hat{x}_{2}\right)-t_{2}^{u}$ and $U_{2}^{2}<b_{2}\left(\hat{x}_{2}\right)$. On the other hand, the harm to India to accept the investment from china but does not get to export the iron ore is less than that from making the side payment but does not get shared. i.e. $U_{3}^{2}>$ $-t_{2}^{u}$. Therefore, interconnecting those two games, China might be willing to share the river in order to win the investment opportunity in India. First of all, let us examine the simple aggregated payoffs of the two games, which are presented below. 


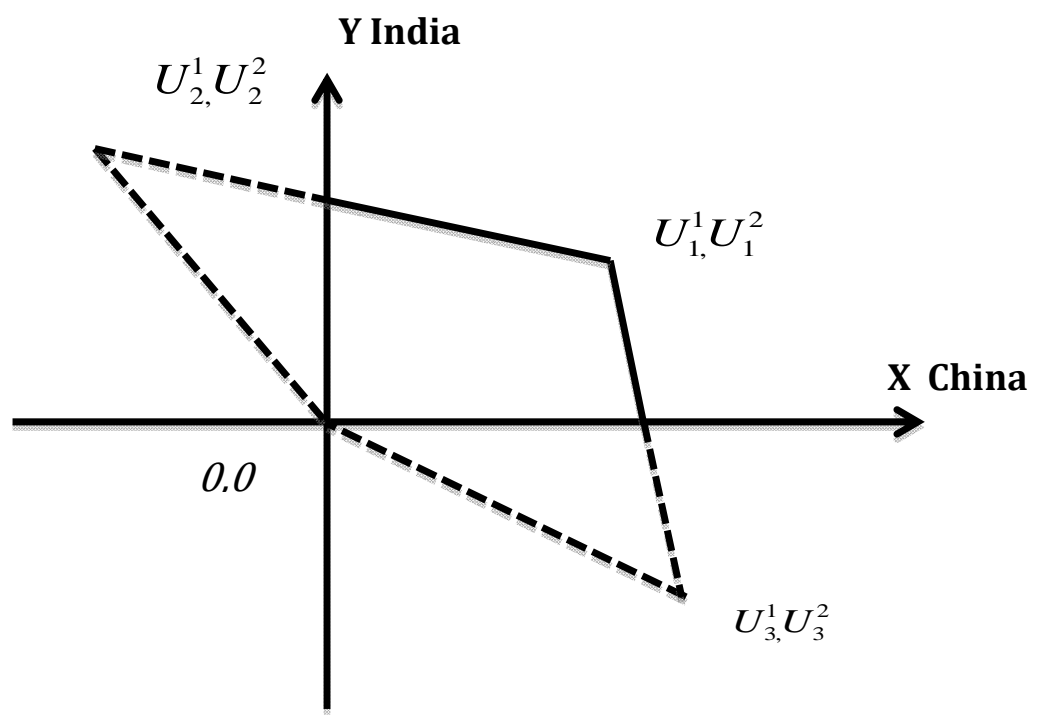

Figure 2-5 Possible frontier of repeated trade game

Therefore, the payoffs that are dominated by others will be ignored and the ones that are not dominated consist the possible frontier. Figure 2.6 demonstrates this result, with the frontier points

$$
\begin{aligned}
& \left(v_{1}^{u, d}-b_{1}\left(e_{1}^{\prime}\right)+U_{1}^{1}+\frac{U_{1}^{1}-U_{2}^{1}}{U_{1}^{2}-U_{3}^{2}} U_{1}^{2}, b_{2}\left(\hat{x}_{2}\right)-t_{2}^{u}\right), \\
& \left(t_{1}^{u}-\frac{v_{1}^{u, d}-b_{1}\left(e_{1}^{\prime}\right)-t_{1}^{u},}{b_{2}\left(\hat{x}_{2}\right)} t_{2}^{u}+U_{1}^{1}+\frac{U_{1}^{1}-U_{2}^{1}}{U_{1}^{2}-U_{3}^{2}} U_{1}^{2}, 0\right), \\
& \left(U_{1}^{1}, U_{1}^{2}+b_{2}\left(\hat{x}_{2}\right)-t_{2}^{u}+\frac{t_{2}^{u}\left(v_{1}^{u, d}-b_{1}\left(e_{1}^{\prime}\right)\right)}{v_{1}^{u, d}-b_{1}\left(e_{1}^{\prime}-\left(e_{1}-\hat{x}_{1}\right)\right)}\right),\left(U_{1}^{1}+\frac{U_{1}^{1}-U_{2}^{1}}{U_{1}^{2}-U_{3}^{2}} U_{1}^{2}, b_{2}\left(\hat{x}_{2}\right)-t_{2}^{u}+\right. \\
& \left.\frac{t_{2}^{u}\left(v_{1}^{u, d}-b_{1}\left(e_{1}^{\prime}\right)\right)}{v_{1}^{u, d}-b_{1}\left(e_{1}^{\prime}-\left(e_{1}-\hat{x}_{1}\right)\right)}\right), \\
& \left(0, b_{2}\left(\hat{x}_{2}\right)-t_{2}^{u}+\frac{t_{2}^{u}\left(v_{1}^{u, d}-b_{1}\left(e_{1}^{\prime}\right)\right)}{v_{1}^{u, d}-b_{1}\left(e_{1}^{\prime}-\left(e_{1}-\hat{x}_{1}\right)\right)}+U_{1}^{2}+\frac{U_{1}^{2}-U_{2}^{2}}{U_{1}^{1}-U_{2}^{1}} U_{1}^{1}\right.
\end{aligned}
$$


Table 2-1 Aggregated isolated game (Refer to the points in Figure2-5)

\begin{tabular}{|c|c|c|c|}
\hline $\begin{array}{l}\text { Payoffs of water sharing } \\
\text { game }\end{array}$ & $\begin{array}{l}\text { Payoffs of trade } \\
\text { game }\end{array}$ & Aggregated payoffs & $\begin{array}{l}\text { Other payoffs that dominate } \\
\text { this one }\end{array}$ \\
\hline $\begin{array}{l}\left(0, b_{2}\left(\hat{x}_{2}\right)-t_{2}^{u}+\right. \\
\frac{t_{2}^{u}}{v_{1}^{u, d}-b_{1}\left(e_{1}^{\prime}-\left(e_{1}-\hat{x}_{1}\right)\right)}\left(v_{1}^{u, d}-\right. \\
\left.\left.b_{1}\left(e_{1}^{\prime}\right)\right)\right)\end{array}$ & $\left(0, U_{1}^{2}+\frac{U_{1}^{2}-U_{2}^{2}}{U_{1}^{1}-U_{2}^{1}} U_{1}^{1}\right)$ & $\begin{array}{l}\left(0, b_{2}\left(\hat{x}_{2}\right)-t_{2}^{u}+\frac{t_{2}^{u}\left(v_{1}^{u, d}-b_{1}\left(e_{1}^{\prime}\right)\right)}{v_{1}^{u, d}-b_{1}\left(e_{1}^{\prime}-\left(e_{1}-\hat{x}_{1}\right)\right)}\right. \\
\left.+U_{1}^{2}+\frac{U_{1}^{2}-U_{2}^{2}}{U_{1}^{1}-U_{2}^{1}} U_{1}^{1}\right)\end{array}$ & \\
\hline $\begin{array}{l}\left(0, b_{2}\left(\hat{x}_{2}\right)-t_{2}^{u}+\right. \\
\frac{t_{2}^{u}}{v_{1}^{u, d}-b_{1}\left(e_{1}^{\prime}-\left(e_{1}-\hat{\mathrm{x}}_{1}\right)\right)}\left(v_{1}^{u, d}-\right. \\
\left.\left.b_{1}\left(e_{1}^{\prime}\right)\right)\right)\end{array}$ & $\left(U_{1}^{1}+\frac{U_{1}^{1}-U_{2}^{1}}{U_{1}^{2}-U_{3}^{2}} U_{1}^{2}, 0\right)$ & $\begin{array}{l}\left(U_{1}^{1}+\frac{U_{1}^{1}-U_{2}^{1}}{U_{1}^{2}-U_{3}^{2}} U_{1}^{2}, b_{2}\left(\hat{x}_{2}\right)-t_{2}^{u}+\right. \\
\left.\frac{t_{2}^{u}\left(v_{1}^{u, d}-b_{1}\left(e_{1}^{\prime}\right)\right)}{v_{1}^{u, d}-b_{1}\left(e_{1}^{\prime}-\left(e_{1}-\hat{x}_{1}\right)\right)}\right)\end{array}$ & \\
\hline $\begin{array}{l}\left(0, b_{2}\left(\hat{x}_{2}\right)-t_{2}^{u}+\right. \\
\frac{t_{2}^{u}}{v_{1}^{u, d}-b_{1}\left(e_{1}^{\prime}-\left(e_{1}-\hat{x}_{1}\right)\right)}\left(v_{1}^{u, d}-\right. \\
\left.\left.b_{1}\left(e_{1}^{\prime}\right)\right)\right)\end{array}$ & $\left(U_{1}^{1}, U_{1}^{2}\right)$ & $\begin{array}{l}\left(U_{1}^{1}, U_{1}^{2}+b_{2}\left(\hat{x}_{2}\right)-t_{2}^{u}+\right. \\
\left.\frac{t_{2}^{u}\left(v_{1}^{u, d}-b_{1}\left(e_{1}^{\prime}\right)\right)}{v_{1}^{u, d}-b_{1}\left(e_{1}^{\prime}-\left(e_{1}-\hat{x}_{1}\right)\right)}\right)\end{array}$ & \\
\hline$\left(t_{1}^{u}-\frac{v_{1}^{u, d}-b_{1}\left(e_{1}^{\prime}\right)-t_{1}^{u}}{b_{2}\left(\hat{x}_{2}\right)} t_{2}^{u}, 0\right)$ & $\left(0, U_{1}^{2}+\frac{U_{1}^{2}-U_{2}^{2}}{U_{1}^{1}-U_{2}^{1}} U_{1}^{1}\right)$ & $\begin{array}{l}\left(t_{1}^{u}-\frac{v_{1}^{u, d}-b_{1}\left(e_{1}^{\prime}\right)-t_{1}^{u}}{b_{2}\left(\hat{x}_{2}\right)} t_{2}^{u}, U_{1}^{2}+\right. \\
\left.\frac{U_{1}^{2}-U_{2}^{2}}{U_{1}^{1}-U_{2}^{1}} U_{1}^{1}\right)\end{array}$ & $\begin{array}{l}\left(U_{1}^{1}+\frac{U_{1}^{1}-U_{2}^{1}}{U_{1}^{2}-U_{3}^{2}} U_{1}^{2}, b_{2}\left(\hat{x}_{2}\right)-\right. \\
\left.t_{2}^{u}+\frac{t_{2}^{u}\left(v_{1}^{u, d}-b_{1}\left(e_{1}^{\prime}\right)\right)}{v_{1}^{u, d}-b_{1}\left(e_{1}^{\prime}-\left(e_{1}-\hat{x}_{1}\right)\right)}\right)\end{array}$ \\
\hline$\left(t_{1}^{u}-\frac{v_{1}^{u, d}-b_{1}\left(e_{1}^{\prime}\right)-t_{1}^{u}}{b_{2}\left(\hat{x}_{2}\right)} t_{2}^{u}, 0\right)$ & $\left(U_{1}^{1}+\frac{U_{1}^{1}-U_{2}^{1}}{U_{1}^{2}-U_{3}^{2}} U_{1}^{2}, 0\right)$ & $\begin{array}{l}\left(t_{1}^{u}-\frac{v_{1}^{u, d}-b_{1}\left(e_{1}^{\prime}\right)-t_{1}^{u}}{b_{2}\left(\hat{x}_{2}\right)} t_{2}^{u}+U_{1}^{1}+\right. \\
\left.\frac{U_{1}^{1}-U_{2}^{1}}{U_{1}^{2}-U_{3}^{2}} U_{1}^{2}, 0\right)\end{array}$ & \\
\hline
\end{tabular}




\begin{tabular}{|l|l|l|l|}
\hline$\left(t_{1}^{u}-\frac{v_{1}^{u, d}-b_{1}\left(e_{1}^{\prime}\right)-t_{1}^{u}}{b_{2}\left(\hat{x}_{2}\right)} t_{2}^{u}, 0\right)$ & $\left(U_{1}^{1}, U_{1}^{2}\right)$ & $\left(t_{1}^{u}-\frac{v_{1}^{u, d}-b_{1}\left(e_{1}^{\prime}\right)-t_{1}^{u}}{b_{2}\left(\hat{x}_{2}\right)} t_{2}^{u}+U_{1}^{1}, U_{1}^{2}\right)$ & $\begin{array}{l}\left(v_{1}^{u, d}-b_{1}\left(e_{1}^{\prime}\right)+U_{1}^{1}+\right. \\
\left.\frac{U_{1}^{1}-U_{2}^{1}}{U_{1}^{2}-U_{3}^{2}} U_{1}^{2}, b_{2}\left(\hat{x}_{2}\right)-t_{2}^{u}\right)\end{array}$ \\
\hline $\begin{array}{l}\left(v_{1}^{u, d}-b_{1}\left(e_{1}^{\prime}\right), b_{2}\left(\hat{x}_{2}\right)-\right. \\
\left.t_{2}^{u}\right)\end{array}$ & $\left(0, U_{1}^{2}+\frac{U_{1}^{2}-U_{2}^{2}}{U_{1}^{1}-U_{2}^{1}} U_{1}^{1}\right)$ & $\begin{array}{l}\left(v_{1}^{u, d}-b_{1}\left(e_{1}^{\prime}\right), b_{2}\left(\hat{x}_{2}\right)-t_{2}^{u}+U_{1}^{2}+\right. \\
\left.\frac{U_{1}^{2}-U_{2}^{2}}{U_{1}^{1}-U_{2}^{1}} U_{1}^{1}\right)\end{array}$ & $\begin{array}{l}\left(U_{1}^{1}, U_{1}^{2}+b_{2}\left(\hat{x}_{2}\right)-t_{2}^{u}+\right. \\
\left.\frac{t_{2}^{u}\left(v_{1}^{u, d}-b_{1}\left(e_{1}^{\prime}\right)\right)}{v_{1}^{u, d}-b_{1}\left(e_{1}^{\prime}-\left(e_{1}-\hat{x}_{1}\right)\right)}\right)\end{array}$ \\
\hline $\begin{array}{l}\left(v_{1}^{u, d}-b_{1}\left(e_{1}^{\prime}\right), b_{2}\left(\hat{x}_{2}\right)-\right. \\
\left.t_{2}^{u}\right)\end{array}$ & $\left(U_{1}^{1}+\frac{U_{1}^{1}-U_{2}^{1}}{U_{1}^{2}-U_{3}^{2}} U_{1}^{2}, 0\right)$ & $\begin{array}{l}\left(v_{1}^{u, d}-b_{1}\left(e_{1}^{\prime}\right)+U_{1}^{1}+\frac{U_{1}^{1}-U_{2}^{1}}{U_{1}^{2}-U_{3}^{2}} U_{1}^{2},\right. \\
\left.b_{2}\left(\hat{x}_{2}\right)-t_{2}^{u}\right)\end{array}$ & $\begin{array}{l}\left(v_{1}^{u, d}-b_{1}\left(e_{1}^{\prime}\right)+U_{1}^{1}, b_{2}\left(\hat{x}_{2}\right)-t_{2}^{u}+\right. \\
\left.U_{1}^{2}\right)\end{array}$ \\
\hline $\begin{array}{l}\left(v_{1}^{u, d}-b_{1}\left(e_{1}^{\prime}\right), b_{2}\left(\hat{x}_{2}\right)-\right. \\
\left.t_{2}^{u}\right)\end{array}$ & $\left(U_{1}^{1}, U_{1}^{2}\right)$ & & $\begin{array}{l}U_{1}^{1}+\frac{U_{1}^{1}-U_{2}^{1}}{U_{1}^{2}-U_{3}^{2}} U_{1}^{2}, b_{2}\left(\hat{x}_{2}\right)- \\
t_{2}^{u}+\frac{t_{2}^{u}\left(v_{1}^{u, d}-b_{1}\left(e_{1}^{\prime}\right)\right)}{v_{1}^{u, d}-b_{1}\left(e_{1}^{\prime}-\left(e_{1}-\hat{x}_{1}\right)\right)}\end{array}$ \\
\hline
\end{tabular}

Table 2-1 (Continued) Aggregated isolated game 


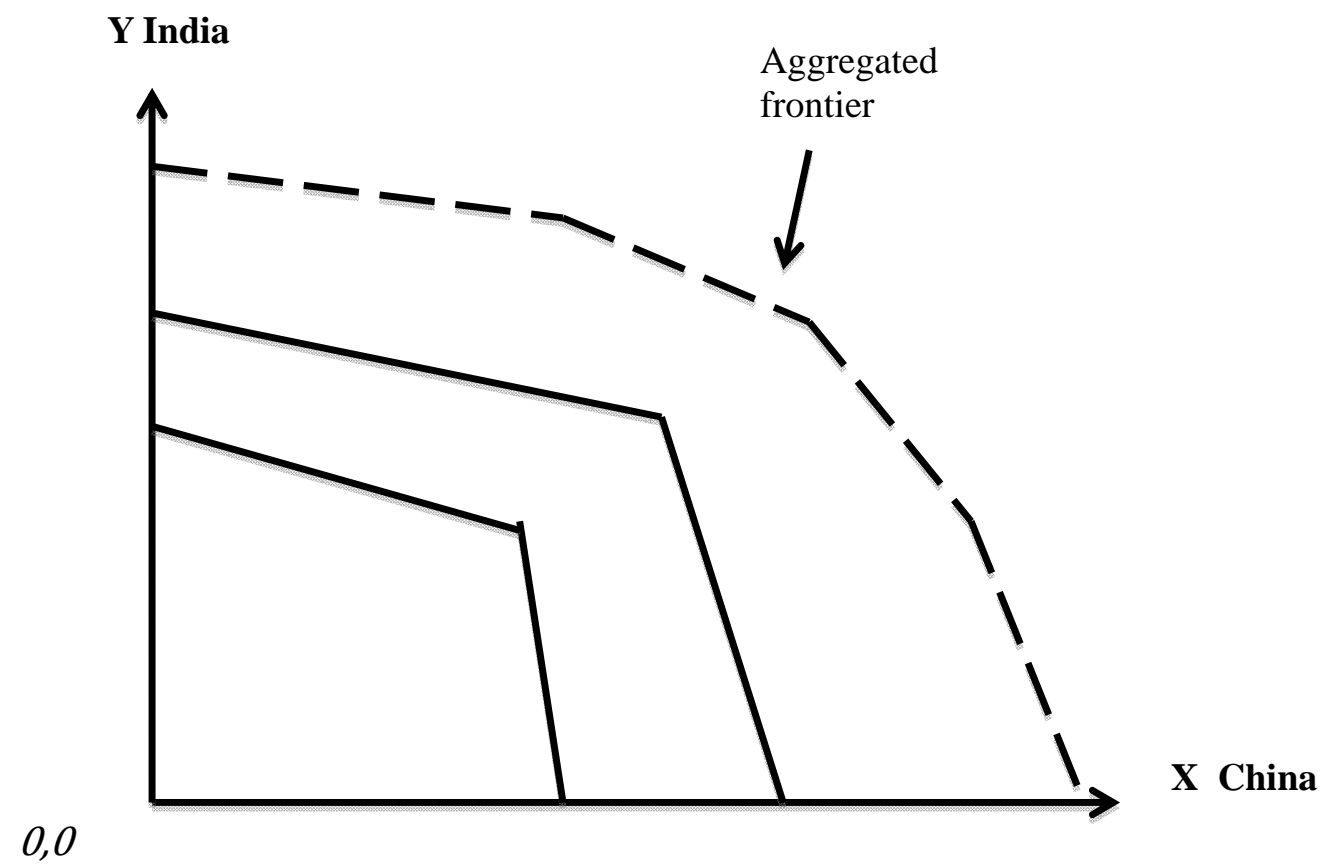

Figure 2-6 Possible frontier of aggregated game

Then the interconnected game are represented as the following Table 2-2. Each country has eight combined strategies and payoffs for each player is calculated as the ones shown in the matrix cells. The values of the payoffs are aggregated from Game 1 and Game 2. For example, if China chooses to not share the water but import iron from India, and India makes a side payment in order for China to share the water, and not accept the investment project, then the payoffs for China and India are respectively $U_{2}^{1}+t_{1}^{u}$ and $U_{2}^{2}-t_{1}^{u}$. The same reasoning as the simple aggregated game, the possible frontier should be the payoffs that are not dominated by any one.

It is proven that (column two, row four) is dominated by (column one, row four), (column three, row three) is dominated by (column one, row one), etc.. 
Table 2-2 Interconnected game

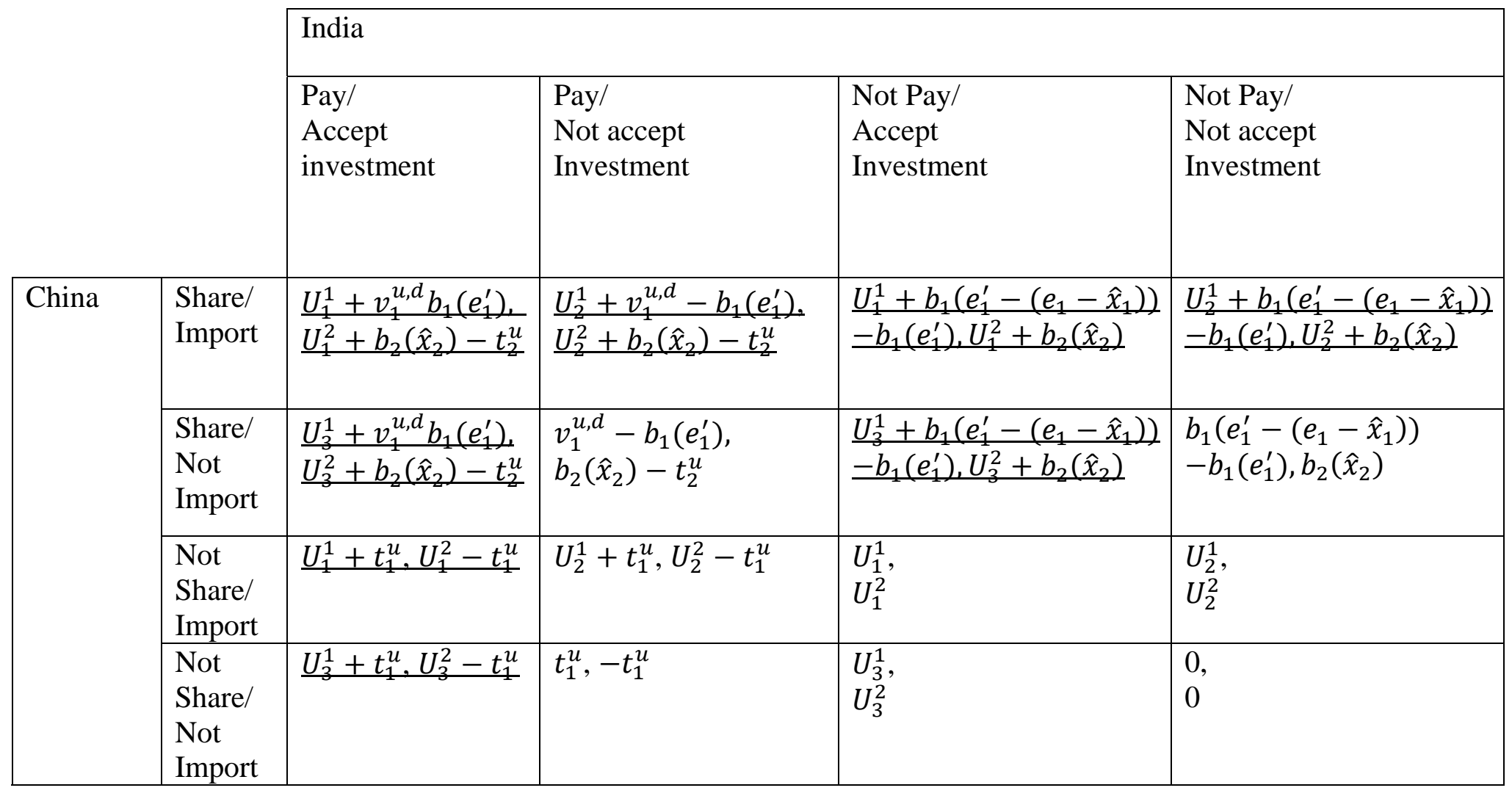


From Table 2.2, it is not hard to get that the frontier payoffs are $\left(U_{3}^{1}+t_{1}^{u}\right.$,

$$
\begin{aligned}
& \left.U_{3}^{2}-t_{1}^{u}\right),\left(U_{1}^{1}+v_{1}^{u, d}-b_{1}\left(e_{1}^{\prime}\right), U_{1}^{2}+b_{2}\left(\hat{x}_{2}\right)-t_{2}^{u}\right),\left(U_{1}^{1}+t_{1}^{u}, U_{1}^{2}-t_{1}^{u}\right),\left(U_{3}^{1}+v_{1}^{u, d}-\right. \\
& \left.b_{1}\left(e_{1}^{\prime}\right), \quad U_{3}^{2}+b_{2}\left(\hat{x}_{2}\right)-t_{2}^{u}\right),\left(U_{2}^{1}+v_{1}^{u, d}-b_{1}\left(e_{1}^{\prime}\right), U_{2}^{2}+b_{2}\left(\hat{x}_{2}\right)-t_{2}^{u}\right), \quad\left(U_{1}^{1}+\right. \\
& \left.b_{1}\left(e_{1}^{\prime}-\left(e_{1}-\hat{x}_{1}\right)\right)-b_{1}\left(e_{1}^{\prime}\right), U_{1}^{2}+b_{2}\left(\hat{x}_{2}\right)\right),\left(U_{3}^{1}+b_{1}\left(e_{1}^{\prime}-\left(e_{1}-\hat{x}_{1}\right)\right)-b_{1}\left(e_{1}^{\prime}\right), U_{3}^{2}+\right. \\
& \left.b_{2}\left(\hat{x}_{2}\right)\right),\left(U_{2}^{1}+b_{1}\left(e_{1}^{\prime}-\left(e_{1}-\hat{x}_{1}\right)\right)-b_{1}\left(e_{1}^{\prime}\right), U_{2}^{2}+b_{2}\left(\hat{x}_{2}\right)\right) .
\end{aligned}
$$

Compared to the frontier with the aggregated ones, $\left(v_{1}^{u, d}-b_{1}\left(e_{1}^{\prime}\right)+U_{1}^{1}+\right.$

$\left.\frac{U_{1}^{1}-U_{2}^{1}}{U_{1}^{2}-U_{3}^{2}} U_{1}^{2}, \quad b_{2}\left(\hat{x}_{2}\right)-t_{2}^{u}\right),\left(t_{1}^{u}-\frac{v_{1}^{u, d}-b_{1}\left(e_{1}^{\prime}\right)-t_{1}^{u}}{b_{2}\left(\hat{x}_{2}\right)} t_{2}^{u}+U_{1}^{1}+\frac{U_{1}^{1}-U_{2}^{1}}{U_{1}^{2}-U_{3}^{2}} U_{1}^{2}, 0\right), \quad\left(U_{1}^{1}, \quad U_{1}^{2}+\right.$ $\left.b_{2}\left(\hat{x}_{2}\right)-t_{2}^{u}+\frac{t_{2}^{u}\left(v_{1}^{u, d}-b_{1}\left(e_{1}^{\prime}\right)\right)}{v_{1}^{u, d}-b_{1}\left(e_{1}^{\prime}-\left(e_{1}-\hat{x}_{1}\right)\right)}\right), \quad\left(U_{1}^{1}+\frac{U_{1}^{1}-U_{2}^{1}}{U_{1}^{2}-U_{3}^{2}} U_{1}^{2}, b_{2}\left(\hat{x}_{2}\right)-t_{2}^{u}+\frac{t_{2}^{u}\left(v_{1}^{u, d}-b_{1}\left(e_{1}^{\prime}\right)\right)}{v_{1}^{u, d}-b_{1}\left(e_{1}^{\prime}-\left(e_{1}-\hat{x}_{1}\right)\right)}\right)$, $\left(0, b_{2}\left(\hat{x}_{2}\right)-t_{2}^{u}+\frac{t_{2}^{u}\left(v_{1}^{u, d}-b_{1}\left(e_{1}^{\prime}\right)\right)}{v_{1}^{u, d}-b_{1}\left(e_{1}^{\prime}-\left(e_{1}-\hat{x}_{1}\right)\right)}+U_{1}^{2}+\frac{U_{1}^{2}-U_{2}^{2}}{U_{1}^{1}-U_{2}^{1}} U_{1}^{1}\right)$, and it is proven that payoff frontier in interconnected game dominates all the payoffs in the aggregated game. Based on those combined possibilities, India, as the downstream country could change its payoffs (with the superscript 2) in the contract to force china to share the water in the dry season.

The possible frontier of interconnect game is shown in figure 6. To avoid the side payment, feasible frontier are $\left(U_{3}^{1}+b_{1}\left(e_{1}^{\prime}-\left(e_{1}-\hat{x}_{1}\right)\right)-b_{1}\left(e_{1}^{\prime}\right), U_{3}^{2}+b_{2}\left(\hat{x}_{2}\right)\right)$ and $\left(U_{1}^{1}+b_{1}\left(e_{1}^{\prime}-\left(e_{1}-\hat{x}_{1}\right)\right)-b_{1}\left(e_{1}^{\prime}\right), U_{1}^{2}+b_{2}\left(\hat{x}_{2}\right)\right)$. That is when India chooses to not make a side payment for the river sharing, but accept China to implement the investment project, and China agree to share the river, but either import or not import iron ore from India does not harm neither country. 


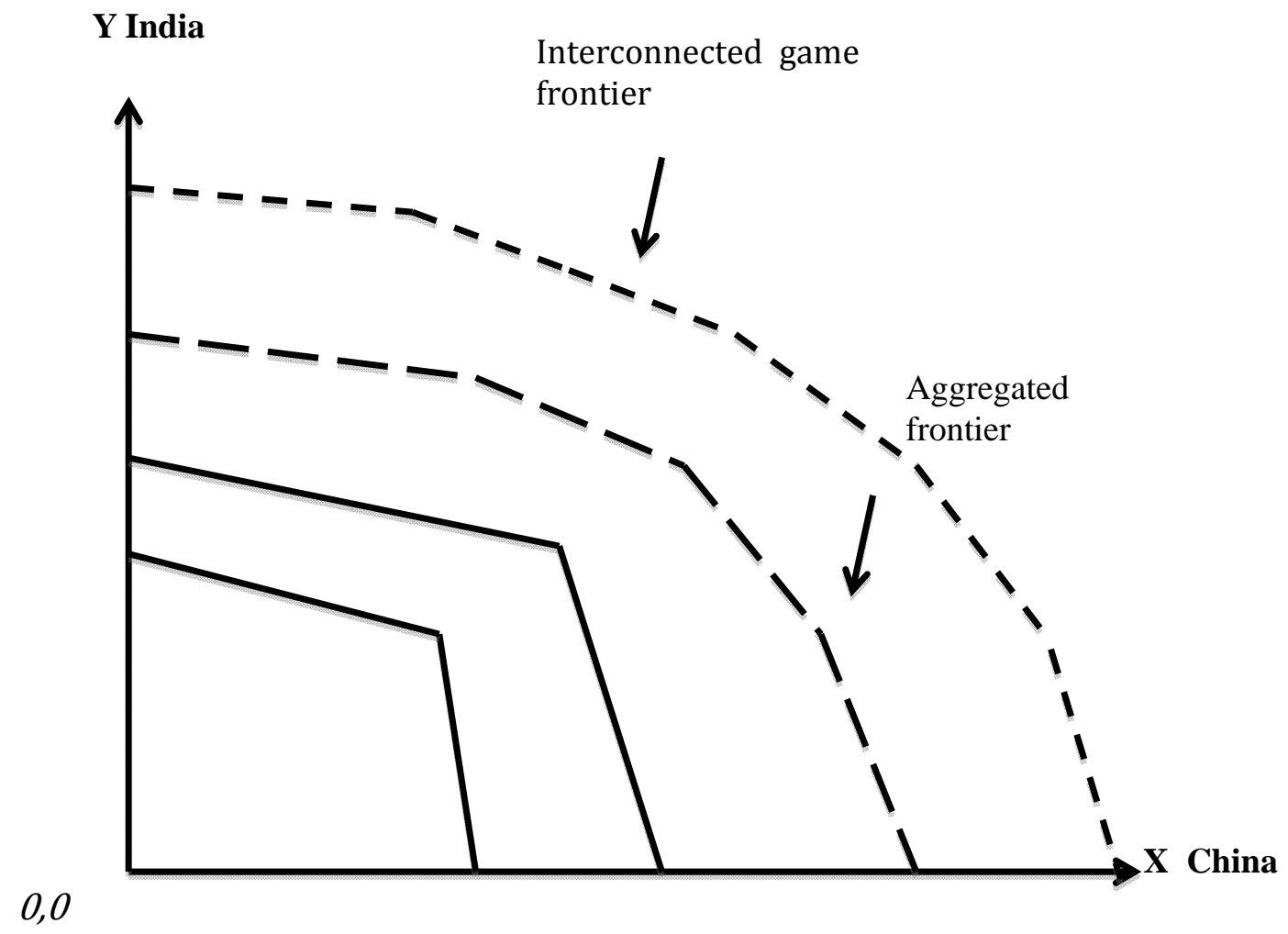

Figure 2-7 Possible frontier of interconnected game in dry season

\subsubsection{Flood season}

Very few studies have discussed about trans-boundary countries interaction with each other when there is flood. During the monsoon season (June-October), floods are a common occurrence. Deforestation in the Brahmaputra watershed has resulted in increased siltation levels, flash floods, and soil erosion in critical downstream habitat such as the Kaziranga National Park in middle Assam Occasionally, massive flooding causes huge losses to crops, life and property. Periodic flooding is a natural phenomenon, which is ecologically important because it helps maintain the lowland grasslands and associated wildlife. Periodic floods also deposit fresh alluvium replenishing the fertile soil of the Brahmaputra River Valley. Thus flooding, Agriculture, and agricultural 
practices are closely connected. Water resource department and the Brahmaputra Board take flood control measures but until now the flood problem remains unsolved. At least a third of the Land of Majuli Island has been eroded by the mighty river. Recently it is suggested that a highway protected by concrete mat along the river and excavation of the riverbed can curb this menace (Shrivastava et al, 2005).. This project, named The Brahmaputra River Restoration Project, is yet to be approved by the Government.

During this season, downstream country (India) certainly would desire less water or flood control from upstream country (China) once the river flow is above its satiated level, China instead tends to release more water to downstream to avoid upstream flood. I can picture different scenarios. First of all, China will release the excess water to India until reaching India's satiated level, and the released water fills exactly up to India's satiated water level. Of course in this case China is willing to share and India does not have to pay for it. I will not discuss this scenario in detail. Secondly, there is too much excessive water in the upstream. If China releases all the excessive water to India, which causes flood in the latter country, the water released from China makes India's water level exceed its satiated level), then India expect China to take some measure to control the flood. In this situation, either downstream incremental or constrained upstream incremental River Sharing Agreement is not appropriate, since the method to equalize both countries' benefit will not work. However, I will use the similar setups as the scenario of dry season.

Agreement is to let China control water flow, and release the amount of water $e_{1}-\hat{x}_{1}$ and India receives this amount of water and just fill up its satiated level $x_{2}^{*}$. Therefore, $e_{1}-\hat{x}_{1}=x_{2}^{*}-e_{2}$, where $e_{1}$ and $e_{2}$ are water controlled by China and India. 
India will pay China to control the flood upstream, and therefore, China will have more water than its satiated level, i.e. $\hat{x}_{1}>x_{1}^{*}$.

$$
\begin{gathered}
v_{1}=b_{1}\left(x_{1}^{*}\right)=b_{1}\left(\hat{x}_{1}\right)+t_{1} \\
t_{1}=b_{1}\left(x_{1}^{*}\right)-b_{1}\left(\hat{x}_{1}\right) \\
-t_{1}=t_{2}
\end{gathered}
$$

$v$ is the welfare for each country, which is represented by the benefit function $b(x)$. Since $\hat{x}_{1}>x_{1}^{*}, b_{1}\left(\hat{x}_{1}\right)<b_{1}\left(x_{1}^{*}\right)$. Superscripts stand for the index of water sharing agreement scheme. $t$ is the payment transfer in exchange of flood control. The payment is to compensate upstream country for control the river flood which exceeds its satiated level. Negative value means the payment for the water to the other country, and positive value, on the contrary, means receiving payment from the other country. For India, its welfare function is

$$
\begin{gathered}
v_{2}=b_{2}\left(x_{2}^{*}\right)-t_{2} \\
t_{2}=b_{2}\left(x_{2}^{*}\right)-v_{2}=b_{2}\left(e_{2}+e_{1}-\hat{x}_{1}\right)-v_{2} \\
t_{1}=-t_{2}
\end{gathered}
$$

Therefore, the water sharing game becomes India pays China to control the volume of water, and the payoff matrix is as Figure 2-8:

\begin{tabular}{|l|l|}
\hline India & \multicolumn{2}{|l|}{ Not Pay } \\
\hline Pay &
\end{tabular}




\begin{tabular}{|l|l|l|l|}
\hline China & Control & $b_{1}\left(\hat{x}_{1}\right)+t_{1}, b_{2}\left(e_{2}+e_{1}-\hat{x}_{1}\right)-t_{2}$ & $b_{1}\left(\hat{x}_{1}\right), b_{2}\left(x_{2}^{*}\right)$ \\
\cline { 2 - 4 } & Not Control & $b_{1}\left(x_{1}^{*}\right)+t_{1}, b_{2}\left(e_{2}+e_{1}-x_{1}^{*}\right)-t_{2}$ & $b_{1}\left(x_{1}^{*}\right), b_{2}\left(e_{2}+e_{1}-x_{1}^{*}\right)$ \\
\hline
\end{tabular}

Figure 2-8 water sharing game under flood season

To simplify the analysis, subtract $\left(b_{1}\left(x_{1}^{*}\right), b_{2}\left(e_{2}+e_{1}-x_{1}^{*}\right)\right)$ in each cell of the payoff matrix above. The new game is as below:

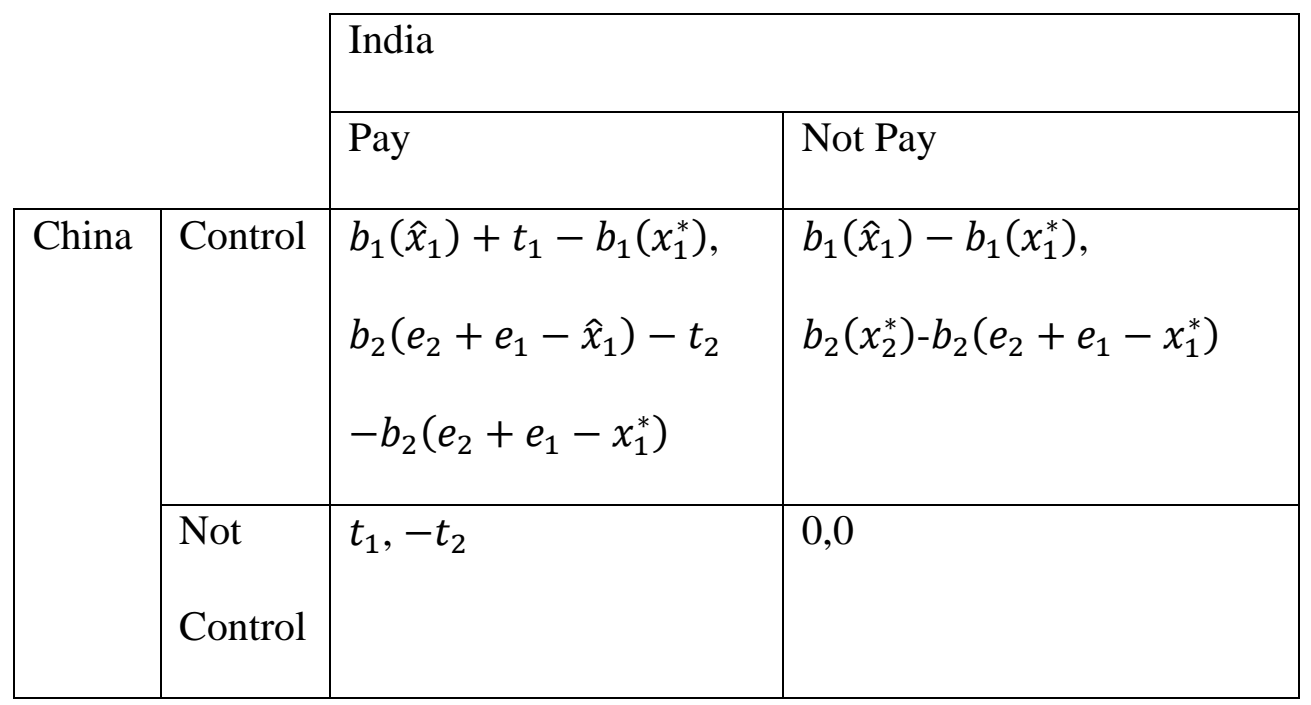

Figure 2-9 simplified water sharing game under flood season

In the scenario of wet season, payoffs have the relationship: $t_{1}>b_{1}\left(\hat{x}_{1}\right)+t_{1}-$ $b_{1}\left(x_{1}^{*}\right)>0>b_{1}\left(\hat{x}_{1}\right)-b_{1}\left(x_{1}^{*}\right)$ and $b_{2}\left(x_{2}^{*}\right)-b_{2}\left(e_{2}+e_{1}-x_{1}^{*}\right)>b_{2}\left(e_{2}+e_{1}-\hat{x}_{1}\right)-$ $t_{2}-b_{2}\left(e_{2}+e_{1}-x_{1}^{*}\right)>0>-t_{2}$. Clearly, this is also a game of prisoner's dilemma and its Nash Equilibrium of single play is when India does not make a side payment and China does not control the flood. Infinite repeat game results the following payoff frontier as shown in figure 2-10. 


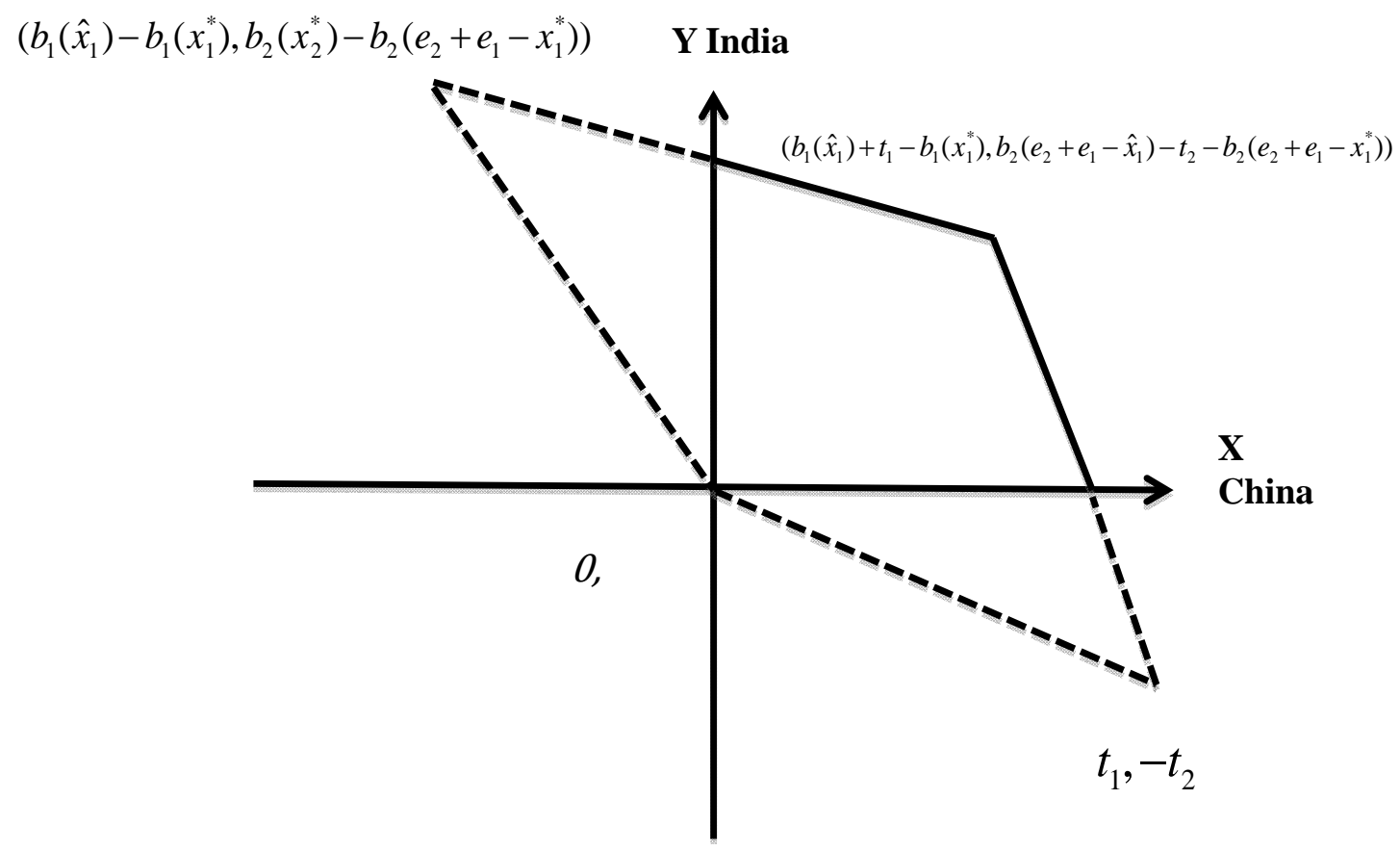

Figure 2-10 Possible frontier in repeated water sharing game under flood season

Same analysis is conducted as the one in dry season. The infinite repeated game results the possible frontier: $\left(\frac{-t_{2}\left[b_{1}\left(\hat{x}_{1}\right)-b_{1}\left(x_{1}^{*}\right)\right]}{b_{2}\left(e_{2}+e_{1}-\hat{x}_{1}\right)-b_{2}\left(e_{2}+e_{1}-x_{1}^{*}\right)}+t_{1}, 0\right), \quad\left(b_{1}\left(\hat{x}_{1}\right)+t_{1}-\right.$ $\left.b_{1}\left(x_{1}^{*}\right), b_{2}\left(e_{2}+e_{1}-\hat{x}_{1}\right)-t_{2}-b_{2}\left(e_{2}+e_{1}-x_{1}^{*}\right)\right),\left(0, b_{2}\left(x_{2}^{*}\right)-b_{2}\left(e_{2}+e_{1}-x_{1}^{*}\right)+\right.$ $\left.\frac{b_{2}\left(e_{2}+e_{1}-\hat{x}_{1}\right)-b_{2}\left(x_{2}^{*}\right)}{t_{1}}\left(b_{1}\left(\hat{x}_{1}\right)-b_{1}\left(x_{1}^{*}\right)\right)\right)$. To avoid the Nash Equilibrium of this game, India could also use the same trade game to constrain China's water sharing behavior. Let us examine the payoffs from simple aggregation of two games 
Table 2-3 Aggregated game under flood season (refer to the point in figure 2-10)

\begin{tabular}{|c|c|c|c|}
\hline $\begin{array}{l}\text { Payoffs of flood control } \\
\text { game }\end{array}$ & Payoffs of trade game & Aggregated payoffs & $\begin{array}{l}\text { Other payoffs that } \\
\text { dominates this one }\end{array}$ \\
\hline $\begin{array}{l}\left(0, b_{2}\left(x_{2}^{*}\right)-b_{2}\left(e_{2}+e_{1}-\right.\right. \\
\left.x_{1}^{*}\right)+ \\
\frac{b_{2}\left(e_{2}+e_{1}-\hat{x}_{1}\right)-b_{2}\left(x_{2}^{*}\right)}{t_{1}}\left(b_{1}\left(\hat{x}_{1}\right)-\right. \\
\left.\left.b_{1}\left(x_{1}^{*}\right)\right)\right)\end{array}$ & $\left(0, U_{1}^{2}+\frac{U_{1}^{2}-U_{2}^{2}}{U_{1}^{1}-U_{2}^{1}} U_{1}^{1}\right)$ & $\begin{array}{l}\left(0, b_{2}\left(x_{2}^{*}\right)-b_{2}\left(e_{2}+e_{1}-x_{1}^{*}\right)+\right. \\
\frac{b_{2}\left(e_{2}+e_{1}-\hat{x}_{1}\right)-b_{2}\left(x_{2}^{*}\right)}{t_{1}}\left(b_{1}\left(\hat{x}_{1}\right)-\right. \\
\left.b_{1}\left(x_{1}^{*}\right)+U_{1}^{2}+\frac{U_{1}^{2}-U_{2}^{2}}{U_{1}^{1}-U_{2}^{1}} U_{1}^{1}\right)\end{array}$ & \\
\hline $\begin{array}{l}\left(0, b_{2}\left(x_{2}^{*}\right)-b_{2}\left(e_{2}+e_{1}-\right.\right. \\
\left.x_{1}^{*}\right)+ \\
\frac{b_{2}\left(e_{2}+e_{1}-\hat{x}_{1}\right)-b_{2}\left(x_{2}^{*}\right)}{t_{1}}\left(b_{1}\left(\hat{x}_{1}\right)-\right. \\
\left.\left.b_{1}\left(x_{1}^{*}\right)\right)\right)\end{array}$ & $\left(U_{1}^{1}+\frac{U_{1}^{1}-U_{2}^{1}}{U_{1}^{2}-U_{3}^{2}} U_{1}^{2}, 0\right)$ & $\begin{array}{l}\left(U_{1}^{1}+\frac{U_{1}^{1}-U_{2}^{1}}{U_{1}^{2}-U_{3}^{2}} U_{1}^{2}, b_{2}\left(x_{2}^{*}\right)-\right. \\
b_{2}\left(e_{2}+e_{1}-x_{1}^{*}\right)+ \\
\frac{b_{2}\left(e_{2}+e_{1}-\hat{x}_{1}\right)-b_{2}\left(x_{2}^{*}\right)}{t_{1}}\left(b_{1}\left(\hat{x}_{1}\right)-\right. \\
\left.b_{1}\left(x_{1}^{*}\right)\right)\end{array}$ & \\
\hline $\begin{array}{l}\left(0, b_{2}\left(x_{2}^{*}\right)-b_{2}\left(e_{2}+e_{1}-\right.\right. \\
\left.x_{1}^{*}\right)+ \\
\frac{b_{2}\left(e_{2}+e_{1}-\hat{x}_{1}\right)-b_{2}\left(x_{2}^{*}\right)}{t_{1}}\left(b_{1}\left(\hat{x}_{1}\right)-\right. \\
\left.\left.b_{1}\left(x_{1}^{*}\right)\right)\right)\end{array}$ & $\left(U_{1}^{1}, U_{1}^{2}\right)$ & $\begin{array}{l}\left(U_{1}^{1}, U_{1}^{2}+b_{2}\left(x_{2}^{*}\right)-\right. \\
b_{2}\left(e_{2}+e_{1}-x_{1}^{*}\right)+ \\
\frac{b_{2}\left(e_{2}+e_{1}-\hat{x}_{1}\right)-b_{2}\left(x_{2}^{*}\right)}{t_{1}}\left(b_{1}\left(\hat{x}_{1}\right)-\right. \\
\left.b_{1}\left(x_{1}^{*}\right)\right)\end{array}$ & \\
\hline $\begin{array}{l}\left(b_{1}\left(\hat{x}_{1}\right)+t_{1}-\right. \\
b_{1}\left(x_{1}^{*}\right), b_{2}\left(e_{2}+e_{1}-\hat{x}_{1}\right)- \\
\left.t_{2}-b_{2}\left(e_{2}+e_{1}-x_{1}^{*}\right)\right)\end{array}$ & $\left(0, U_{1}^{2}+\frac{U_{1}^{2}-U_{2}^{2}}{U_{1}^{1}-U_{2}^{1}} U_{1}^{1}\right)$ & $\begin{array}{l}\left(b_{1}\left(\hat{x}_{1}\right)+t_{1}-b_{1}\left(x_{1}^{*}\right), U_{1}^{2}+\right. \\
\frac{U_{1}^{2}-U_{2}^{2}}{U_{1}^{1}-U_{2}^{1}} U_{1}^{1}+b_{2}\left(e_{2}+e_{1}-\hat{x}_{1}\right)- \\
\left.t_{2}-b_{2}\left(e_{2}+e_{1}-x_{1}^{*}\right)\right)\end{array}$ & $\begin{array}{l}\left(U_{1}^{1}+\frac{U_{1}^{1}-U_{2}^{1}}{U_{1}^{2}-U_{3}^{2}} U_{1}^{2}, b_{2}\left(x_{2}^{*}\right)-\right. \\
b_{2}\left(e_{2}+e_{1}-x_{1}^{*}\right)+ \\
\frac{b_{2}\left(e_{2}+e_{1}-\hat{x}_{1}\right)-b_{2}\left(x_{2}^{*}\right)}{t_{1}}\left(b_{1}\left(\hat{x}_{1}\right)-\right. \\
\left.b_{1}\left(x_{1}^{*}\right)\right)^{-}\end{array}$ \\
\hline $\begin{array}{l}\left(b_{1}\left(\hat{x}_{1}\right)+t_{1}-\right. \\
b_{1}\left(x_{1}^{*}\right), b_{2}\left(e_{2}+e_{1}-\hat{x}_{1}\right)- \\
\left.t_{2}-b_{2}\left(e_{2}+e_{1}-x_{1}^{*}\right)\right)\end{array}$ & $\left(U_{1}^{1}+\frac{U_{1}^{1}-U_{2}^{1}}{U_{1}^{2}-U_{3}^{2}} U_{1}^{2}, 0\right)$ & $\begin{array}{l}\left(b_{1}\left(\hat{x}_{1}\right)+t_{1}-b_{1}\left(x_{1}^{*}\right)+\right. \\
\frac{U_{1}^{1}-U_{2}^{1}}{U_{1}^{2}-U_{3}^{2}} U_{1}^{2}, b_{2}\left(e_{2}+e_{1}-\hat{x}_{1}\right)- \\
\left.t_{2}-b_{2}\left(e_{2}+e_{1}-x_{1}^{*}\right)\right)\end{array}$ & \\
\hline
\end{tabular}




\begin{tabular}{|l|l|l|l|}
\hline $\begin{array}{l}\left(b_{1}\left(\hat{x}_{1}\right)+t_{1}-\right. \\
b_{1}\left(x_{1}^{*}\right), b_{2}\left(e_{2}+e_{1}-\hat{x}_{1}\right)- \\
\left.t_{2}-b_{2}\left(e_{2}+e_{1}-x_{1}^{*}\right)\right)\end{array}$ & $\left(U_{1}^{1}, U_{1}^{2}\right)$ & $\begin{array}{l}\left(b_{1}\left(\hat{x}_{1}\right)+t_{1}-b_{1}\left(x_{1}^{*}\right)+U_{1}^{1},\right. \\
U_{1}^{2}+b_{2}\left(e_{2}+e_{1}-\hat{x}_{1}\right)-t_{2}- \\
\left.b_{2}\left(e_{2}+e_{1}-x_{1}^{*}\right)\right)\end{array}$ & $\begin{array}{l}\left(U_{1}^{1}+\frac{U_{1}^{1}-U_{2}^{1}}{U_{1}^{2}-U_{3}^{2}} U_{1}^{2}, b_{2}\left(x_{2}^{*}\right)-\right. \\
b_{2}\left(e_{2}+e_{1}-x_{1}^{*}\right)+ \\
\frac{b_{2}\left(e_{2}+e_{1}-\hat{x}_{1}\right)-b_{2}\left(x_{2}^{*}\right)}{t_{1}}\left(b_{1}\left(\hat{x}_{1}\right)-\right. \\
\left.b_{1}\left(x_{1}^{*}\right)\right)\end{array}$ \\
\hline $\begin{array}{l}\left(\frac{-t_{2}\left[b_{1}\left(\hat{x}_{1}\right)-b_{1}\left(x_{1}^{*}\right)\right]}{b_{2}\left(e_{2}+e_{1}-\hat{x}_{1}\right)-b_{2}\left(e_{2}+e_{1}-x_{1}^{*}\right)}+\right. \\
\left.t_{1}, 0\right)\end{array}$ & $\left(0, U_{1}^{2}+\frac{U_{1}^{2}-U_{2}^{2}}{U_{1}^{1}-U_{2}^{1}} U_{1}^{1}\right)$ & $\begin{array}{l}\left(\frac{-t_{2}\left[b_{1}\left(\hat{x}_{1}\right)-b_{1}\left(x_{1}^{*}\right)\right]}{b_{2}\left(e_{2}+e_{1}-\hat{x}_{1}\right)-b_{2}\left(e_{2}+e_{1}-x_{1}^{*}\right)}+t_{1},\right. \\
\left.\frac{U_{1}^{2}-U_{2}^{2}}{U_{1}^{1}-U_{2}^{1}} U_{1}^{1}\right)\end{array}$ & $\begin{array}{l}\left(U_{1}^{1}+\frac{U_{1}^{1}-U_{2}^{1}}{U_{1}^{2}-U_{3}^{2}} U_{1}^{2}, b_{2}\left(x_{2}^{*}\right)-\right. \\
b_{2}\left(e_{2}+e_{1}-x_{1}^{*}\right)+ \\
\frac{b_{2}\left(e_{2}+e_{1}-\hat{x}_{1}\right)-b_{2}\left(x_{2}^{*}\right)}{t_{1}}\left(b_{1}\left(\hat{x}_{1}\right)-\right. \\
\left.b_{1}\left(x_{1}^{*}\right)\right)\end{array}$ \\
\hline $\begin{array}{l}\left(\frac{-t_{2}\left[b_{1}\left(\hat{x}_{1}\right)-b_{1}\left(x_{1}^{*}\right)\right]}{b_{2}\left(e_{2}+e_{1}-\hat{x}_{1}\right)-b_{2}\left(e_{2}+e_{1}-x_{1}^{*}\right)}+\right. \\
\left.t_{1}, 0\right)\end{array}$ & $\left(U_{1}^{1}+\frac{U_{1}^{1}-U_{2}^{1}}{U_{1}^{2}-U_{3}^{2}} U_{1}^{2}, 0\right)$ & $\left(\frac{-t_{2}\left[b_{1}\left(\hat{x}_{1}\right)-b_{1}\left(x_{1}^{*}\right)\right]}{b_{2}\left(e_{2}+e_{1}-\hat{x}_{1}\right)-b_{2}\left(e_{2}+e_{1}-x_{1}^{*}\right)}+t_{1}, 0\right)$ & \\
\hline $\begin{array}{l}-\frac{-t_{2}\left[b_{1}\left(\hat{x}_{1}\right)-b_{1}\left(x_{1}^{*}\right)\right]}{\left(b_{2}\left(e_{2}+e_{1}-\hat{x}_{1}\right)-b_{2}\left(e_{2}+e_{1}-x_{1}^{*}\right)\right.}+ \\
\left.t_{1}, 0\right)\end{array}$ & $\left(U_{1}^{1}, U_{1}^{2}\right)$ & $\left(\frac{-t_{2}\left[b_{1}\left(\hat{x}_{1}\right)-b_{1}\left(x_{1}^{*}\right)\right]}{b_{2}\left(e_{2}+e_{1}-\hat{x}_{1}\right)-b_{2}\left(e_{2}+e_{1}-x_{1}^{*}\right)} t_{1}, U_{1}^{2}\right)$ & $\begin{array}{l}\left(b_{1}\left(\hat{x}_{1}\right)+t_{1}-b_{1}\left(x_{1}^{*}\right)+\right. \\
\frac{U_{1}^{1}-U_{2}^{1}}{U_{1}^{2}-U_{3}^{2}} U_{1}^{2}, b_{2}\left(e_{2}+e_{1}-\right. \\
\left.\hat{x}_{1}\right)-t_{2}-b_{2}\left(e_{2}+e_{1}-\right. \\
\left.\left.x_{1}^{*}\right)\right)\end{array}$ \\
\hline
\end{tabular}

Table 2-3 Aggregated game under flood season (continued) 
The aggregated payoff frontier is

$$
\begin{aligned}
& \left(\frac{-t_{2}\left[b_{1}\left(\hat{x}_{1}\right)-b_{1}\left(x_{1}^{*}\right)\right]}{b_{2}\left(e_{2}+e_{1}-\hat{x}_{1}\right)-b_{2}\left(e_{2}+e_{1}-x_{1}^{*}\right)}+t_{1}, 0\right), \\
& \left(b_{1}\left(\hat{x}_{1}\right)+t_{1}-b_{1}\left(x_{1}^{*}\right)+\frac{U_{1}^{1}-U_{2}^{1}}{U_{1}^{2}-U_{3}^{2}} U_{1}^{2}, b_{2}\left(e_{2}+e_{1}-\hat{x}_{1}\right)-t_{2}-b_{2}\left(e_{2}+e_{1}-x_{1}^{*}\right)\right), \\
& \left(U_{1}^{1}, U_{1}^{2}+b_{2}\left(x_{2}^{*}\right)-b_{2}\left(e_{2}+e_{1}-x_{1}^{*}\right)+\frac{b_{2}\left(e_{2}+e_{1}-\hat{x}_{1}\right)-b_{2}\left(x_{2}^{*}\right)}{t_{1}}\left(b_{1}\left(\hat{x}_{1}\right)-b_{1}\left(x_{1}^{*}\right)\right),\left(U_{1}^{1}+\right.\right. \\
& \frac{U_{1}^{1}-U_{2}^{1}}{U_{1}^{2}-U_{3}^{2}} U_{1}^{2}, b_{2}\left(x_{2}^{*}\right)-b_{2}\left(e_{2}+e_{1}-x_{1}^{*}\right)+\frac{b_{2}\left(e_{2}+e_{1}-\hat{x}_{1}\right)-b_{2}\left(x_{2}^{*}\right)}{t_{1}}\left(b_{1}\left(\hat{x}_{1}\right)-b_{1}\left(x_{1}^{*}\right)\right), \\
& \left(0, b_{2}\left(x_{2}^{*}\right)-b_{2}\left(e_{2}+e_{1}-x_{1}^{*}\right)+\frac{b_{2}\left(e_{2}+e_{1}-\hat{x}_{1}\right)-b_{2}\left(x_{2}^{*}\right)}{t_{1}}\left(b_{1}\left(\hat{x}_{1}\right)-b_{1}\left(x_{1}^{*}\right)+U_{1}^{2}+\frac{U_{1}^{2}-U_{2}^{2}}{U_{1}^{1}-U_{2}^{1}} U_{1}^{1}\right)\right.
\end{aligned}
$$

and is as shown as the dash line in figure 2-11

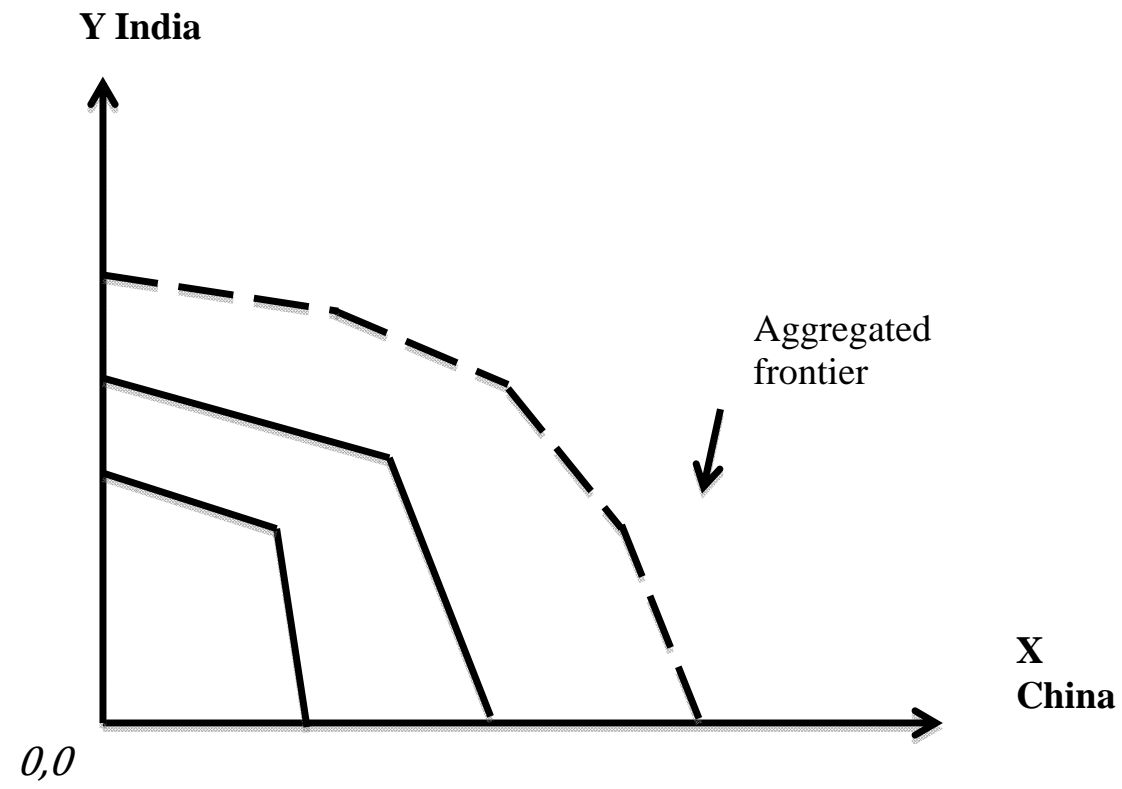

Figure 2-11 Possible frontier of aggregated game

Next, examining the payoffs of interconnected game. It is shown as the matrix as below. 
Table 2-4 Interconnected game under flood season

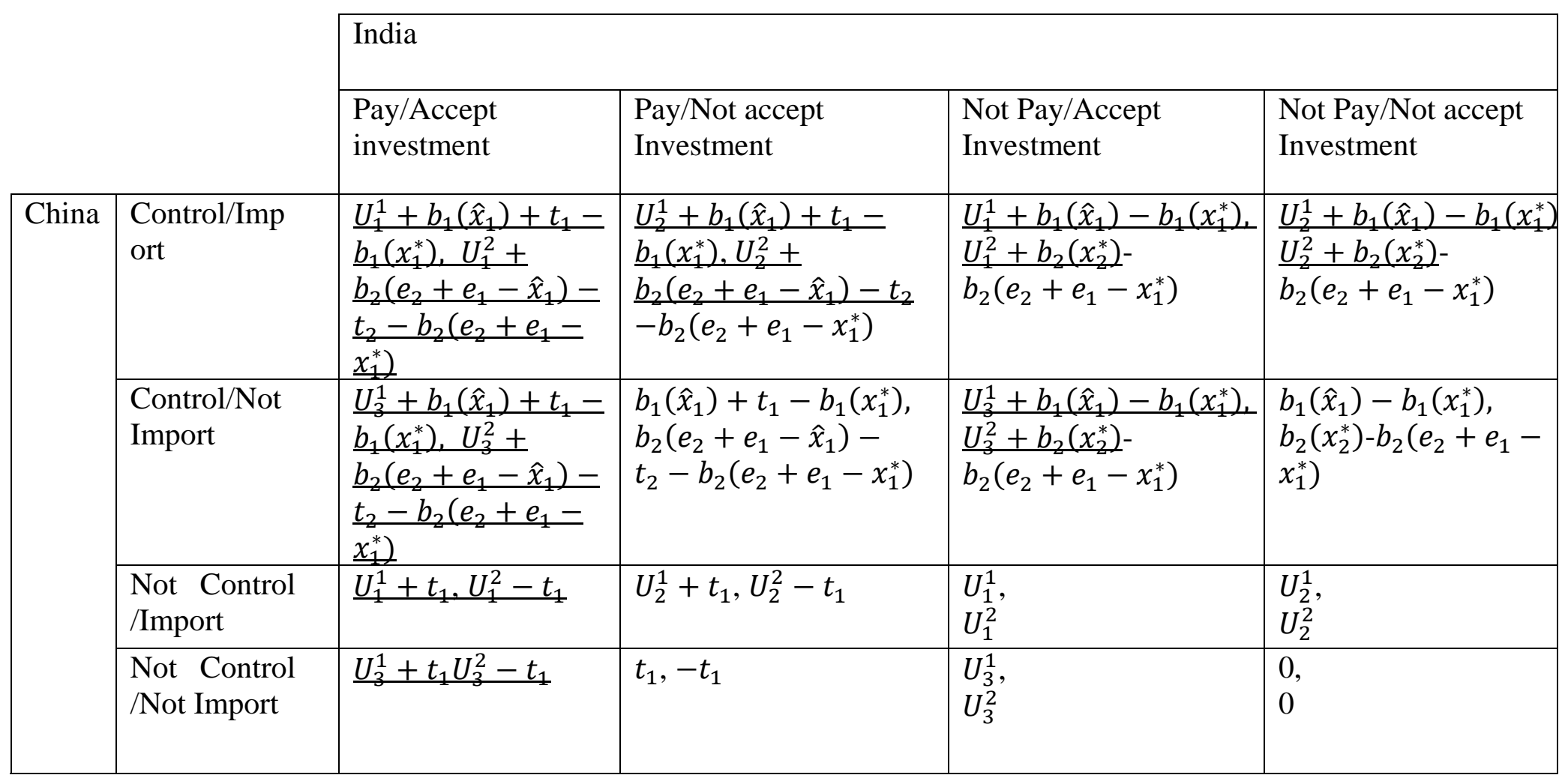


The payoff frontier of interconnected game is shown in figure 13. Comparing to the aggregated frontier, it is clear that the former one has wider range of strategy choices and outcomes. The feasible frontier points are the underlines ones. Meanwhile, to avoid the side payment, strategy not side payment but accept the investment project can be chosen for India. And China controls river flow but chooses either import iron ore or not.

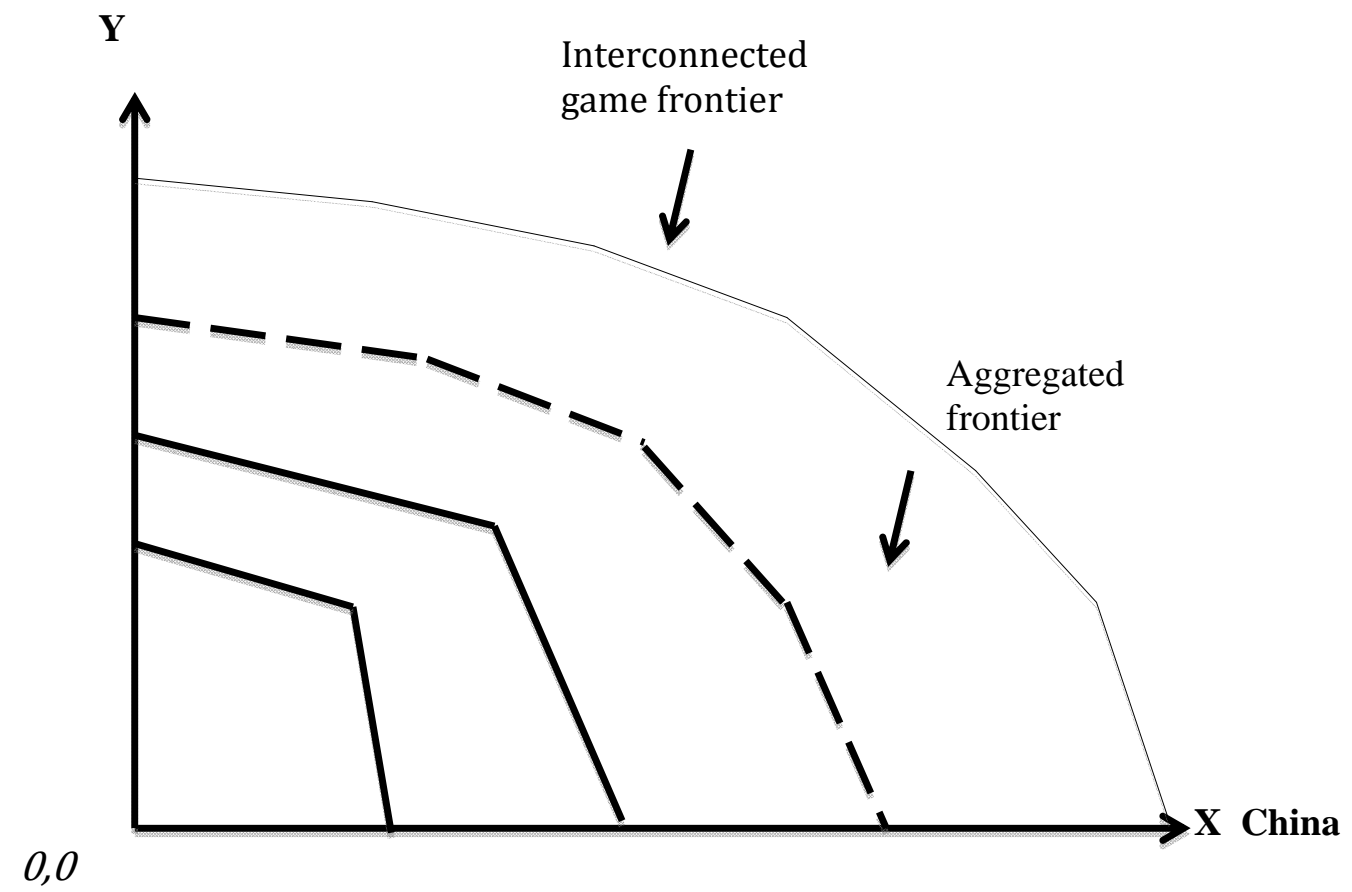

Figure 2-12 Possible frontier of interconnected game vs. aggregated game under flood season

\subsection{Numerical Example}

Suppose in normal season, China controls 100 units of water, $e_{1}=100$. And India controls 60 units, $e_{2}=60$. Both countries have the same benefit function $b(x)=$ $100 x-0.5 x^{2}$, therefore, the satiated level for both countries are 100 units. Then the fair water allocation is 80 units, which means China sharing 20 units to India. Constrained upstream scheme makes the welfare function $v_{1}^{u}=2 v(1,2)-v(2)=2 b(80)-b(60)$ 
and the transfer should be $t_{1}^{u}=v_{1}^{u}-b(80)=b(80)-b(60)=4800-4200=600$. Therefore, the agreement is that India pays China 600 for sharing 20 units of water.

In dry season, China controls 90 units of water, $e_{1}{ }^{\prime}=90$ and India still control the same units. With the agreement above, China still will share 20 units, but with the side payment, China's welfare is $v_{1}^{u}=b(90-20)+600=5150>b(1000)=5000$, which is the welfare of fair allocation in normal season. Therefore, China does not have incentive to deviate. The water sharing game is as the following:

\begin{tabular}{|c|c|c|c|}
\hline \multicolumn{2}{|c|}{ Game 1} & \multicolumn{2}{|r|}{ India } \\
\hline & & Pay & Not Pay \\
\hline \multirow[t]{2}{*}{ China } & Share & $\mathrm{b}(70)+600, \mathrm{~b}(80)-600$ & $\mathrm{~b}(70), \mathrm{b}(80)$ \\
\hline & $\begin{array}{l}\text { Not } \\
\text { Share }\end{array}$ & $\mathrm{b}(90)+600, \mathrm{~b}(60)-600$ & $\mathrm{~b}(90), \mathrm{b}(60)$ \\
\hline \multicolumn{2}{|c|}{ Simplied } & \multicolumn{2}{|c|}{ India } \\
\hline \multicolumn{4}{|c|}{ Game 1} \\
\hline & & Pay & Not Pay \\
\hline \multirow[t]{2}{*}{ China } & Share & 200,0 & $-400,300$ \\
\hline & $\begin{array}{l}\text { Not } \\
\text { Share }\end{array}$ & $600,-600$ & $\underline{0,0}$ \\
\hline
\end{tabular}

Figure 2-13 Numerical Water Sharing Game

N.E. is $(0,0)$ or (not share, not pay) in the single play. The possible frontier with infinite playing is as Figure 2-14. 


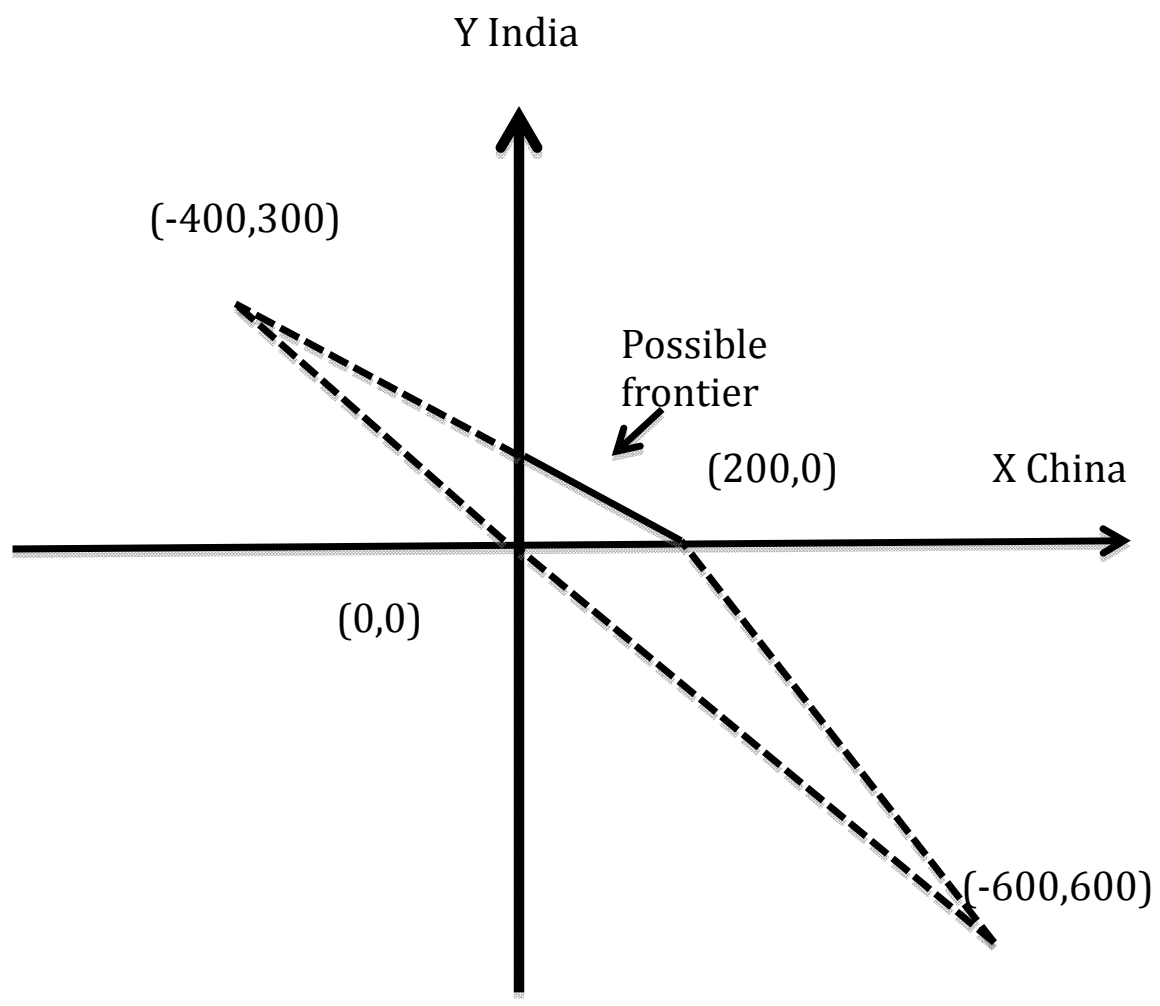

Figure 2-14 Possible frontier of repeated game on water sharing

The frontier is $(200,0)$ and $(0,100)$,Next step is the trade game, and payoff are assume as below.

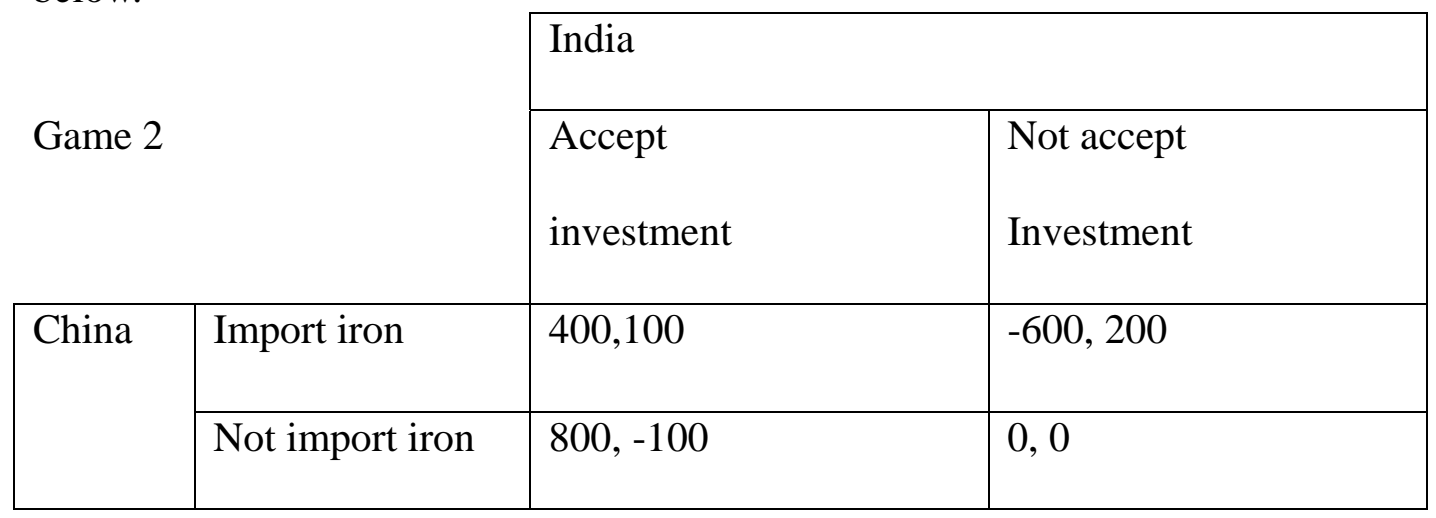

Infinitely repeated game is expressed as Figure 2-15 


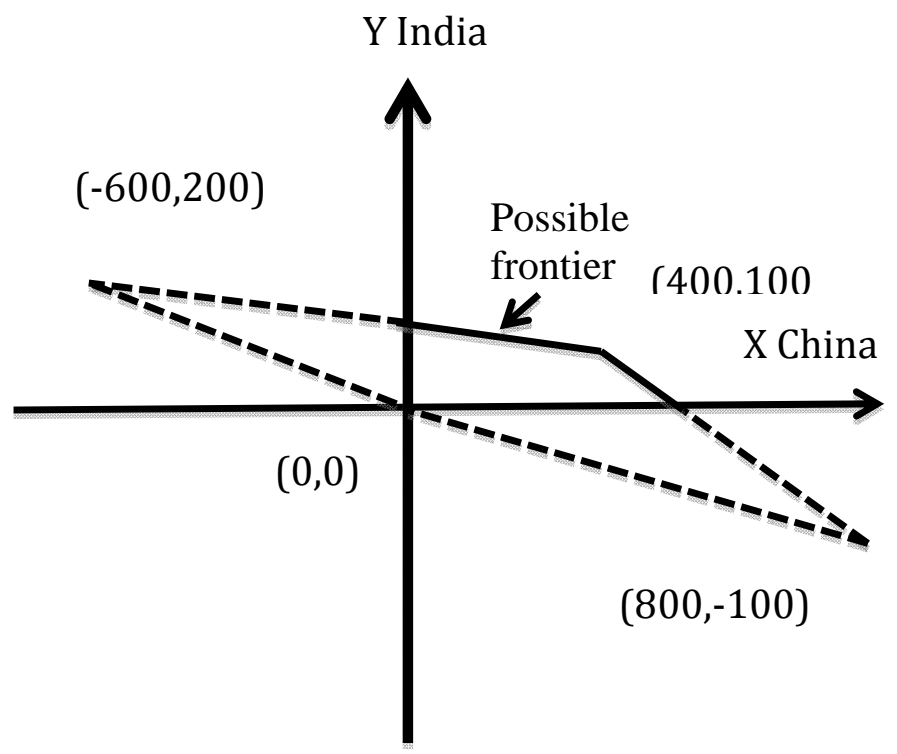

Figure 2-15 Infinite Repeated Water Sharing Game

The possible frontier are $(400,100),(0,140)$ and $(300,0)$. Aggregated isolated game is presented as below

\begin{tabular}{|l|l|l|l|}
\hline $\begin{array}{l}\text { Payoffs of water } \\
\text { sharing game } \\
\text { game }\end{array}$ & $\begin{array}{l}\text { Payoffs of trade } \\
\text { Aggregated } \\
\text { payoffs }\end{array}$ & $\begin{array}{l}\text { Other payoffs that } \\
\text { dominate this one }\end{array}$ \\
\hline$(0,100)$ & $(0,140)$ & $\underline{(0,240)}$ & \\
\hline$(0,100)$ & $(400,100)$ & $(300,200)$ & $(600,100)$ \\
\hline$(0,100)$ & $(0,140)$ & $(200,140)$ & $(300,200)$ \\
\hline$(200,0)$ & $(400,100)$ & $\underline{(600,100)}$ & \\
\hline$(200,0)$ & $(300,0)$ & $(500,0)$ & $(600,100)$, \\
& & & $(500,200)$ \\
\hline
\end{tabular}

So graphically it is presents as: 
Y India

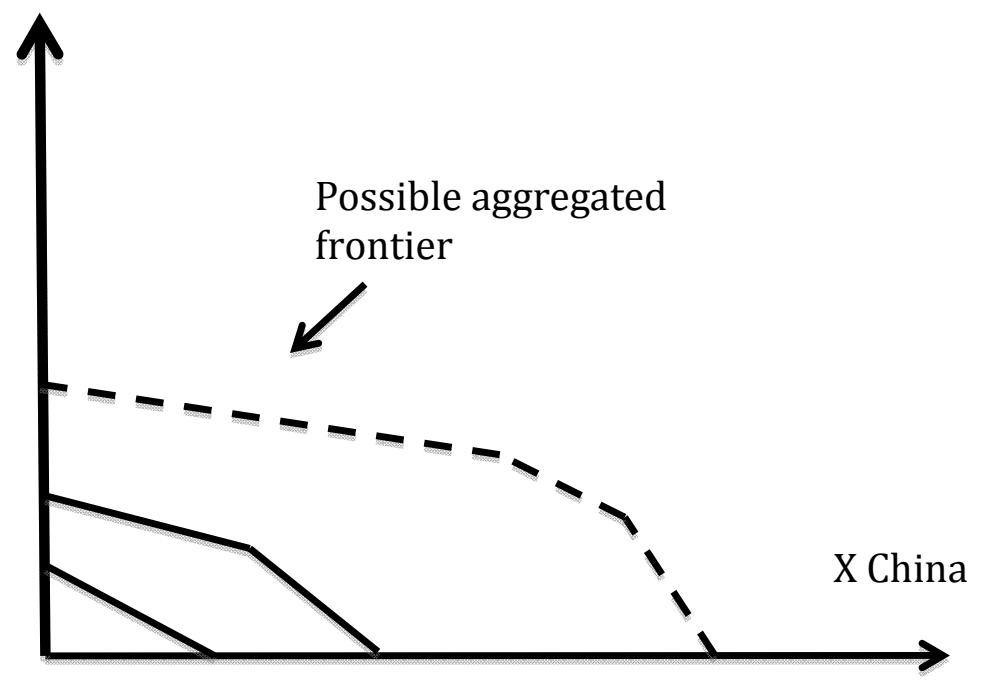

$(0,0)$

The interconnected game:

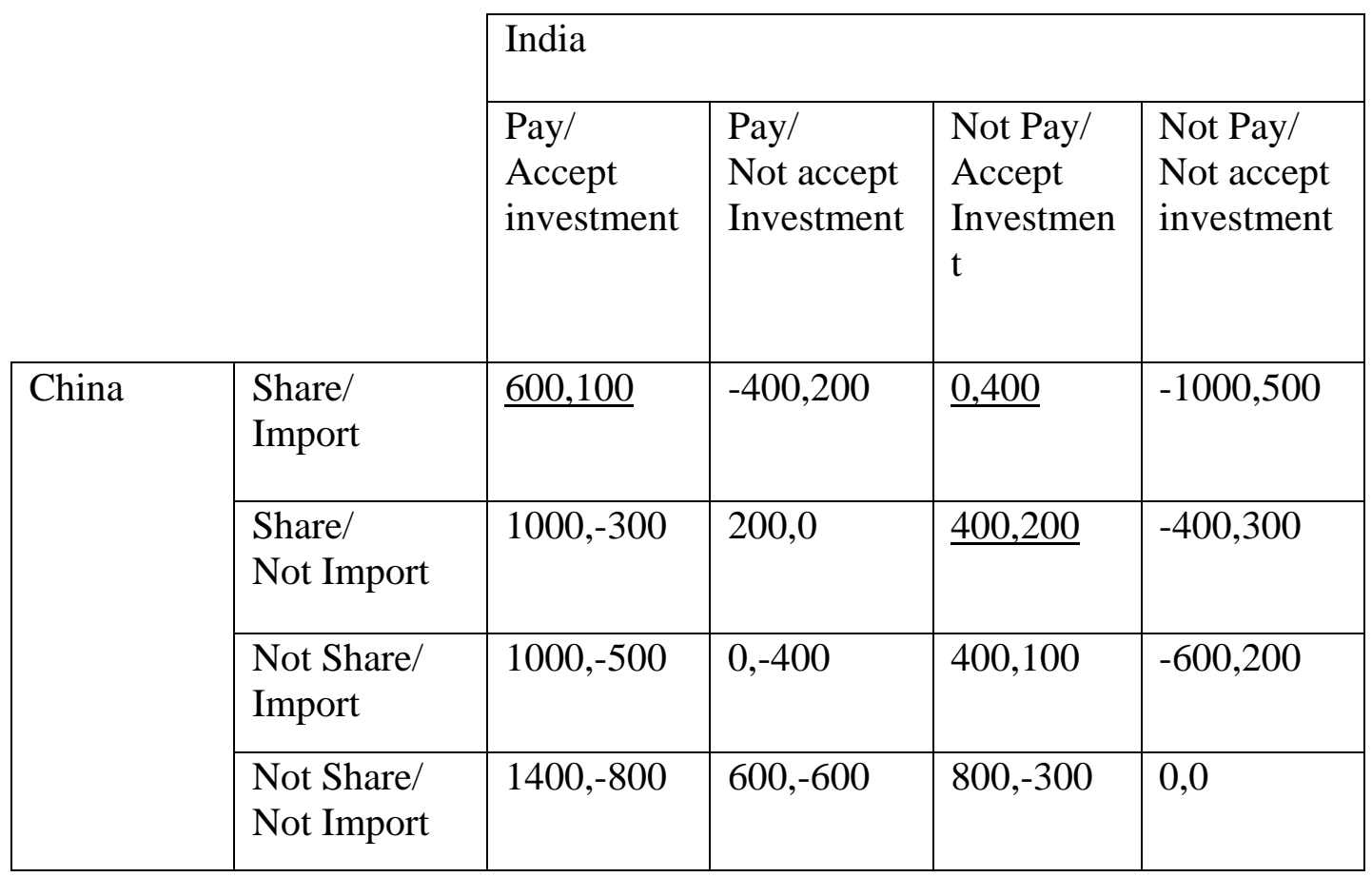


Consider only the payoff sets are non-negative, and eliminate the ones dominated by any other one. Therefore, the frontier is shown as the underline. In this case, the mix strategy (Share/Not Import, Not Pay/Accept Investment) or payoff $(400,200)$ is not better than the frontier of aggregated game. But the mix strategy (Share/ Import, Not Pay/Accept Investment) is better than the frontier of aggregated game.

\subsection{Conclusion}

Interconnected game provides broader vision of water management, especially to the trans-boundary water-sharing issues. Since China and India do not have any official water sharing agreement yet, this research might shed a light to an efficient way of designing a river sharing contract without side payment. I modeled an interconnected game linking water sharing game and international trade game. Model results shows that

the frontier of interconnected game is higher than the aggregated game, and it is feasible for India to get water shared without side payment. No literature so far has researched on the flood scenario, and the virtue of this paper is that extreme weather conditions are considered- drought and flood. I also proved that in flood season, neither the downstream incremental or constrained upstream incremental river sharing agreement would work. Then I constructed a new way to calculate the payoffs in the water sharing game. Even though the payoffs are quite different under two extreme weather, yet interconnect game are preferable than the aggregate game. India does not have to pay for China to control flood by agree to assign the infrastructure investment project to China. Experiment could be implemented in the future to test how efficient the interconnect game is and what the most preferable strategies people would choose under different weather condition. 


\section{REFERENCES}

Abbink, K., Jayne, T. S., \& Moller, L. C. (2008). The relevance of a rules-based maize marketing policy: an experimental case study of Zambia. World Bank Policy Research Working Paper Series, Vol.

Ambec, Stefan A. D. (2010). Hot Stuff: Would Climate Change Alter Transboundary Water Sharing Treaties? TSE Working Papers , 10-216.

Ambec, S., \& Sprumont, Y. (2002). Sharing a river. Journal of Economic Theory, 107(2), 453-462.

Baliga, S., \& Evans, R. (2000). Renegotiation in repeated games with side-payments. Games and Economic Behavior, 33(2), 159-176.

Barrett, S. (1994). Conflict and cooperation in managing international water resources (Vol. 94, No. 4). World Bank Publications.

Bennet, L. L., Ragland, S. E., \& Yolles, P. (1998). Facilitating International Agreements Through an interconnected game approach: the case of river basins. Conflict and cooperation on Trans-boundary water resources , 61-85.

Bernauer, T., \& Siegfried, T. (2012). Climate change and international water conflict in Central Asia. Journal of Peace Research, 49(1), 227-239.

Carraro, A. S. (2011). A Stochastic Multiple Players Multi-Issues Bargaining Model for the Piave River Basin. Strategic Behavior and the Environment , 1, 119-150.

Cooper, R., DeJong, D. V., Forsythe, R., \& Ross, T. W. (1996). Cooperation without reputation: experimental evidence from prisoner's dilemma games. Games and Economic Behavior, 12(2), 187-218.

Dinar, Ariel S. M. (2006). Application of Stochastic Cooperative Games in Water Resources. In D. B. RENAN-ULRICH GOETZ, \& D. Z. Ariel Dinar (Ed.), Frontiers in Water Resource Economics (pp. 1-20). New York: Springer US.

Evans, S. B. (2000). Renegotiation in Repeated Games with Side-Payments. Games and Economic Behavior , 33, 159-176.

Harrison,Glenn W a. E. (1991). Trade Wars, Trade Negotiations and Applied Game Theory. Economic Journal , 101, 420-435.

Hauer, G., \& Runge, C. F. (1999). Trade Environment Linkages in the Resolution of Transboundary Externalities. The World Economy, 22(1), 25-39. 
Folmer, Henk P. v. (1994). Interconnected games and international environmental problems. Annals of Operations Research , 54 (1), 97-117 .

Just, R. E., \& Netanyahu, S. (2004). Implications of "victim pays" infeasibilities for interconnected games with an illustration for aquifer sharing under unequal access costs. Water resources research, 40(5).

Moller, K. A. (2011). The Relevance of a Rules-based Maize Marketing Policy: An Experimental Case Study of Zambia. Journal of Development Studies , 47, 207-230.

Mostert, E. (2003). Conflict and Cooperation in the Management of International Freshwater Resources: A Global Review. UNESCO-IHP.

Ross, R. C. (1996). Cooperation without Reputation: Experimental Evidence from Prisoner's Dilemma Games. GAMES AND ECONOMIC BEHAVIOR , 12, 187-218.

Siegfried, T. B. (2012). Climate change and international water conflict in Central Asia . Journal of Peace Research , 49, 227-239.

Sprumont, S. A. (2000). Sharing a River. Laval - Recherche en Energie. Montréal: the Center for Interuniversity Research in Quantitative Economics (CIREQ).

Tisdell, J. G. (2004). Impact of communication and information on a complex heterogeneous closed water catchment environment. Water Resources Research , 40, W09S03.

Transboundary waters sharing (2008): benefits, sharing responsibilities. Zaragoza: UNWater.

Wolf, A. T. (2001, December). Transboundary waters: Sharing benefits, lessons learned. In International Conference on Freshwater (Hrsg.): Thematic Background Papers. International Conference on Freshwater, Bonn.

Wu, X., \& Whittington, D. (2006). Incentive compatibility and conflict resolution in international river basins: A case study of the Nile Basin. Water resources research, 42(2).

Zara, S., Patrone, F., Moretti, S., \& Dinar, A. (2006). Application of Stochastic Cooperative Games in Water Resources (No. urn: hdl: 123456789/4879). Université Paris-Dauphine. 
CHAPTER 3

VIRTUAL WATER TRADE AND ENVIRONMENTAL POLICIES

\subsection{Introduction}

As water scarcity becomes a major concern in countries around the world, the concept of 'virtual water' (Allan1993) has gained attention from water managers and researchers. 'Virtual water' is a measure of the total water used in producing a good or service. For instance, it takes 4,100 liters of water on average to produce one cotton shirt (medium sized, 500 gram). Hoeskstra and Huang (2003) report that 13\% of the water used for crop production in the world gets exported to other countries in the form of virtual water. Some researchers have found shortcomings in using this measure (Frontier Economics, 2008). It does not differentiate the value of water from different sources; it does not provide any indication of environmental harm nor the extract limit of sustainable usage of water; it might not be economical to reduce the production of water-intensive commodity in order to use the same water to produce an alternative less water-intensive commodity, as 'virtual water' is implicitly assumed and is not re-usable. However, in a study on trade data of Middle Eastern states, Allan (1993) concluded that using 'virtual water trade' could solve some of the water scarce issues. For example, the only way for water-scarce region to survive is to import a large amount of food such as grain, livestock etc. The region, therefore, could purchase the agricultural products with water already embedded in, instead of depending on its own scarce water resources.

Virtual water (VW) is essentially an embedded factor of production, and therefore, makes it an important economic concept. However, as Remier (2012) points out, some economists are not keen on using VW as a legitimate economic concept, 
especially in the context of trade. Remier found three specific arguments made against VW in the literature. First, Merrett (1997) disputes the legitimacy of using the term 'virtual water import' since the water contained in imported products (VW) is much less than the actual water used in their production. Second, Wichelns (2004) argues that VW only considers the absolute advantage but not comparative advantage, the fundamental economic principle underlying international trade (OCED 2050). VW concept only addresses resource endowments (absolute advantage) and that it ignores the underlying differences in production technologies or opportunity costs between trading partners, which form the basis for comparative advantage. Third, Ansink (2010) argues that the standard international trade model only provides a weak support to VW concept. He also argued that VW fails to stand even certain empirical tests. However, Reimer (2012) systematically counter all the above three arguments and argue that relative water endowments of countries are the main sources of comparative cost advantage. The comparative cost advantage arising due to VW may not be obvious but 'latent.' Reimer used a two countries, two factors (capital and water) and two goods model, by maximizing the firms' profit with trade balance constraint, he proved the HeckscherOhlin Theorem. The comparative cost differences may not arise necessarily due to intercountry technology differences in this case, but to the high costs of trade associated with the sector that is most VW-intense, i.e., agriculture. Therefore, Reimer argue that VW must receive due consideration in evaluating trade-related efficiencies and welfare gains and losses. The present study will expand Reimer's idea to explicitly model trade-related welfare gains from importing a VW-rich commodity from another country in exchange for exporting a VW-free commodity. 
Most researches on virtual water, only concerns agricultural products, such as wheat, grains, and etc. This study however includes industrial products and other products of virtual water. The key question that I try to address is how much water is saved for a water scarce country via import and what the local and global welfare gains will be. Are there policies (subsidies and taxes) to match the market economic welfare goals and other social welfare? Peterson et al, 2002 shed some light on the social welfare calculation with environmental externality when different policies applied. They constructed a two-countries, one agricultural good, two factors (land and non-land), model with externalities, and then by empirically test, they found out the optimal policy tool. It was predicted that all small countries support a positive land subsidies for the production of non-market agricultural good I will extend the international trade model of Reimer (2012) and Peterson et al. (2002) by explicitly integrating not only virtual water but also other environmental factors such as water pollution, water scarcity rent into a two country, two factors (water and non-water), two products general equilibrium trade model. One country produces only one water-embedded commodity with different technology and trade with each other. By solving the above modified general equilibrium model, I will determine the social welfare, which is the sum of consumer surplus representing the utility from consumption net of externality (such as environmental degradation or improvement), and producer surplus, representing the firm's profit. The model will result in equilibrium quantities and prices of water-embedded products. The quantity of water saved by virtual trade could be determined by the net import. Meanwhile, social planner may design policies such as subsidies and taxes to match the optimal social welfare with the market-determined welfare The above model is empirically 
tested by using data from the USDA, FAOSTAT, World bank and USEIA (US Energy Information Administration). USDA publishes national data on wheat consumptions, import, and average cost of growing wheat in United States. FAOSTAT provides wheat prices, production and food CPI in different countries all over the world. Real world oil price (taking inflation into account) is available from the databank of World Bank. USEIA provides data on domestic oil price in United States, oil production and consumption in US and Saudi Arabia. Using the above data, I will be able to estimate the various components of the general equilibrium model and compute welfare gains and losses from different market and policy scenarios.

This paper concerns international efficiency of virtual water trade. From the data of www.waterfootprint.org, top net virtual water importers are North America and East Asia, however, the water scarce countries like African countries involve much less in the virtual water trade. My study will analyze the extent to which virtual water will influence the overall welfare, and if there is any need for policy intervention to align trade-related economic welfare goals with water-related environmental goals. I will also take the sustainability indicators into a general equilibrium model. Following Wurtenberger et al. [2006], environmental indicators such as pollution impacts of production is factored into the two-country trade model.

I will focus on the water pollution, since as virtual water trade takes place, water pollution is 'transferred' to the exporting country. There will be a trade-of of environmental cost of water pollution and producer's or/and consumer's surplus. The model will solve for maximum social welfare, which is the sum of consumer surplus that consists of utility from demand and externality (such as environmental degradation or improvement), 
and producer surplus that is the firm's profit.. By trading the virtual water products, world equilibrium price can be obtained by equating the home production and home demand plus foreign demand. My model also calculates how much water is saved by trading the virtual water products. Meanwhile, social planner can make policies such as subsidy or tax to match the optimal social welfare based on the results. The model provides insights on VW-related policy solutions to domestic water scarcity issues, for instance, water transfer from South to North in China. By testing the data, some of the shortcomings of virtual water will be minimized.

The rest of the paper is organized as follows. The next section introduces the conceptual international trade model of virtual water. Some policy suggestions are made in Section 3.3. Section 3.4 explains the data from difference sources I will use to test the model developed in Section 3.2. In Section 3.5, I will simulate a model and use the data to estimate related parameter and test the variables needs in the model. Test results will be well explained in Section 3.6, and then section 3.7 will be the conclusion.

\subsection{Model}

\subsubsection{Environment}

Following the standard Heckscher-Ohlin trade model (Heckscher, 1919; Ohlin, 1933), I assume that there are two countries, Home and Foreign, in the world producing the two commodities, one is water intensive and the other is less water intensive. Two factors will be input in the production of those two goods: water and non-water. The technology form of any products that are embedded with water, is expressed as its general transformation form (Peterson et al., 2002): 
$T\left(y_{1}, y_{2}, D, W, N_{i}\right)=0$

$T\left(y_{1}^{*}, y_{2}^{*}, D, W^{*}, N_{i}^{*}\right)=0(i=1,2, \ldots, n)$

Where $\mathrm{y}$ is the output of the product in question, $\mathrm{D}$ is a negatively valued damage from pollution, $\mathrm{W}$ is the input of water and $\mathrm{Ni}$ is the input of non- water. $\mathrm{i}$ is the index of nonwater based inputs. Both countries consume this commodity. All asterisks represent the foreign country. I assume that Home is a water scare country, while Foreign is water abundant. I will analyze the problem under the circumstances with and without trade. During the international virtual water trade, the environmental pollution or damage is being transferred as well. For example, with virtual water trade, the water abundant country (foreign country) will focus on producing the water intensive product and therefore, water in the Home country can be used for other more important sectors or in the future. At the same time, since the technologies of producing this product are different, then the production functions are as below:

$$
\begin{aligned}
& y_{1}=F_{1}\left(W_{1}, N_{1 i}\right), y_{1}^{*}=F_{1}^{*}\left(W_{1}^{*}, N_{1 i}^{*}\right) \\
& y_{2}=F_{2}\left(W_{2}, N_{2 i}\right), y_{2}^{*}=F_{2}^{*}\left(W_{2}^{*}, N_{2 i}^{*}\right)
\end{aligned}
$$

Function D is the damage function which has the same functional form in every country. To simplify the problem, I assume that VW-related damage will is a function of production of good 1 and good 2, and in turn, a function of embedded factors of production.

$$
\begin{aligned}
& D=D\left(F_{1}\left(W_{1}, N_{1 i}\right)\right)=D\left(W_{1}, N_{1 i}\right) \\
& D^{*}=D^{*}\left(F_{1}^{*}\left(W_{1}^{*}, N_{1 i}^{*}\right)\right)=D^{*}\left(W_{1}^{*}, N_{1 i}^{*}\right)
\end{aligned}
$$

Function $F$ and $D$ are both concave, twice differentiable and satisfy the general transformation form as follows $T\left(F_{1}\left(W_{1}, N_{1 i}\right), F_{2}\left(W_{2}, N_{2 i}\right), D\left(W_{1}, N_{1} i\right), W, N i\right)=0,(i=1,2, \ldots, \mathrm{n})$ 
$T^{*}\left(F_{1}^{*}\left(W_{1}^{*}, N_{1 i}^{*}\right), F_{2}^{*}\left(W_{2}^{*}, N_{2 i}^{*}\right), D^{*}\left(W_{1}^{*}, N_{i}^{*}\right), W, N_{i}\right)=0,(i=1,2, \ldots, n)$

\subsubsection{Autarky Economy}

Under autarky economy, firms from home country are producing both commodities with the maximized profit.

$$
\begin{aligned}
& \pi\left(p_{y}, p_{W}, p_{N_{i}}\right)=\max \left\{p_{1} F_{1}\left(W_{1}, N_{1 i}\right)+p_{2} F_{2\left(W_{2}, N_{2 i}\right)}-p_{W}\left(W_{1}+W_{2}\right)-p_{N_{i}}\left(N_{1 i}+\right.\right. \\
& \left.\left.N_{2 i}\right)\right\}
\end{aligned}
$$

Therefore, taking first order conditions with respect to the input of water and nonwater factors, we obtain

$$
p_{W}=p_{1} F_{1 W_{1}}=p_{2} F_{2 W_{2}}, \quad p_{N_{i}}=p_{1} F_{1 N_{1}}=p_{2} F_{2 N 2 i}
$$

Since home country is supposed to be a relative water scarce country, it does not produce that commodity in big enough quantity to influence the world output price. That is, it takes the world price as given. Factor price is equal to the value of its marginal productivity contributed to the final product. Since the price of good 1, the water intensive product, is taken as given, the factor price is completely determined by the value of the marginal productivity.

$$
\begin{aligned}
& W_{1} / y_{1}=a_{1 w}, W_{2} / y_{2}=a_{2 w}, N_{1 i} / y_{1}=a_{1 N_{i}}, N_{2 i} / y_{2}=a_{2 N_{i}} \\
& W_{1}^{*} / y_{1}^{*}=a_{1 w}^{*}, W_{2}^{*} / y_{2}^{*}=a_{2 w}^{*}, N_{1 i}^{*} / y_{1}^{*}=a_{1 N_{i}}^{*}, N_{2 \mathrm{i}}^{*} / y_{2}^{*}=a_{2 N_{i}}^{*}
\end{aligned}
$$

This ratio above is the factor needed to produce one unit of good. i.e. $a_{1 W}$ is the amount of water needed for producing good 1 for the home country. When factor market in each country clears, $W_{1}+W_{2}=W$, and $N_{1 i}+N_{2 i}=N_{i}$. Same applies for the foreign country, where $W_{1}^{*}+W_{2}^{*}=W^{*}$ and $N_{1}^{*}+N_{2}^{*}=N^{*}$. Perfect competitive market condition makes zero profit and free entry with 


$$
\begin{aligned}
& a_{1_{w}} p_{w}+a_{1 N i} p_{N_{i}}=p_{1} \\
& a_{2 w} p_{w}+a_{2 N i} p_{N_{i}}=p_{2}
\end{aligned}
$$

Where $p_{W}, P_{N_{i}}$, and $p_{1}, p_{2}$ stand for factor prices of water and non-water, price of good 1 and good 2. Left hand side represents the average total cost of each good.

$$
\begin{aligned}
& W_{1} / N_{1 i}>W_{2} / N_{2 i^{\prime}} \\
& \mathrm{W}_{1}^{*} / N_{1 i}^{*}>W_{2}^{*} / N_{2 i}^{*}
\end{aligned}
$$

Therefore,

$$
\frac{a_{1 W}}{a 1 N_{1 i}}>\frac{a_{2 W}}{a 2 N_{2 i}}, \frac{a * 1 W}{a * 1 N_{1 i}}>\frac{a * 2 W}{a * 2 N_{2 i}}
$$

And assume that home country is relatively water scarce, whereas foreign country is relatively water abundant. $W / N i<W^{*} / N^{*} i$

\subsubsection{Social Welfare (Autarky)}

For the social planner, the problem is maximizing the social welfare, which is the sum of consumer surplus (the area between the demand curve and equilibrium price), and producer surplus (the firms' profit), net of water related environmental damage.

$$
\begin{aligned}
& \Omega_{\text {autarky }}=\max _{W, N_{i}}\left\{\int_{\hat{p}_{1}}^{\infty}\left(p_{1}\right) d\left(p_{1}\right)+\int_{\hat{p}_{1}}^{\infty}\left(p_{2}\right) d\left(p_{2}\right)+p_{1} F_{1}\left(W_{1}, N_{1_{i}}\right)+p_{2} F_{2}\left(W_{2}, N_{2 i}\right)-\right. \\
& \left.p_{W}\left(W_{1}+W_{2}\right)-\sum p_{N_{i}}\left(N_{1 i}+N_{2 i}\right)-C\left(F\left(W_{1}, N_{1 i}\right)\right)\right\}
\end{aligned}
$$

Let $c(p)$ be the consumption of the commodity, Market clears when

$$
c_{1}\left(p_{1}\right)=y_{1}=F_{1}\left(W_{1}, N_{1 i}\right), c_{2}\left(p_{2}\right)=y_{2}=F_{2}\left(W_{2}, N_{2 i}\right)
$$

which is consumption/demand equals to the output. The product price $p 1, p 2$, therefore, can be expressed as a function of $p_{1}=p_{1}\left(W_{1}, N_{1 i}\right), p_{2}=p_{2}\left(W_{2}, N_{2 i}\right)$. And $C\left(F\left(W_{1}, N_{1 i}\right)\right)$ is the social cost function, a concave, twice differentiable function of production. Social cost includes the opportunity cost of using the water to the other usage, 
cost of water pollution cleaning and the user cost which is the scarcity rent for future usage. It is assumed that only good 1 or water-intensive good production generates social cost, and the externalities from the production of good 2, less water-intensive good is ignored. Solving this social optimal problem:

$$
\begin{aligned}
& -c_{1}\left(p_{1}\right) \frac{\partial p_{1}}{\partial W_{1}}+\frac{\partial p_{1}}{\partial W_{1}} F_{1}(.)+p_{2} F_{1 W_{1}}-C_{F} F_{1 W_{1}}=p_{W} \\
& -c_{1}\left(p_{1}\right) \frac{\partial p_{1}}{\partial N_{1}}+\frac{\partial p_{1}}{\partial N_{1}} F_{1}(.)+p_{1} F_{1 N_{1 i}}-C_{F} F_{1 N_{1 i_{i}}}=p_{N 1 i} \\
& -c_{2}\left(p_{2}\right) \frac{\partial p_{2}}{\partial W_{2}}+\frac{\partial p_{2}}{\partial W_{2}} F_{2}(.)+p_{2} F_{2 W_{2}}-C_{F} F_{2 W_{2}}=p_{W} \\
& -c_{2}\left(p_{2}\right) \frac{\partial p_{1}}{\partial N_{1}}+\frac{\partial p_{1}}{\partial N_{1}} F_{2}(.)+p_{2} F_{2 N_{2 i}}-C_{F} F_{2 N_{2 i_{i}}}=p_{N 1 i}
\end{aligned}
$$

When market clear at $c_{1}\left(p_{1}\right)=y_{1}=F_{1}\left(W_{1}, N_{1 i}\right), c_{2}\left(p_{2}\right)=y_{2}=F_{2}\left(W_{2}, N_{2 i}\right)$, Equations (3.4) to (3.7) become,

$$
\begin{aligned}
& p_{1} F_{1 W_{1}}-p_{W_{1}}-C_{F} F_{1 W_{1}}=0 \\
& p_{1} F_{1 N_{1 \mathrm{i}}}-p_{N 1 i}-C_{F} F_{11_{1}}=0 \\
& p_{2} F_{2 W_{2}}=p_{W} \\
& p_{2} F_{22_{2}}=p_{N i}
\end{aligned}
$$

It is obvious that $p_{2}$ does not change whether or not considering the social welfare. However, there is a difference between the price of good $1, p_{1}$ when considering social welfare and not. Denote the price of good 1 as $\widehat{p_{1}}$ when taking taking social welfare into account and from (6)

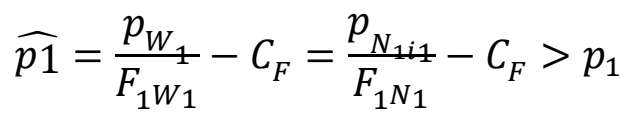

Since social cost of the environmental damage is included in $\widehat{p_{1}}$. On the one hand, policy in such case could be the subsidies to the consumers, which is equal to the social 
cost, to raise their consumers' surplus. On the other hand, social cost can be internalized by subsiding the firm's output to reduce its cost. The solution to the first integration is the water embedded in good 1 , denoted as $W_{1}$. In addition to the water embedded in good 2 , $W_{2}$, the total water used in domestic production of home country is $W^{\wedge}=\left(W_{1}\right)^{\wedge}+$ $\left(W_{2}\right)^{\wedge}$ Meanwhile, the factor price ratio is as below and still equals to the marginal product of input ratio. Therefore, the externality does not affect equality of per dollar marginal productivity of each factor.

$F_{1 W_{1}} / F_{1 N_{1}}=p_{W 1} / p_{N 1 i}$ or $\frac{F_{1 W_{1}}}{p_{W}}=\frac{F_{1 N_{1}}}{\mathrm{p}_{\mathrm{Ni}}}$

Physical water used in production is traced though (8) and (10), $W=W_{1}+$ $W_{2}=F_{1}^{-1}\left(\frac{p_{W}}{p_{1}-C_{F}}\right)+F_{2}^{-1}\left(\frac{p_{W}}{p_{2}}\right)$

\subsubsection{Open Economy with free trade (countries produce and trade both goods)}

Open economy allows countries to trade; home countries could produce and trade both goods. For the water scarce country, I assume it is a small country when it produces water-intensive products, therefore, it takes world price as given, or the open economy make the price of good 1 drop to the world price, consumer surplus of good 1 increases. New world price is denoted as p1. However, the water relative abundant country (foreign country) is assumed as a large economy when it produces water-intensive products. Hence, when it increase any of its factor input, e.g., water, the output rises, which results that the output price/ world price drops ( $\partial p_{y} / \partial W<0, \partial p_{y_{i}} / \partial N_{i}<0$ ), ceteris paribus. And open economy does not change the price of good 2, so does the consumer surplus of good 2 . Home country import the amount of $M_{1}=c_{1}-y_{1}$ of good 1 from foreign country and export $X_{2}=y_{2}-c_{2}$ to the foreign country. And foreign country import $\mathrm{M}_{2}^{*}=c_{2}^{*}-$ 
$y_{2}^{*}$ and export $X_{2}^{*}=y_{1}^{*}-c_{1}^{*}$. Market clears at $M_{1}=X_{1}^{*}$ and $X_{2}=M_{2}^{*}$ Therefore, $c_{1}-$ $y_{1}=y_{1}^{*}-c_{1}^{*}$ and $y_{2}-c_{2}=c_{2}^{*}-y_{2}^{*}$.

Welfare of home country in the trade is as the following:

$$
\begin{gathered}
\Omega_{\text {trade }}=\max _{\widetilde{W}, N_{l}}\left\{\int_{\widetilde{p}_{1_{1}}}^{\infty} c_{1}\left(p_{1}\right) d\left(p_{1}\right)+\int_{\widetilde{p}_{2_{1}}}^{\infty} c_{2}\left(p_{2}\right) d\left(p_{2}\right)+\widetilde{p_{1}} F_{-} 1\left(\widetilde{W}_{1}, \widetilde{N}_{1 i}\right)+\widetilde{p}_{1} F_{2}\left(\widetilde{W}_{2}, \widetilde{N}_{2 i}\right)\right. \\
\left.-p_{W}\left(\widetilde{W}_{1}+\widetilde{W_{2}}\right)-p_{N_{i}}\left(\widetilde{N}_{1 i}+\widetilde{N}_{2 i}\right)-C\left(F\left(\widetilde{W}_{1}, \widetilde{N}_{1 i}\right)\right)\right\}
\end{gathered}
$$

And foreign country's welfare in the trade is:

$$
\begin{aligned}
\Omega^{*}{ }_{\text {trade }}=\max _{\widetilde{W}, \bar{N}_{l}}\left\{\int_{\widetilde{p_{1}}}^{\infty} c_{1}^{*}\left(p_{1}\right) d\left(p_{1}\right)+\int_{{\widetilde{p_{1}}}_{1}}^{\infty} c_{2}^{*}\left(p_{2}\right) d\left(p_{2}\right)+\widetilde{p_{1}} F_{1}^{*}\left(\widetilde{W^{*}}{ }_{1},{\widetilde{N^{*}}}^{*}{ }_{1 i}\right)\right. \\
+\widetilde{p_{1}} F_{2}^{*}\left(\widetilde{W^{*}}{ }_{2}, \widetilde{N^{*}}{ }_{2 i}\right)-p W\left(\widetilde{W_{1}^{*}}+\widetilde{W^{*}}{ }_{2}\right)-p N_{i}\left(\widetilde{N_{1 l}^{*}}+\widetilde{N^{*}}{ }_{{ }_{i}}\right) \\
\left.\quad-C\left(F\left(\widetilde{W^{*}}{ }_{1},{\widetilde{N^{*}}}^{*}{ }_{1 i}\right)\right)\right\}
\end{aligned}
$$

F.O.C.s are as the follows:

$$
\begin{aligned}
& \tilde{p} 1 \tilde{F} 1 W 1-\tilde{C} F \tilde{F} W_{1}=(\tilde{p} 1-\tilde{C} F) \tilde{F} 1 W 1=p W \\
& \tilde{p} 1 \tilde{F} 1{ }_{N}-\tilde{C} F \tilde{F} 1_{i}=(\tilde{p} 1-\tilde{C} F) \tilde{F} 1 N 1_{i}=p N \\
& -c\left(p_{2}\right) \frac{\partial p_{2}}{\partial W_{2}}+\frac{\partial p_{2}}{\partial W_{2}} F_{2}(.)+p_{2} F_{2 W_{2}}-p_{W}=0 \\
& -c\left(p_{2}\right) \frac{\partial p_{2}}{\partial N_{2 i}}+\frac{\partial p_{2}}{\partial N_{2 i}} F_{2}(.)+p_{2} F_{2 N_{2 i}}-p_{N_{i}}=0 \\
& -c_{1}^{*}\left(\tilde{p}_{1}\right) \frac{\partial \tilde{p}_{1}}{\partial W_{1}^{*}}+\frac{\partial \tilde{p}_{1}}{\partial W_{1}^{*}} F_{1}^{*}(.)+\tilde{p}_{1} F_{1 W_{1}^{*}}^{*}(.)-C_{F} F_{W_{1}^{*}}^{*}=p_{W} \\
& -c_{1}^{*}\left(\tilde{p}_{1}\right) \frac{\partial \tilde{p}_{1}}{\partial N_{1}^{*}}+\frac{\partial \tilde{p}_{1}}{\partial N_{1}^{*}} F_{1}^{*}(.)+\tilde{p}_{1} F_{1 N_{1}^{*}}^{*}(.)-C_{F} F_{N_{1 i}^{*}}=p_{N_{i}} \\
& p_{2} F_{2 W_{1}^{*}}^{*}(.)-C_{F} F_{W_{2}^{*}}^{*}=p_{W} \\
& p_{2} F_{2 N_{2}^{*}}^{*}(.)-C_{F} F_{N_{2 i}^{*}}=p_{N_{i}}
\end{aligned}
$$


If the country is a small economy of one good production, then it factor price is net of the value its marginal productivity and marginal social cost to the environment. In another word, the value of the factor's marginal productivity in a certain good is the sum of the factor's price and its marginal social cost. If the country is a large economy, on the contrary, the value of a factor's marginal productivity is the sum of the factor price and its marginal social cost subtract the other country's marginal consumption value of this factor change. Therefore, the value of the factor's marginal productivity is higher in the commodity produced in large country that in small country. Both countries also face budget constraints, where home country's budget constraint is:

$p_{1} c_{1}+p_{2} c_{2}=p_{1} y_{1}+p_{2} y_{2}=p_{1} F_{1}()+.p_{2} F_{2}($.

While foreign's is as follows with free trade (prices of both goods are the same which is the world price): $\tilde{p}_{1} c_{1}^{*}+p_{2} c_{2}^{*}=\tilde{p}_{1} F_{1}^{*}()+.p_{2} F_{2}^{*}($.

Open economy expands the demand of good 2 which is from the foreign country because the price of good 2 is relatively cheaper than that in the foreign country. Therefore, home country mount up its production of good 2 to match such extra demand. Physical water amount used in the production can be traced through equation $3.12 \tilde{W}_{1}=F^{-1}\left(\frac{p_{W}}{p_{1}^{\prime}-C_{F^{\prime}}}\right)$, and equation 3.14: $F_{2}^{-1}\left(c\left(p_{2}\right) \frac{\partial p_{2}}{\partial W_{2}}-\frac{\partial p_{2}}{\partial W_{2}} F_{2}()+.p_{W}\right) / p_{2}=W_{2}$ Therefore, domestic water saved from open economy is

$$
\begin{aligned}
W_{1}+W_{2}-\tilde{W}_{1} & -\tilde{W}_{2} \\
& =F_{1}^{-1}\left(\frac{p_{W}}{p_{1}-C_{F}}\right)+F_{2}^{-1}\left(\frac{p_{W}}{p_{2}}\right)-F_{1}^{-1}\left(\frac{p_{W}}{\tilde{p}_{1}-C_{F^{\prime}}}\right)-F_{2}^{-1}\left(\left(c\left(p_{2}\right) \frac{\partial p_{2}}{\partial W_{2}}\right.\right. \\
& \left.\left.-\frac{\partial p_{2}}{\partial W_{2}} F_{2}(.)+p_{W}\right) / p_{2}\right)
\end{aligned}
$$


Equations (3.12) and (3.13) explains that as long as factor prices do not change, change of the value of marginal factor productivity is equal to the change of the value of marginal social cost of the factor. For the home country, social welfare will be decreased by consumer surplus but gained from producer surplus and less social cost of the environment because of using less water during the production process of water-intensive good. Domestic government does not have to impose any distortions like tax or subsidies as in autarky economy. Instead, the gains and loss from the international trade can be mutually compensated. Moreover, since output prices of good $1\left(p_{1}\right)$ and good $2\left(p_{2}\right)$ are determined by water and non water input, optimal domestic welfare does not guarantee optimal global welfare. The global welfare optimization problem is as follows,

$$
\begin{array}{r}
\Omega_{\text {trade }}+\Omega_{\text {trade }}^{*} \\
\text { s.t. } c_{1}-y_{1}=y_{1}^{*}-c_{1}^{*} \text { and } y_{2}-c_{2}=c_{2}^{*}-y_{2}^{*}
\end{array}
$$

3.2.4 Open Economy with free trade and each country export the product they have comparative advantage in

As assumed above, home country is relatively water scarce. Reimer (2012) proved that even though some economists opposed using 'virtual water trade' concept to international trade because this concept relied on absolute value, there was still a hint of comparative advantage embedded in this concept. Hence, when it is an open economy, water abundant country (foreign country) produces more water intensive good (good 1) than that they consume, and water scarce country (home country) produces more of less water intensive good (good 2) than that they consume. Even though completely giving up 
production of one good might be risky and makes the country vulnerable to this good, for water scarce countries like Saudi Arabia, it is not a bad idea to do so.

$y_{1}^{*}>c_{1}^{*}$ and $y_{2}>c_{2}$

Home country import the amount of $M_{1}=c_{1}$ of good 1 from foreign country and export $X_{2}=y_{2}-c_{2}$ to the foreign country. And foreign country import $\mathrm{M}_{2}^{*}=c_{2}^{*}$ nd export $\mathrm{X}_{1}^{*}=y_{1}^{*}-c_{1}^{*}$ Market clear at $M_{1}=X_{1}^{*}$ and $X_{1}=M_{1}^{*}$ Home country faces its budget constraint:

$p_{1} c_{1}=p_{2} y_{2}-p_{2} c_{2}=p_{2} c_{2}^{*}$

While foreign country's budget constraint is as follows with free trade (prices of both goods are the same which is the world price): $p_{2} c_{2}^{*}=p_{1} y_{2}^{*}-p_{1} c_{2}^{*}=p_{1} c_{1}$

In the international trade, both countries produce only what they have comparative advantage, therefore, both of them are considered as large economy for the goods they produce. Therefore, the domestic factor prices change influence the world price, such that $\frac{\partial p_{y}}{\partial W}<0, \frac{\partial p_{y_{i}}}{\partial N_{i}}<0$. As the import of water intensive good, the environmental damage is exported. In this case, home country does not produce good 1 , and all the environmental damages from this good are transferred to foreign country. Therefore, even though there might be higher producer's surplus and consumer's surplus, yet there is a trade-off of the environmental quality. Social welfare of both countries might change.

The objectives for each country's social planner are formulated as the following. Welfare of home country in the trade is : 


$$
\begin{array}{r}
\Omega_{\text {VWtrade }}=\max _{W, N_{i}}\left\{\int_{\hat{p}_{1}}^{\infty} c_{1}\left(\hat{p}_{1}\right) d\left(\hat{p}_{1}\right)+\int_{\hat{p}_{2}}^{\infty} c\left(\hat{p}_{2}\right) d\left(\hat{p}_{2}\right)\right. \\
\left.+p_{2} F_{2}\left(W_{2}, N_{2 i}\right)-p_{W} W_{2}-\sum_{i=1}^{n} p_{N_{i}} N_{2 i}\right\}
\end{array}
$$

and foreign country's welfare in the trade is:

$$
\begin{gathered}
\Omega_{V W \text { trade }}^{*}=\max _{W, N_{i}}\left\{\int_{\hat{p}_{1}}^{\infty} c_{1}^{*}\left(\hat{p}_{1}\right) d\left(\hat{p}_{1}\right)+\int_{\hat{p}_{2}}^{\infty} c_{2}^{*}\left(\hat{p}_{2}\right) d\left(\hat{p}_{2}\right)+p_{1} F_{1}^{*}\left(W_{1}^{*}, N_{1 i}^{*}\right)-p_{W} W_{1}^{*}\right. \\
\left.-\sum_{i=1}^{n} p_{N_{i}} N_{1 i}^{*}-C\left(D\left(W_{1}^{*}, N_{1 i}^{*}\right)\right)\right\}
\end{gathered}
$$

The home welfare, therefore, does not include producer's surplus of good 1, costs of producing good 1 and the externality of environmental damage. Meanwhile, the foreign welfare does not include producer's surplus of good 2 and costs of producing good 2 . Nevertheless, the social/externality cost from environmental damage increases since it produces more of good 1 than autarky scenario. The first order conditions of the optimal solution are derived.

$$
\begin{aligned}
& -c_{2}\left(p_{2}\right) \frac{\partial p_{2}}{\partial W_{2}}+\frac{\partial p_{2}}{\partial W_{2}} F_{2}(.)+p_{2} F_{2 W_{2}}=p_{W} \\
& -c_{2}\left(p_{2}\right) \frac{\partial p_{2}}{\partial N_{2 i}}+\frac{\partial p_{2}}{\partial N_{2 i}} F_{2}(.)+p_{2} F_{2 N_{2 i}}=p_{N} \\
& -c_{1}^{*}\left(p_{1}\right) \frac{\partial p_{1}}{\partial W_{1}^{*}}+\frac{\partial p_{1}}{\partial W_{1}^{*}} F_{1}^{*}(.)+p_{1} F_{1 W_{1}^{*}}^{*}(.)-C_{F} F_{W_{1}^{*}}=p_{W} \\
& -c_{1}^{*}\left(p_{1}\right) \frac{\partial p_{1}}{\partial N_{1}^{*}}+\frac{\partial p_{1}}{\partial N_{1}^{*}} F_{1}^{*}(.)+p_{1} F_{1 N_{1}^{*}}^{*}(.)-C_{F} F_{N_{1 i}^{*}}=p_{N_{1 i}}
\end{aligned}
$$

First of all, $\partial p_{1} / \partial W_{1}^{*}$ marginal price change of water- intensive products in water input in foreign county, need to be specified. By the chain rule, $\partial p_{1} / \partial W_{1}^{*}$ is expressed as follows: 
$\frac{1}{\frac{\partial c_{1}^{*}}{\partial p_{1}}+\frac{\partial c_{1}}{\partial p_{1}}} \times \frac{\partial y_{1}^{*}}{\partial W_{1}^{*}} c_{1}\left(p_{1}\right)+p_{1} F_{1 W_{1}^{*}}^{*}()-.C_{F} F_{W_{1}^{*}}^{*}=p_{W}$

Therefore, the market clearing condition (3.24) is simplified as below: $F^{-1}\left(\frac{p_{W}}{p_{1}-C_{F}}\right)+$

$F_{2}^{-1}\left(\frac{p_{W}}{p_{2}}\right)-\hat{F}_{2}^{-1}\left(\left(c\left(p_{2}\right) \frac{\partial p_{2}}{\partial W_{2}}-\frac{\partial p_{2}}{\partial W_{2}} \hat{F}_{2}()+.p_{W}\right) / p_{2}\right)$

Define the optimal levels of water usage $\mathrm{W}_{2}$ and non-water usage $\mathrm{N}_{2} \mathrm{i}$ Hence, optimal output level is $\tilde{y} 1=F\left(\widetilde{W}_{1}, \widetilde{N_{1}}\right)$. If considering comparative advantage of virtual water trade, water is saved for the home country (home country) by the amount of $F^{-1}\left(\frac{p_{W}}{p_{1}-C_{F}}\right)+F_{2}^{-1}\left(\frac{p_{W}}{p_{2}}\right)-\hat{F}_{2}^{-1}\left(\left(c\left(p_{2}\right) \frac{\partial p_{2}}{\partial W_{2}}-\frac{\partial p_{2}}{\partial W_{2}} \hat{F_{2}}()+.p_{W}\right) / p_{2}\right.$

Global welfare maximizing is as the following:

$$
\Omega_{\text {trade }}+\Omega_{\text {trade }}^{*}
$$

F.O.C.s are as below

$$
\begin{aligned}
& -c_{2}\left(p_{2}\right) \frac{\partial p_{2}}{\partial W_{2}}-c_{2}^{*}\left(p_{2}\right) \frac{\partial p_{2}}{\partial W_{2}}+\frac{\partial p_{2}}{\partial W_{2}} F_{2}(.)+p_{2} F_{2 W_{2}}-p_{W}=0 \\
& -c_{2}\left(p_{2}\right) \frac{\partial p_{2}}{\partial N_{2}}-c_{2}^{*}\left(p_{2}\right) \frac{\partial p_{2}}{\partial W_{2}}+\frac{\partial p_{2}}{\partial N_{2}} F_{2}(.)+p_{2} F_{2 N_{2}}-p_{N}=0 \\
& -c_{1}^{*}\left(p_{1}\right) \frac{\partial p_{1}}{\partial W_{1}^{*}}-c_{1}\left(p_{1}\right) \frac{\partial p_{1}}{\partial W_{1}^{*}}+\frac{\partial p_{1}}{\partial W_{1}^{*}} F_{1}^{*}(.)+p_{1} F_{1 W_{1}^{*}}^{*}(.)-C_{F} F_{W_{1}^{*}}=p_{W} \\
& -c_{1}^{*}\left(p_{1}\right) \frac{\partial p_{1}}{\partial N_{1}^{*}}-c_{2}\left(p_{2}\right) \frac{\partial p_{1}}{\partial N_{1}}+\frac{\partial p_{1}}{\partial N_{1}^{*}} F_{1}^{*}(.)+p_{1} F_{1 N_{1}^{*}}^{*}(.)-C_{F} F_{N_{1 i}^{*}}=p_{N_{1 i}}
\end{aligned}
$$

With the international market clearing conditions $y_{1}^{*}-c_{1}^{*}=c_{1}$ and $y_{2}-c_{2}=c_{2}^{*}$. The F.O.C.s are simplified as below, and are the same expression as the ones in the small economy. Output prices are not affected by the large countries' inputs.

$$
\begin{aligned}
& p_{2} F_{2 W_{2}}-p_{W}=0 \\
& p_{2} F_{2 N_{2}}-p_{N}=0
\end{aligned}
$$


$p_{1} F_{1 W_{1}^{*}}^{*}()-.C_{F} F_{W_{1}^{*}}=p_{W}$

$p_{1} F_{1 N_{1}^{*}}^{*}()-.C_{F} F_{N_{1 i}^{*}}=p_{N_{1 i}}$

However, it does not mean global efficiency automatically ignores the input effects of large countries on the world output prices as shown in Peterson et al. (2002). It depends on what the functional form is for the production. Conditions (3.30) and (3.31) mean zero profit for the non-agricultural product firm.

\subsubsection{Terms of Trade}

As the trade of "virtual water" from water relatively abundant country to water relatively scarce country, the related environmental damage is going to be transferred with counter flow. Trade with externalities is one of the features in virtual water trade, Since externality or water pollution in this case negatively affects the social welfare, and if the total welfare is reduced by 'virtual water' trade, then there must be a compensation, such as side payment to the export country (water abundant country). However, side payment is not quite politically preferable since it might weaken the country's international bargain power. Therefore, terms of trade (TOT) need to be carefully made. The following social welfare condition has to be satisfied:

$1 . \Omega_{\text {vwtrade }} \geq \Omega_{\text {trade }} \geq \Omega_{\text {autarky }}$ 
2. $\Omega_{\text {vwtrade }}^{*} \geq \Omega_{\text {trade }}^{*} \geq \Omega_{\text {autarky }}^{*}$

That is, with virtual water trade, especially with comparative advantage, the individual social welfare of each country should not be lower than the one in partial trade economy and autarky economy. Therefore, if domestic and global social welfare when considering virtual water is greater than the one without considering virtual water or the one under autarky, no government policy/instrument is needed. Further, instruments could be applied, like tax on water use or subsidies to the farmers who used to produce water-intensive commodity.

\subsection{Empirical Application of the Model: The case of Saudi Arabia}

Saudi Arabia had implemented an aggressive wheat production program to achieve self-sufficiency in wheat production. However, in the process it had depleted the country's scarce water supplies. Recently, the country has decided to abandon the 30year old wheat production program, and instead, to rely entirely on wheat import by 2016. Countries like Saudi Arabia could shift its resources, especially water resources, from the production of water-intensive commodities to the production of less water-intensive commodities or the products that has much higher water productivity. As long as the trade of virtual water is applied, then the country with scarce water have to pay the comparative water abundant country for the extra externalities cost (environmental damage), $C^{*}\left(F^{*} \hat{W}^{*}, \hat{N_{i}^{*}}\right)-C\left(F^{*}\left(W^{*}, N_{i}^{*}\right)\right)$.. Virtual water trade is preferable as long as total welfare that includes the external cost for home country (welfare minus payment to the foreign country for the environmental damage because of the extra 
production for home country) will not be less than the one in Autarky economy or partial trade.

\subsection{Data for the Empirical Model}

Water scarcity already affects every continent. Around 1.2 billion people, i.e., almost one-fifth of the world's population, live in areas of physical scarcity, and 500 million more people are approaching this situation (UNICEF and WHO, 2008). Another 1.6 billion people, or almost one quarter of the world's population, face economic water shortage primarily in countries that lack the necessary infrastructure to take water from rivers and aquifers.

I choose two trading partners: the water scarce country, Saudi Arabia and the United States, which is abundant in physical water and is one of the major wheat exporters and oil importers for Saudi Arabia. Two goods are selected: wheat (a waterintensive product) and petroleum (a less water- intensive product). Water-intensive wheat needs green, blue and grey water. However, since green water is free of charge, I only consider blue and grey water. Data are from FAOSTAT, USDA, World Bank and EIA.

To keep the integrity of the simulation model, I choose a ten-year period data of every category of water from year 2001 to year 2010, and take the value in 2010 as the base value. Since the quantity of value of oil export of Saudi Arabia is so much greater than the value of wheat import, and the United States, the wheat export to Saudi Arabia is just a small portion of its production, there would be a problem of mismatch 
of scale. For a two-country model, as per the budget constraint 20 and 21, the value of import and export for both countries in terms of these two products should be the same. Therefore, I take just a portion of the oil export of Saudi Arabia, which is equivalent to the value of wheat import. Foreign country I choose.

\subsection{Simulation model and solution}

In order to keep the model and its results tractable, I present below a simplified version of the theoretical models developed in the previous sections, using specific functional forms for consumption, production, and social cost.

$$
\begin{aligned}
& c_{1}=k_{1} p_{1}^{-\eta_{c_{1}}}, c_{1}^{*}=k_{1}^{*} p_{1}^{-\eta_{c_{1}^{*}}} \\
& c_{2}=k_{2} p_{2}^{-\eta_{c_{2}}}, c_{2}^{*}=k_{2}^{*} p_{2}^{-\eta_{c_{2}}^{*}} \\
& c_{1}+c_{1}^{*}=y_{1}^{*}=k_{y_{1}}^{*} W^{* \eta_{1}} N^{* 1-\eta_{1}} \\
& c_{2}+c_{2}^{*}=y_{2}=k_{y_{2}} W^{\eta_{2}} N^{1-\eta_{2}} \\
& C=\alpha y_{1}^{*}+b
\end{aligned}
$$

First of all, through a log-transformation of the above functions, we can obtain simple estimating equations. For example, the log-linear version of equation (3.34) is, $\ln c_{1}=\ln k_{1}-\eta_{c_{1}} \ln p_{1}+\varepsilon_{1}$

The parameters from above equations are then estimated using the data for the study countries and the regression estimates are presented in the Table 3-1. The estimated regression results match the intuition that the price elasticity of wheat demand is less than 1 because it is a necessary good. Price elasticity of crude oil/petroleum demand is also less than 1, showing it is also necessary. Both wheat prices and oil prices in Saudi 
Arabia and United States are all real prices, taking year 2000 as the base year. According to IME's report, between 500 and 4,000 liters of water are required to produce $1 \mathrm{~kg}$ of wheat. That is 500,000 to $4,000,000$ liters of water needed for 1 metric ton wheat production. Higher technology or better water management is wheatgrowing makes less water required for the same harvest. According to Li et al. (2007), Crop Water Productivity (CWP) is $0.589 \mathrm{~kg} / \mathrm{L}$ in US, and $1.066 \mathrm{~kg} / \mathrm{L}$ in Saudi Arabia. $\eta_{1}$, and $\eta_{2}$ in represents the productivity of the water and non-water inputs respectively. Per Ali (2002), US has the water input cost share, $\eta_{1}^{*}=0.004$ and $\eta_{2}$ in Saudi Arabia is assumed to be 0.00001 . Normalize the price of non-water input, taking 2000 price as the base value of 1 . Average social cost is taken from Tegtmeier and Duffy, 2004. Linear regression also results the marginal social cost and fix social cost. Using the parameters below, I estimated the international equilibrium water and non-water factor inputs for oil and wheat production. By plugging those equations back to (3.30) to (3.33). $W_{1}^{*}, N_{1}^{*}$ and $W_{2} N_{2}$ in the simulation model are solved explicitly. Equilibrium input levels are obtained through the simulated model, then numerical values of each optimal level are calculated by the parameters in Table 3-1.

Table 3-1 Parameters and values

\begin{tabular}{|c|l|l|l|}
\hline Parameter & Description & Value & Source \\
\hline$\eta_{c_{1}}$ & $\begin{array}{l}\text { SA Price elasticity of demand for } \\
\text { wheat }\end{array}$ & 0.001 & $\begin{array}{l}\text { Estimated from } \\
\text { data }\end{array}$ \\
\hline$\eta_{c_{1}^{*}}$ & $\begin{array}{l}\text { US Price elasticity of demand for } \\
\text { wheat }\end{array}$ & 0.03 & Assumed \\
\hline$\eta_{c_{2}}$ & $\begin{array}{l}\text { SA Price elasticity of demand for } \\
\text { oil }\end{array}$ & 0.218 & Estimated \\
\hline
\end{tabular}




\begin{tabular}{|c|l|l|l|}
\hline$\eta_{c_{2}^{*}}$ & $\begin{array}{l}\text { US Price elasticity of demand for } \\
\text { oil }\end{array}$ & 0.008 & Estimated \\
\hline $\ln k_{1}$ & $\begin{array}{l}\text { Log value of Wheat consumption } \\
\text { constant in SA }\end{array}$ & 17.13 & Estimated \\
\hline $\ln k_{1}^{*}$ & $\begin{array}{l}\text { Log value of Wheat consumption } \\
\text { constant in US }\end{array}$ & 4.1 & Estimated \\
\hline $\ln k_{2}$ & $\begin{array}{l}\text { Log value of oil consumption } \\
\text { constant in SA }\end{array}$ & 19.54 & Estimated \\
\hline $\ln k_{2}^{*}$ & $\begin{array}{l}\text { Log value of oil consumption } \\
\text { constant in US }\end{array}$ & 22.74 & Estimated \\
\hline$\eta_{2}$ & $\begin{array}{l}\text { Water productivity in oil production } \\
\text { in SA }\end{array}$ & 0.00001 & Assumed \\
\hline$k_{y_{1}}^{*}$ & $\begin{array}{l}\text { Production technology constant of } \\
\text { oil in US }\end{array}$ & 0.01 & $\begin{array}{l}\text { Calculated from } \\
\text { assumption }\end{array}$ \\
\hline $\ln k_{y_{2}}$ & $\begin{array}{l}\text { Production technology constant of } \\
\text { oil in SA }\end{array}$ & 0.03 & $\begin{array}{l}\text { Calculated from } \\
\text { assumption }\end{array}$ \\
\hline$\eta_{1}^{*}$ & $\begin{array}{l}\text { Water productivity in wheat } \\
\text { production in US }\end{array}$ & 0.004 & $\begin{array}{l}\text { Calculated from } \\
\text { assumption }\end{array}$ \\
\hline$\alpha$ & Marginal social cost & 4.3 & Estimated \\
\hline $\mathrm{b}$ & Fix social cost & 354000000 & Estimated \\
\hline
\end{tabular}

Table 3-1Parameters and values (continued)

$W_{1}^{*}=$

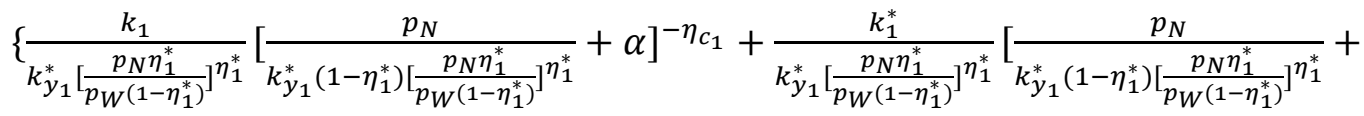

$$
\begin{aligned}
& \alpha]^{\left.-\eta_{c_{1}}^{*}\right\} \frac{p_{N} \eta_{1}}{p_{W}\left(1-\eta_{1}\right)}} \\
& N_{1}^{*}=\frac{k_{1}}{k_{y_{1}}^{*}\left[\frac{p_{N} \eta_{1}^{*}}{p_{W}\left(1-\eta_{1}^{*}\right)}\right]^{\eta_{1}^{*}}}\left[\frac{p_{N}}{k_{y_{1}}^{*}\left(1-\eta_{1}^{*}\right)\left[\frac{p_{N} \eta_{1}^{*}}{p_{W}\left(1-\eta_{1}^{*}\right)}\right]_{1}^{\eta_{1}^{*}}}+\alpha\right]^{-\eta_{c_{1}}} \\
& +\frac{k_{1}^{*}}{k_{y_{1}}^{*}\left[\frac{p_{N} \eta_{1}^{*}}{p_{W}\left(1-\eta_{1}^{*}\right)}\right]_{1}^{\eta_{1}^{*}}}\left[\frac{p_{N}}{k_{y_{1}}^{*}\left(1-\eta_{1}^{*}\right)\left[\frac{p_{N} \eta_{1}^{*}}{p_{W}\left(1-\eta_{1}^{*}\right)}\right]^{\eta_{1}^{*}}}+\alpha\right]^{-\eta_{c_{1}}^{*}} \\
& W_{2}=\left\{k_{2} k_{y 2}^{\eta_{c_{2}}-1}\left[\frac{p_{N}}{\left(1-\eta_{2}\right)}\right]^{\eta_{2} \eta_{c_{2}}-\eta_{2}-\eta_{c_{2}}}\left[\frac{\eta_{2}}{p_{W}}\right]^{\eta_{2} \eta_{c_{2}}-\eta_{2}}\right. \\
& \left.+k_{2}^{*} k_{y 2}^{\eta_{c_{2}}^{*}-1}\left[\frac{p_{N}}{\left(1-\eta_{2}\right)}\right]^{\eta_{2} \eta_{c_{2}}^{*}-\eta_{2}-\eta_{c_{2}}^{*}}\left[\frac{\eta_{2}}{p_{W}}\right]^{\eta_{2} \eta_{c_{2}}^{*}-\eta_{2}}\right\} \frac{p_{N} \eta_{1}}{p_{W}\left(1-\eta_{1}\right)}
\end{aligned}
$$




$$
\begin{aligned}
N_{2}=k_{2} k_{y 2}^{\eta_{c_{2}}-1} & {\left[\frac{p_{N}}{\left(1-\eta_{2}\right)}\right]^{\eta_{2} \eta_{c_{2}}-\eta_{2}-\eta_{c_{2}}}\left[\frac{\eta_{2}}{p_{W}}\right]^{\eta_{2} \eta_{c_{2}}-\eta_{2}} } \\
& +k_{2}^{*} k_{y 2}^{\eta_{c_{2}}^{*}-1}\left[\frac{p_{N}}{\left(1-\eta_{2}\right)}\right]^{\eta_{2} \eta_{c_{2}}^{*}-\eta_{2}-\eta_{c_{2}}^{*}}\left[\frac{\eta_{2}}{p_{W}}\right]^{\eta_{2} \eta_{c_{2}}^{*}-\eta_{2}}
\end{aligned}
$$

The solution suggests that if production function is Cobb-Douglas and social cost is a linear function of production, the world output price for any country, even for the large country, is not related to the input. On another word, the power of the large country to change world price can be ignored.

Thirdly, by plugging these optimal input levels back into the simulation model, the optimal levels of consumption, production, and welfare are solved.

\subsection{Results}

This section presents an empirical application of the above model to the water scarcity problem of Saudi Arabia. If VW trade is considered and comparative advantage applies, Saudi Arabia, a water scarce country, may consider cutting back on growing wheat crops that it does not have comparative advantage in, and import instead to meet its domestic demand. On the contrary, if VW trade or comparative advantage of water use is not considered, Saudi Arabia would still produce wheat crops domestically, and may also import some in order to match its demand of wheat. Therefore, the difference between water embedded in completely imported wheat and that in domestically produced wheat is the amount of water saved considering comparative advantage in VW trade. (see Table 3-2). Sensitivity analysis shows the water productivity ratio in both wheat and oil production is sensitive (Changes of parameters keeping others constant). 
From the results, it is clear that if there is no international trade, growing water intensive wheat crops for Saudi Arabia makes water shortage more severe because of the increasing domestic consumption (see Table 3-3). From 2008, Saudi Arabia grows much less wheat and chooses to import from foreign countries. Data shows that after a reduction in wheat production, considering virtual water trade with no trade distortion (totally give up production of water intensive good-wheat, and let import support domestic wheat consumption), and then water is saved by a great amount. 
Table 3-2 Actual domestic production and import of Wheat and oil in Saudi Arabia and United State

\begin{tabular}{|l|l|l|l|l|l|}
\hline Variable & Country & Commodity & Units & Values \\
\hline Actual annual average of 2008 to 2010 & \multicolumn{5}{l|}{} \\
\hline Domestic production & SA & Wheat & \multicolumn{2}{l|}{1000 tons } & 1496 \\
\hline & USA & Wheat & 1000 tons & 62814 \\
\hline & SA & Oil & Million barrel & 3801 \\
\hline & USA & Oil & Million barrel & 3331 \\
\hline Imports & SA & Wheat & 1000 tons & 1254 \\
\hline & USA & Wheat & 1000 tons & -35692 \\
\hline & SA & Oil & Million barrel & -3004 \\
\hline $\begin{array}{l}\text { Average Water saved (partial trade } \\
\text { compared to autarky) }\end{array}$ & SA & Oil & Million barrel & 3658 \\
\hline Average Water saved (VW trade & SA & Wheat & Million L & 1160 \\
\hline
\end{tabular}


Table 3-3 Physical water saved for Saudi Arabia by importing wheat (From Observed value)

\begin{tabular}{|c|c|c|c|c|c|}
\hline Year & $\begin{array}{l}\text { Domestic wheat production } y_{1} \\
\text { (Unit: } 1000 \text { Ton) }\end{array}$ & $\begin{array}{l}\text { Consumption } c_{1} \\
\text { (Unit: } 1000 \text { Ton) }\end{array}$ & $\begin{array}{l}\text { Import } \\
\text { (Unit: } \\
1000 \text { Ton) }\end{array}$ & $\begin{array}{l}\text { Water saved by } \\
\text { partial import } \\
\text { (Unit: million } \\
\text { L) } \\
\end{array}$ & $\begin{array}{l}\text { Water saved by Fully } \\
\text { import } \\
\text { (Unit: million L)) }\end{array}$ \\
\hline 2001 & 2081 & 2050 & -31 & -29 & 1896 \\
\hline 2002 & 2436 & 2150 & -286 & -264 & 1988 \\
\hline 2003 & 2524 & 2250 & -274 & -253 & 2081 \\
\hline 2004 & 2775 & 2350 & -425 & -393 & 2173 \\
\hline 2005 & 2648 & 2450 & -198 & -183 & 2266 \\
\hline 2006 & 2630 & 2500 & -130 & -12 & 2312 \\
\hline 2007 & 2558 & 2550 & -8 & -7 & 2358 \\
\hline 2008 & 1985 & 2650 & 664 & 614 & 2451 \\
\hline 2009 & 1152 & 2750 & 1597 & 1477 & 2543 \\
\hline 2010 & 1349 & 2850 & 1500 & 1388 & 2636 \\
\hline
\end{tabular}


At the equilibrium, world price from the model is lower than the data on average as shown in Table 3-4. This is true intuitively since world trade will lower the output price. The increase of foreign demand will raise domestic production , and the supply curve will shift outward which cause price drop.

Table 3-4 Price comparison: Equilibrium price VS observed price

\begin{tabular}{|c|c|c|c|c|}
\hline Year & $\begin{array}{c}p_{1} \\
\text { (simulated) }\end{array}$ & $\begin{array}{c}p_{1} \\
\text { (observed) }\end{array}$ & $\begin{array}{c}p_{2} \\
\text { (simulated) }\end{array}$ & $\begin{array}{c}p_{2} \\
\text { (observed) }\end{array}$ \\
\hline 2001 & 107.14 & 98.84 & 40.21 & 22.54 \\
\hline 2002 & 109.03 & 124.76 & 40.92 & 23.64 \\
\hline 2003 & 111.28 & 116.50 & 41.81 & 29.57 \\
\hline 2004 & 114.94 & 112.61 & 43.25 & 40.81 \\
\hline 2005 & 117.52 & 110.92 & 44.27 & 57.12 \\
\hline 2006 & 120.29 & 135.00 & 45.32 & 69.42 \\
\hline 2007 & 125.04 & 196.86 & 47.11 & 80.42 \\
\hline 2008 & 131.70 & 195.14 & 49.72 & 120.00 \\
\hline 2009 & 133.80 & 137.80 & 50.62 & 73.20 \\
\hline 2010 & 134.87 & 159.66 & 51.01 & 97.80 \\
\hline Average & 120.56 & 138.80 & 45.42 & 61.45 \\
\hline
\end{tabular}

And the effect of Saudi Arabia's social welfare and Global welfare from VW trade is shown in Table 3-5. It is clear that from Table 3-5 without any government distortion, both Saudi Arabia's and world's social welfare increases with VW trade. Therefore, VW trade will automatically compensate the wheat crop growers by the gains from the social cost reduction. 
Table 3-5 Local welfare change VS. Global welfare change (From observed value to optimal VW trade level)

(Unit: Billion \$)

\begin{tabular}{|c|c|c|c|}
\hline Year & $\begin{array}{c}\text { SA WELFARE } \\
\text { GAIN }\end{array}$ & US WELFARE & $\begin{array}{c}\text { WORLD } \\
\text { WELFARE }\end{array}$ \\
\hline 2001 & 57536 & -114 & 57422 \\
\hline 2002 & 67338 & 218 & 67555 \\
\hline 2003 & 69767 & 72 & 69839 \\
\hline 2004 & 76718 & -32 & 76685 \\
\hline 2005 & 73203 & -91 & 73112 \\
\hline 2006 & 72705 & 203 & 72909 \\
\hline 2007 & 70707 & 994 & 71701 \\
\hline 2008 & 54888 & 877 & 55764 \\
\hline 2009 & 31857 & 56 & 31913 \\
\hline 2010 & 37299 & 346 & 37645 \\
\hline
\end{tabular}

\subsection{Conclusion}

For agricultural production, other than increase in the efficiency of irrigation, VW trade is another way to save water. As the trade of virtual water from water-abundant country to water-scarce country, the related environmental damage is going to be transferred with counter flow. Trade with externalities is one of the features in virtual water trade. How to calculate the external cost/ social cost is the key to figure out the local and global social welfare. This paper only considered the environmental cost as discussed in Tegtmeier and Duffy, 2004. However, it will be more accurate if taking the opportunity cost of water in other uses and user cost/ scarcity rent for the future use into consideration. Since externality or water pollution in this case negatively affects the social welfare, and if the totally welfare is reduced by 
VW trade, then there must be a compensation, such as side payment to the export country (water abundant country). It is not wise for countries like Saudi Arabia, which is a water scarce country but still has a very high growth of wheat production, since they will face water shortage faster. In order for sustainable water use and economic growth, it is more preferable for those countries to shift the production of water-intensive goods to that of less water-intensive good, or that with much higher value of water productivity. Therefore, terms of trade (TOT) need to be carefully made. My empirical test shows that VW trade not only saves a huge amount of water, but it avoids the need for government interference for the social welfare, since both local and global welfare increases through VW trade. This paper also provides a methodology for calculating input price, especially water price that consists of social cost. Nevertheless, irrigation water for crops includes blue, green and grey water, and it is difficult to convert the value of all three types of water into one. If such conversion could be developed in the future study, the local and global welfare gain or loss from VW trade will be more accurate. 


\section{GLOSSARY}

Blue water: Fresh surface and groundwater, in other words, the water in freshwater lakes, rivers and aquifers.

Green water: The precipitation on land that does not run of or recharge the groundwater but is stored in the soil or temporarily stays on top of the soil or vegetation. Eventually, this part of precipitation evaporates or transpires through plants. Green water can be made productive for crop growth (although not all green water can be taken up by crops, because there will always be evaporation from the soil and because not all periods of the year or areas are suitable for crop growth).

Grey Water: is defined as wastewater generated showers and baths, which can be recycled on-site for uses such as WC flushing, land irrigation and constructed wetlands. Grey water often includes discharge from laundry, dishwashers and kitchen sinks. It differs from the discharge of WC's, which is designated sewage, or black water to indicate it contains human waste. 


\section{REFERENCES}

Ahearn, M. (2008). Agricultural Productivity in the US. DIANE Publishing.

Allan, J. A. (2003). Virtual water-the water, food, and trade nexus. Useful concept or misleading metaphor? Water International, 28(1), 106-113.

Allan, J.A..(1993). Fortunately there are substitutes for water otherwise our hydropolitical futures would be impossible. Priorities for Water Resources Allocation and Management, ODA, London, pages 13-26.

Ball, V. E., Bureau, J. C., Nehring, R., \& Somwaru, A. (1997). Agricultural productivity revisited. American Journal of Agricultural Economics, 79(4), 10451063.

Carter, D. W., \& Milon, J. W. (1999). Marginal Opportunity Cost Vs. Average Cost Pricing of Water Service: Timing Issues for Pricing Reform. Food and Resource Economics Department, Institute of Food and Agricultural Sciences, University of Florida.

De Fraiture, C., Cai, X., Amarasinghe, U., Rosegrant, M., \& Molden, D. (2004). Does international cereal trade save water?: the impact of virtual water trade on global water use (Vol. 4). IWMI.

Frankel, J. A. (2009). Environmental effects of international trade. (No. rwp09-006).

Frija, A., \& Chebil, A. (2013). Marginal Value of Irrigation Water in Wheat Production Systems of Central Tunisia.

Frontier Economics. The concept of 'virtual water' - a critical review. Technical report, a report prepared for the Victorian Department of Primary Industries, 2008.

Gawel, E., \& Bernsen, K. (2011). What is wrong with virtual water trading? (No. 1/2011). UFZ-Diskussionspapiere.

Hoeskstra, A Y and Huang, P.Q.. Virtual water trade: a quantification of virtual water flows between nations in relation to international crop trade. Value of Water Research Report, Series No.11, IHE, Delft, the Netherlands, 2002.

Hoekstra, A. Y. (Ed.). (2003, February). Virtual water trade: Proceedings of the international expert meeting on virtual water trade. Delft, the Netherlands: IHE. 
OECD Environmental Outlook to 2050 The Consequences of Inaction. Organization for Economic Cooperation and Development, March 2012.

Peterson, Jefery M., Boisvert,Richard N. and Gorter, Harry de. Environmental policies for multifunctional agriculture sector in open economies. European Review of Agricultural Economics, 29(4):423-443, 2002.

Reimer, J. J. (2012). On the economics of virtual water trade. Ecological Economics, 75, 135-139.

Renault, D. (2003). Value of virtual water in food: Principles and virtues. Hoekstra, AY (Ed.).

Sadras, V., Grassini, P., \& Steduto, P. (2011). Status of water use efficiency of main crops: SOLAW Background Thematic Report-TR07. Rome: Food and Agricultural Organization.

Tegtmeier, E. M., \& Duffy, M. D. (2004). External costs of agricultural production in the United States. International Journal of agricultural sustainability, 2(1), 1-20.

Wichelns, D. (2004). The policy relevance of virtual water can be enhanced by considering comparative advantages. Agricultural Water Management, 66(1), 49-63.

Würtenberger, L., Koellner, T., \& Binder, C. R. (2006). Virtual land use and agricultural trade: Estimating environmental and socio-economic impacts. Ecological Economics, 57(4), 679-697.

Zimmer, D., \& Renault, D. (2003). Virtual water in food production and global trade: Review of methodological issues and preliminary results. In Proceedings of the International Expert meeting on Virtual Water Trade, Value of Water-Research Rapport Series (No. 12, pp. 93-109). 


\section{CHAPTER 4 SUMMARY}

Growing water scarcity is one of the fundamental problems facing humanity. This dissertation addressed three different economic problems relating to managing scarce water resources. The first chapter analyzed the factors that influence the altruistic behavior of the current generation on the availability of water for their offspring irrespective of their intentions. It looks at the trade-offs between three types of bequests-monetary, water resource, and individual's contribution to pollution abatement. It explains how different economic, demographic and environmental factors could influence the degree of parental altruism, and therefore, the amount of water allocated during multiple time periods. The study shows that there may be a gap in the amount of resource bequest between private individuals and a social planner. A mixture of different policy instruments is suggested to close this gap. On the one hand, raising the interest rate for individuals will make them lower their current consumption of private goods, and in turn, save money towards pollution abatement or monetary bequest. In addition, a lump sum subsidy could also promote individuals' contribution towards pollution abatement. On the other hand, a lump sum tax or fine to the firm that causes the pollution would force the firm to advance its technology to decrease the pollution level. The above combination of policies result in increased water bequest by promoting water conservation in industries and pollution abatement without compromising the direction current consumption. 
So far, there is no river sharing agreement between China and India, even though there exists an ongoing water sharing conflict between the two countries. The second chapter studies the water allocation of Brahmaputra River shared by those two countries when the water rights do not exist. Traditional side payment is not politically appealing for the victim country risking a reputation of being a weak negotiator. India, in a geographically weaker position to bargain, expects China share water in drought season and control flood in wet season. This study uses the interconnected game, combining water-sharing game, in which China has advantage on water sharing/controlling in exchange for side payment, and trading game, in which India has advantage on approving China to invest on its infrastructure in exchange of China importing iron ore from India. As a result, India exercises the combined strategies in order to force China to share/control water without side payments under the condition of either drought season or wet season.

As global warming exacerbates water shortage, it is essential for the countries, which are water scarce to enhance the capability of handling natural shocks. For example, cotton growing, one of the largest projects in Sub-Saharan African countries, requires strict natural conditions like rainfall or enough irrigation. Nonetheless, water is what Sub-Saharan African countries lack the most. It is not wise to concentrate on the cotton growing in the long term. Virtual water (water embedded in producing a commodity) trade will solve this contradiction. From the theory of comparative advantage, countries like Sub-Saharan African countries should import cotton, a water 
intensive good, instead of growing the crop. A two-country, two-product trade model developed in the third chapter uses data from World Bank, FAO, USDA and other sources and calculates the welfare gains by virtual water trade between Saudi Arabia and United States (Saudi Arabia import wheat from and export oil to US), including the consumer's surplus, producer's surplus and benefit from dodging the risk of economic loss by drought. This study also proves that without government intervention, both countries would still achieve trade-related economic welfare goals and water-related environmental goals. Therefore, the African countries may produce the goods that they have comparative advantage without consuming a huge amount of water, such as tourism and related industry. 
VITA

\section{YU CHEN}

Born, Chongqing, China

2001-2005

B.A., Economics

Chongqing Technology and Business University

Chongqing, China

2005-2008

Development planner and project manager

South Air International Co., Ltd.

Chongqing, China

2008-2010

M.S., Economics

Florida International University

Miami, FL

$2008-2014$

Ph.D., Economics

Florida International University

Miami, FL

2008-2014

Teaching Assistant

Florida International University

Miami Florida

2011

Instructor

Florida International University

Miami Florida

\section{PUBLICATIONS AND PRESENTATIONS}

Chen, Y., and Bhat, M. (June, 2012). Parental Altruism in Freshwater Management. ISEE 2012 (International Society for Ecological Economics) Conference- Ecological Economics and Rio+20, Rio De Janeiro, Brazil 